\title{
WestVirginiaUniversity
}

THE RESEARCH REPOSITORY @ WVU

Graduate Theses, Dissertations, and Problem Reports

2003

\section{Trip generation characteristics of rural clinics in West Virginia}

Andrew Paul Morgan

West Virginia University

Follow this and additional works at: https://researchrepository.wvu.edu/etd

\section{Recommended Citation}

Morgan, Andrew Paul, "Trip generation characteristics of rural clinics in West Virginia" (2003). Graduate Theses, Dissertations, and Problem Reports. 1329.

https://researchrepository.wvu.edu/etd/1329

This Thesis is protected by copyright and/or related rights. It has been brought to you by the The Research Repository @ WVU with permission from the rights-holder(s). You are free to use this Thesis in any way that is permitted by the copyright and related rights legislation that applies to your use. For other uses you must obtain permission from the rights-holder(s) directly, unless additional rights are indicated by a Creative Commons license in the record and/ or on the work itself. This Thesis has been accepted for inclusion in WVU Graduate Theses, Dissertations, and Problem Reports collection by an authorized administrator of The Research Repository @ WVU. For more information, please contact researchrepository@mail.wvu.edu. 


\title{
Trip Generation Characteristics of Rural Clinics in West Virginia
}

\author{
Andrew P. Morgan \\ Thesis submitted to the \\ College of Engineering and Mineral Resources \\ at West Virginia University
}

In partial fulfillment of the requirements for the degree of

Master of Science In

Civil Engineering

Ronald W. Eck, Ph.D., P.E., Chair

L. James French, III, Ph.D., P.E. Darrell R. Dean, Ph.D., P.S.

Morgantown, WV

2003

Keywords: Rural Clinics, Trip Generation, Traffic Projections, Traffic Impact Studies 


\section{Abstract \\ Trip Generation Rates for Rural Clinics in West Virginia}

\section{Andrew P. Morgan}

With the decreasing number of hospitals in rural areas, more rural clinics are being established to meet the health care needs in rural areas. Rural clinics are small health care facilities that serve the primary care needs of rural areas. There are currently no published trip generation rates available for rural clinics. The only rates available are those presented for "clinics" in ITE's Trip Generation (1997). These rates are based on very small sample sizes and on facilities that do not adequately reflect the traffic characteristics of rural clinics.

Trip generation rates were developed for rural clinics in West Virginia. Traffic counts were collected at five rural clinics the state. The clinics were relatively small with gross floor areas of 1500 to 3400 square feet and 3 to 12 employees. Rates were computed for:

- trips per employee

- trips per thousand square feet of gross floor area

- trip per doctor

These rates were based on average weekday, average weekday peak hour, and average weekday a.m. and p.m. peak hour volumes.

The results of this study indicated that there is a considerable difference between the rates presented in ITE (1997) and those for rural clinics in West Virginia. These results are considered reliable for rural clinics, since they were developed by following the procedures and criteria set forth by ITE. Several recommendations for additional research were presented. 


\section{Acknowledgments}

The author would like to thank the people who helped in the completion of this thesis. Foremost, appreciation is expressed to Dr. Ronald W. Eck, graduate advisor and committee chairperson, for assistance and guidance in formulating the research plan and in the preparation of this thesis. The author would like to thank Dr. L. James French and Dr. Darrell Dean for their participation on the Examination Committee and their helpful suggestions.

The author would also like to thank William Wyant for sharing his personal knowledge and loaning of personal references on clinic characteristics. Finally, the author greatly appreciates the cooperation and assistance provided by the facility managers and administrators that permitted the use of their facilities for this research. 


\section{Table of Contents}

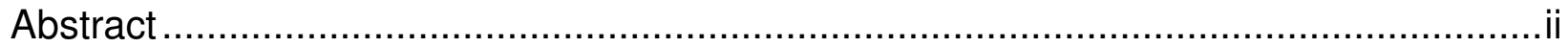

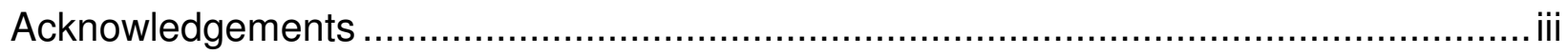

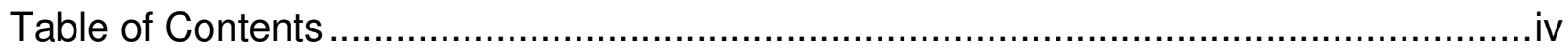

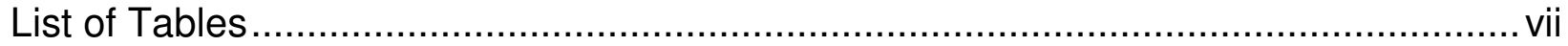

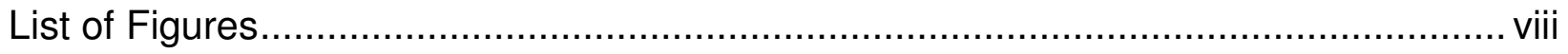

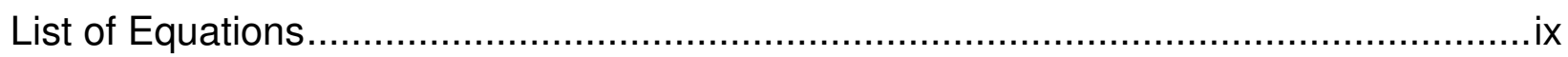

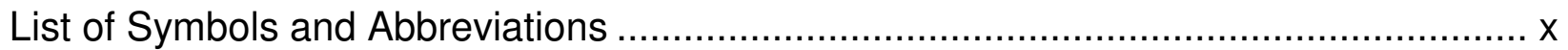

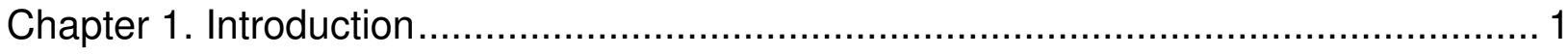

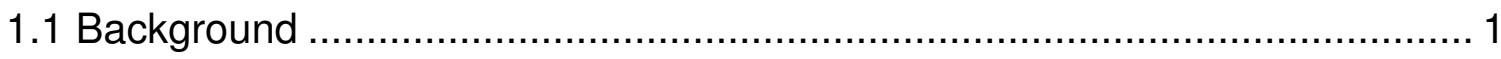

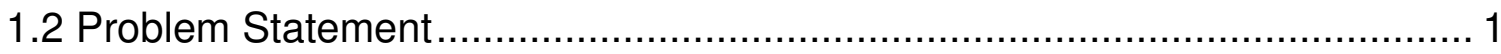

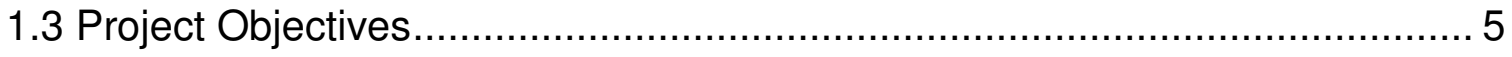

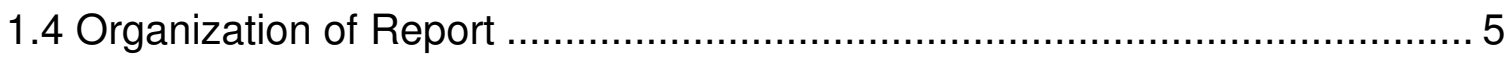

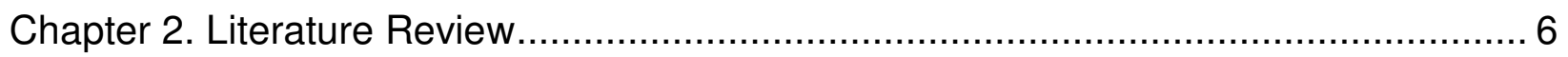

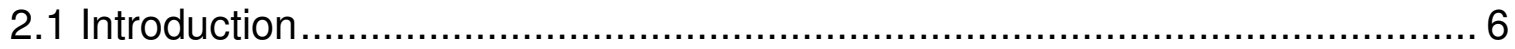

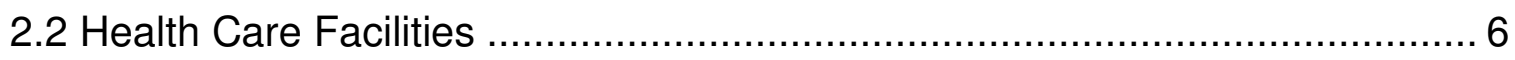

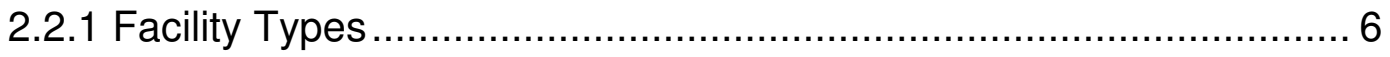

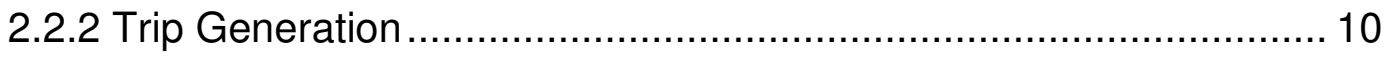

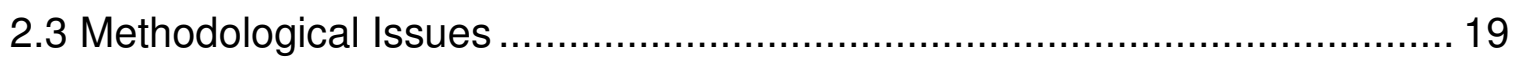

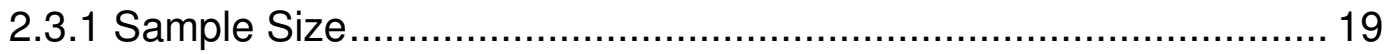

2.3.2 Average Trip Rate.............................................................. 20

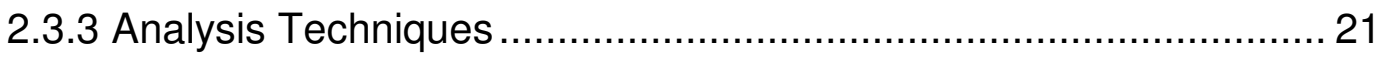

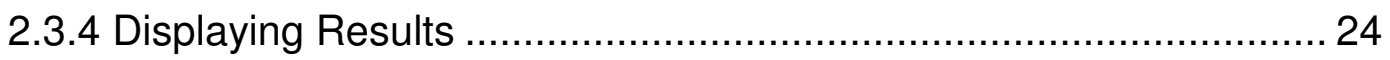

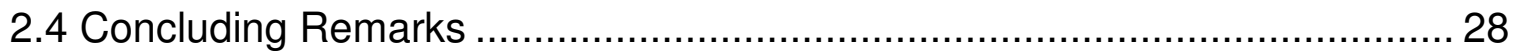

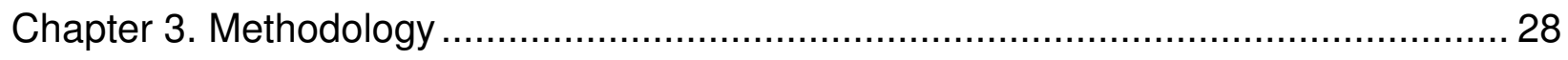

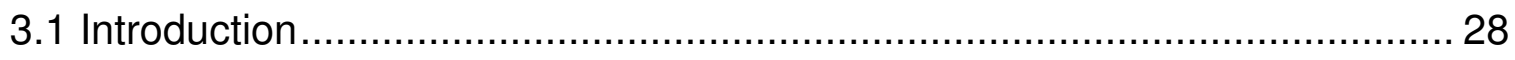

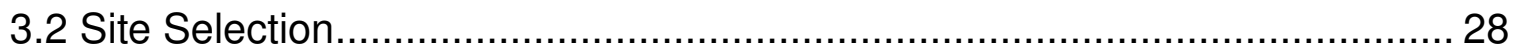

3.2.1 Site Selection Criteria ........................................................ 28

3.2.2 Identification of Clinics ........................................................... 30

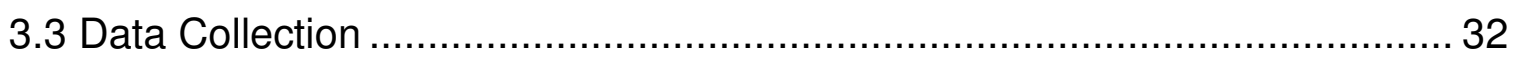

3.3.1 Site Characteristics ............................................................... 32 


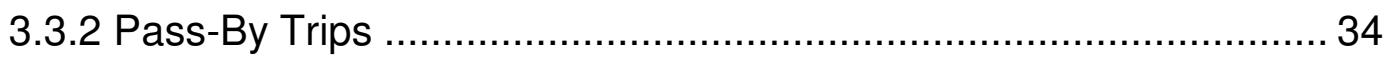

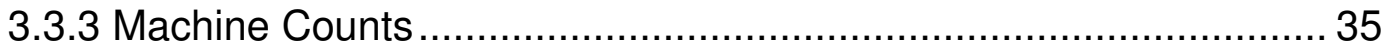

3.4 Data Analysis and Computations........................................................ 36

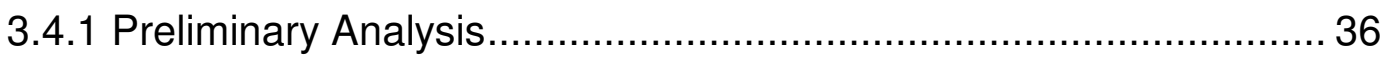

3.4.2 Independent Variable Selection .................................................. 37

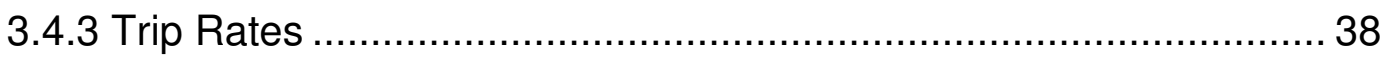

3.4.3.1 Trip Rates for Individual Sites ..................................... 38

3.4.3.2 Average Weighted Trip Rate ......................................... 39

3.4.3.3 Regression Trip Rate Plot ............................................. 39

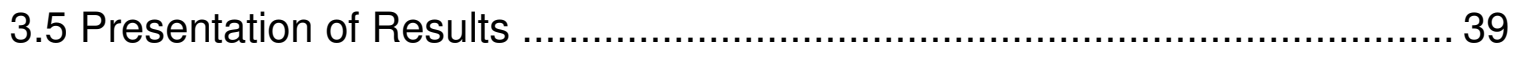

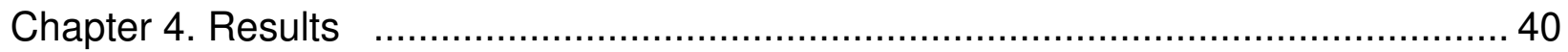

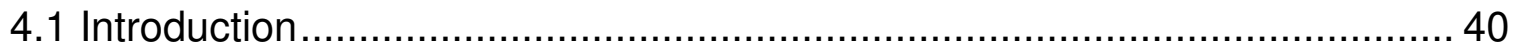

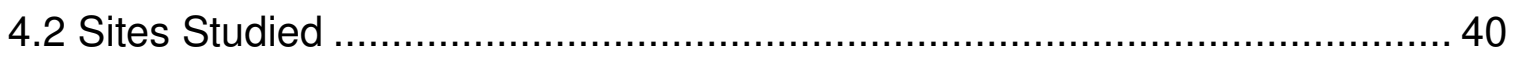

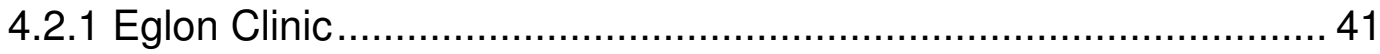

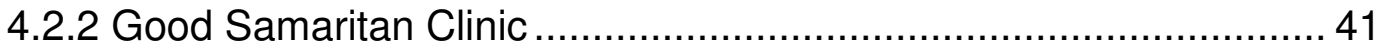

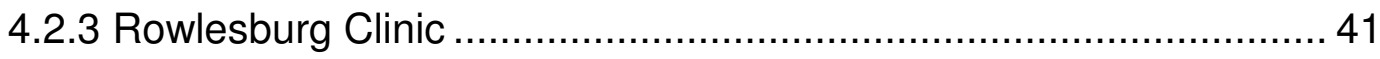

4.2.4 Shinnston Medical Center ....................................................... 42

4.2.5 St. George Medical Clinic, Inc.................................................... 42

4.2.6 Comparison of Sites............................................................... 42

4.3 Daily and Hourly Variations in Trips..................................................... 44

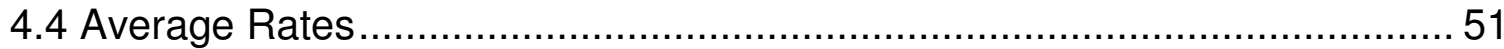

4.5 Comparison with Trip Generation Values ............................................ 54

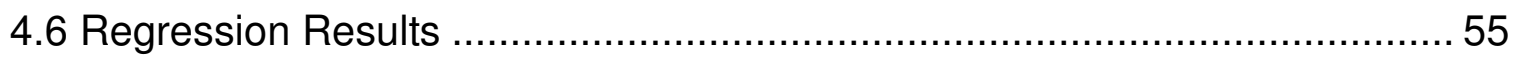

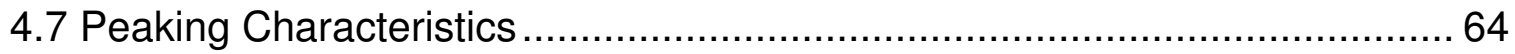

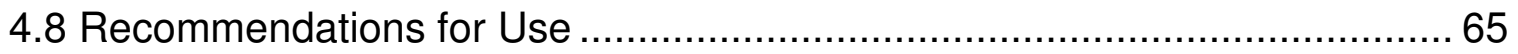

Chapter 5. Conclusions and Recommendations .................................................. 67

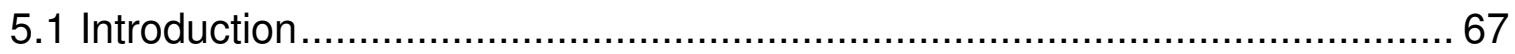

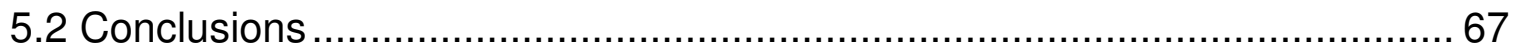

5.3 Recommendations for Further Research............................................. 68

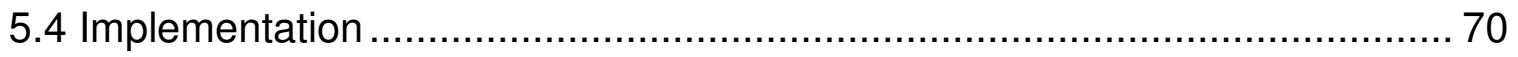

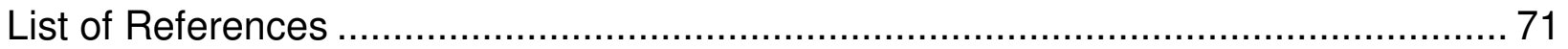


Appendix A Sample of Method of Presentation Recommended by ITE (1997) ........... 74

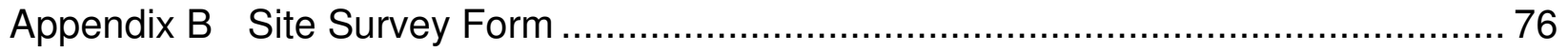

Appendix C Completed Site Survey Forms for and Photographs of the Five Study Sites

Appendix D Regression Plots for the 13 Rates Not Meeting ITE Requirements for Equations (Presented for Information Only) ......................................... 95

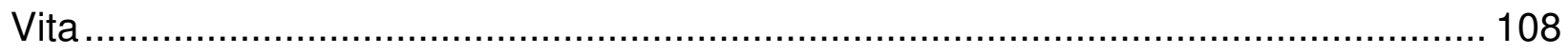




\section{List of Tables}

2-1 Daily Population Distribution for General Hospitals and Medical Centers

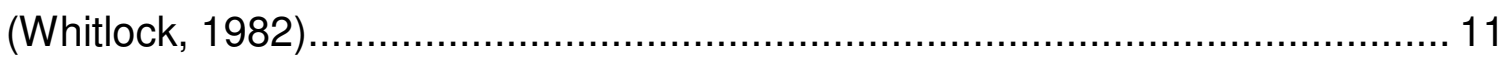

2-2 Daily Population Activity at General Hospitals and Medical Centers

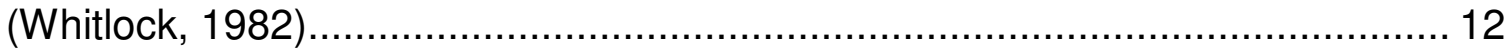

2-3 ITE (1997) Trip Generation Data for Hospitals ............................................. 13

2-4 ITE (1997) Trip Generation Data for Nursing Homes ..................................... 14

2-5 ITE (1997) Trip Generation Data for Medical-Dental Office Building …............... 15

2-6 ITE (1997) Trip Generation Data for Pharmacies/Drugstores............................. 16

2-7 Clinic Trip Generation Rates as Presented in ITE Trip Generation Handbook

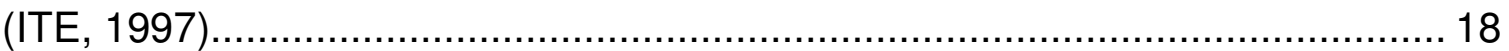

3-1 Characteristics of Rural Clinics Identified as Possible Study Locations.............. 31

4-1 Physical Facility Characteristics of the Five Clinics ........................................ 43

4-2 Staffing Characteristics of the Five Clinics ................................................. 43

4-3 Facility Characteristics on a Per Unit Basis ................................................ 43

4-4 Hours of Operation for the 5 Clinics Studied .................................................. 44

4-5 Trip Ends Per Employee for the 5 Study Sites .......................................... 51

4-6 Trip Ends Per Gross Floor Area for the 5 Study Sites ................................... 52

4-7 Trip Ends Per Employee for the 4 Study Sites (all but Good Samaritan)............ 53

4-8 Trip Ends Per Gross Floor Area for the 4 Study Sites (all but Good Samaritan) 53

4-9 Trip Ends Per Doctor for the 4 Study Sites (all but Good Samaritan) ................. 54

4-10 Comparison of Rates for West Virginia Rural Clinics with ITE (1997) Data........ 54

4-11 $R^{2}$ Values for Regression Analysis Performed on Trip Generation Data ............ 56

4-12 Weekday "K" Values for the Five Sites Studied ............................................... 64

4-13 Range of Socio Economic Values for West Virginia Rural Clinics ......................66 


\section{List of Figures}

1-1 Locations of Clinics in West Virginia Supported by the OCRHS ......................... 3

2-1 ITE (1997) Trip Rate Form for Clinics

(Trips per Employee on Average Weekday) .................................................. 27

4-1 Locations of Clinics Visited and Studied .................................................... 40

4-2 Hourly and Daily Variation in Trips for Eglon Clinic

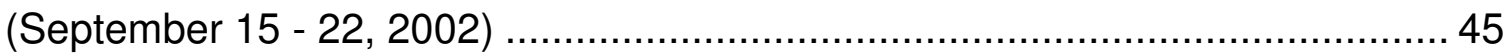

4-3 Hourly and Daily Variation in Trips for Good Samaritan Clinic

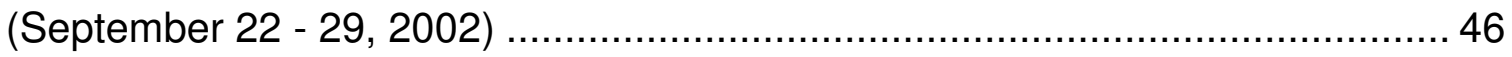

4-4 Hourly and Daily Variation in Trips for Rowlesburg Clinic

(September 15 - 22, 2002) .

4-5 Hourly and Daily Variation in Trips for Shinnston Medical Center

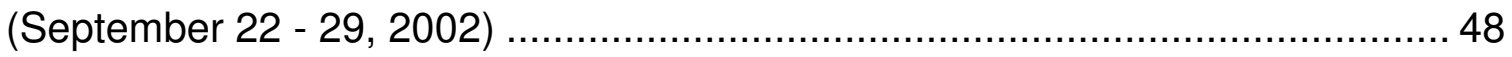

4-6 Hourly and Daily Variation in Trips for St. George Clinic

(September 8 - 15, 2002)

4-7 Regression Plot and Equation for Five West Virginia Rural Clinics

(Weekday Trips per Employee)

4-8 Regression Plot and Equation for Five West Virginia Rural Clinics

(Average Weekday Peak Hour Trips per Employee)

4-9 Regression Plot and Equation for Five West Virginia Rural Clinics

(Maximum AM Weekday Peak Hour Trips per Employee)

4-10 Regression Plot and Equation for Five West Virginia Rural Clinics (Maximum PM Weekday Peak Hour Trips per Employee) 60

4-11 Regression Plot and Equation for Four West Virginia Rural Clinics

(Maximum AM Weekday Peak Hour Trips per Employee)

4-12 Regression Plot and Equation for Four West Virginia Rural Clinics

(Maximum AM Weekday Peak Hour Trips per $1000 \mathrm{ft}^{2}$ GFA)

4-13 Regression Plot and Equation for Four West Virginia Rural Clinics

(Maximum AM Weekday Peak Hour Trips per Doctor).... 63 


\section{Equations}

2-1 Weighted Average Trip Ends per Land-Use-Specific SEV (Trip Rate) ............... 20

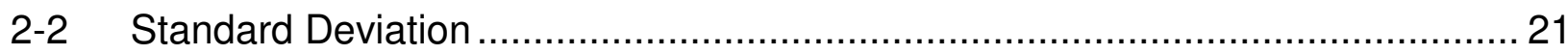

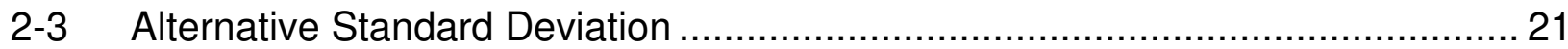

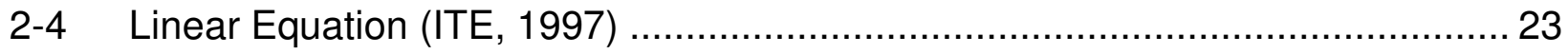

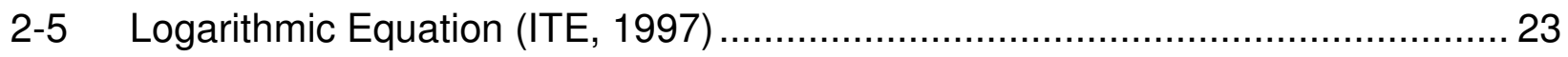

2-6 Constant "a"

2-6 Constant "b" 


\section{List of Symbols and Abbreviations}

AADT Annual Average Daily Traffic

AASHTO American Association of State Highway and Transportation Officials

ADT Average Daily Traffic

$\mathrm{CAH} \quad$ Critical Access Hospital

CMS US Center for Medicare and Medicaid Services

EKG Electrocardiogram

FTE Full Time Equivalent

GFA Gross Floor Area

HCFA Health Care Financing Administration

HRSA Health Resources and Service Administration

ITE Institute of Transportation Engineers

MRI Magnetic Resonance Imaging

K Peak Hour Factor

NRHA National Rural Health Administration

OCRHS Office of Community Rural Health Services, WV Division of Primary Care

ORHP Office of Rural Health Policy

$\mathrm{R}^{2} \quad$ Coefficient of Determination

RHC Rural Health Clinic

SEV Socio Economic Variable 


\section{Chapter 1 Introduction}

\section{$1.1 \quad$ Background}

Trip generation is the process of determining the number and characteristics of vehicle trips originating or terminating at a particular site or land use. Different land uses and/or activities generate different levels of trips depending on the nature and magnitude of the land use activity. This attraction, expressed in the form of trip generation rates, is related to certain independent variables. An independent variable is a physical, measurable unit describing the study land use or activity, such as gross floor area, number of employees, seats, or dwelling units.

Trip generation rates are important to traffic engineers and planners involved with solving problems created by traffic associated with existing or proposed development. Accurate trip generation rates for existing sites are very important in considering possible improvements to increase the capacity of a road or road system. Trip generation rates can also be used to assess the likely impact that proposed development will have on a roadway.

A considerable number of trip generation studies have been done for traffic generators in the United States. Rates from many of the studies have been included in the Institute of Transportation Engineers' [ITE] Trip Generation (1997), which is the principal source for trip generation rates.

\subsection{Problem Statement}

The health needs of a population are served in many ways by various healthcare-related facilities: hospitals, nursing homes, pharmacies, physician offices, and 
clinics. A hospital is an institution with the primary function of providing inpatient diagnostic and therapeutic services for a variety of medical conditions, both surgical and non-surgical. Hospitals typically include an emergency medicine or trauma unit. Nursing homes provide various levels of maintenance and personal care for people who are unable to care for themselves. Pharmacies provide prescription and over-thecounter medications for customers. Physicians' offices perform medical examinations and consultations by appointment. Clinics provide a combination of these services: diagnosis and treatment of outpatients, pharmacy services, and geriatrics.

Rural Americans face health issues that are much different from their urban counterparts. According to the National Rural Health Association [NRHA] (2003), rural areas have nearly half as many physicians per population in comparison to urban areas. Rural residents tend to engage in more hazardous occupations, such as agriculture, mining, and forestry. Rural residents are twice as likely to die in automobile crashes. Rural residents generally have lower incomes and are more likely to live under the poverty level; $24 \%$ of rural children live in poverty (NHRA, 2003). Alcohol abuse and smokeless tobacco use among rural youth are considered serious problems.

The preceding paragraph has shown that there are significant health care needs in rural areas. However, travel to hospitals and physicians is often difficult due to long distances and lack of limited access highways. Health care in rural areas is getting harder to find. For a variety of reasons, nationwide more than 470 rural hospitals closed in the last 25 years (NRHA, 2003). 
The West Virginia Office of Community and Rural Health Services [OCRHS] recognized that the small number of rural hospitals in the state were unable to handle the health care needs of the state's rural residents. The state's predicament was based on its low population density, rugged terrain, severe winters, and long distances separating the residents from care. Consequently, a network of rural health clinics [RHC] has been established to improve access for rural residents to medical care. The Division of Primary Care supports 65 pay clinics and 10 free care clinics throughout the state. The locations of these clinics are shown in Figure 1.1. These clinics are able to provide their services to nearly 320,000 patients annually through approximately 1.1 million visits (OCRHS, 2002). Nationally, the number of rural clinics grew by $250 \%$ between 1992 and 1998, and this trends are expected to continue (Farley, 2003).

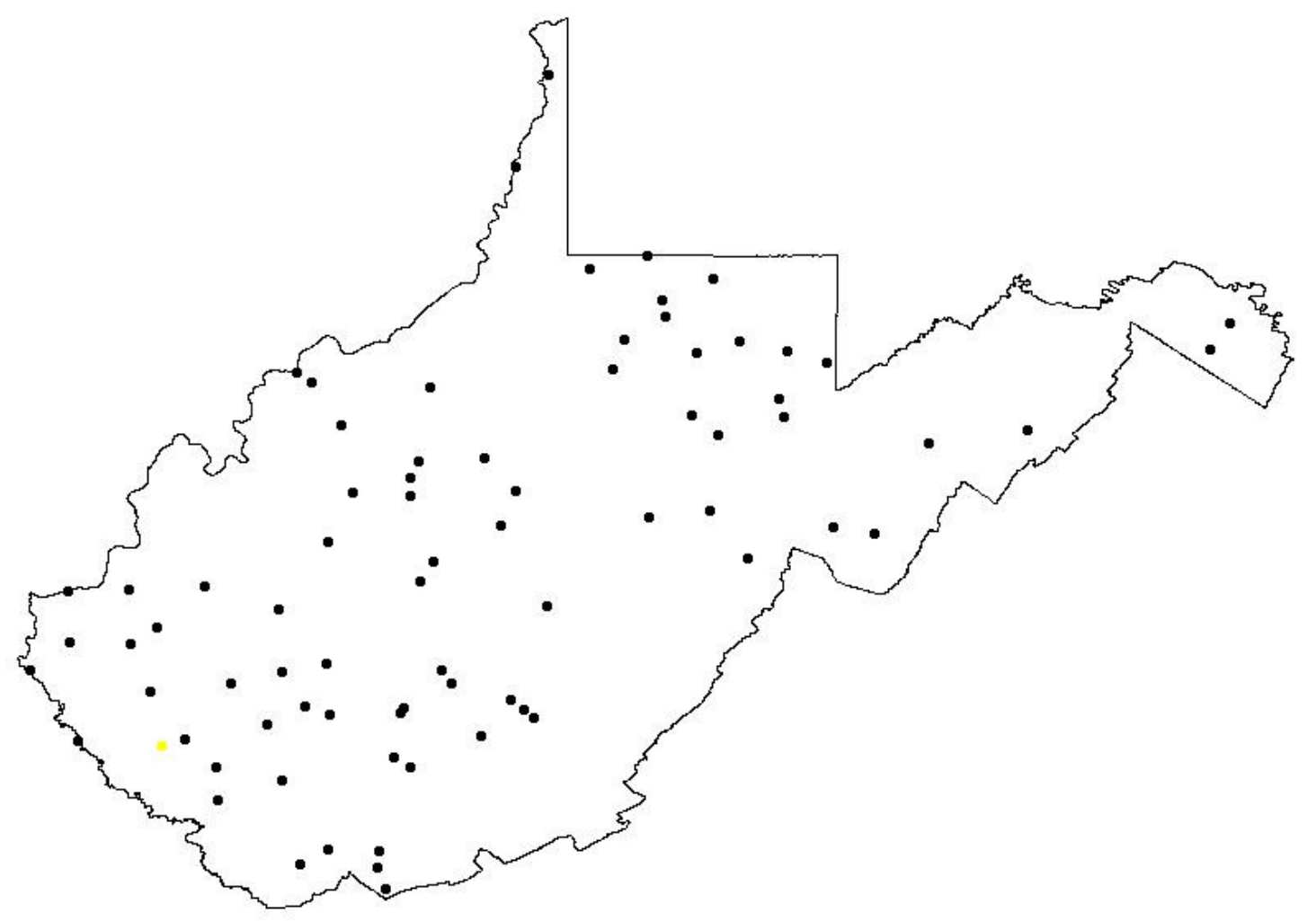

Figure 1- 1Location of Clinics in West Virginia supported by the OCRHS 
The rural clinics are located in both small incorporated and unincorporated communities throughout the state in order to serve the local residents. Although relatively small in terms of square footage, each clinic consists of rooms that provide the general functions of waiting area, administration/operations, examination rooms, pharmacy, and lab. A typical clinic is staffed by a physician, nurse, and office staff. The clinics are charged with providing a variety of health services for their clients including triage, ailment evaluation, preventative check-ups, pharmacy, and informal education. Access is primarily by private motor vehicle.

Given their nature and location, the motor vehicle traffic associated with rural clinics would not normally be expected to create capacity or congestion problems. However, other traffic impact related issues might be of concern. Turning movements entering and exiting the facility may affect traffic operations and safety on the public roadway. Given their rural nature, adjoining land uses are likely to be residential. Thus, local residents may have concerns regarding traffic, noise, and other quality-of-life issues associated with additional traffic. It is also important that sufficient parking be provided on-site so that employees or patients do not have to use local roads and streets for parking.

So that both traffic engineers and facility planners can better predict the traffic impact of rural clinics, it would be desirable to understand their traffic generation characteristics. However, a review of the traffic engineering literature indicates that since rural clinics are a relatively new phenomenon, and are not major traffic generators, there is no published information about their trip characteristics. Thus, it 
would be desirable to collect such data at a sample of sites, to analyze the data, and to determine the trip generation rates and characteristics of rural primary care clinics.

\subsection{Project Objectives}

The overall goal of the project was to determine trip generation characteristics for rural clinics in West Virginia. In order to accomplish this goal, several objectives were identified. These were:

- Review relevant literature on health care facilities and associated trip generation

- Determine a methodology for collecting and analyzing data

- Identify appropriate socio-economic variables for rate calculations

- Identify rural clinics in West Virginia suitable for study and collect socio-economic and traffic data for each site

- Analyze the data to obtain trip generation rates for rural clinics in West Virginia, their peaking characteristics, and vehicle mix classification.

- Prepare a final technical report documenting the results of the study.

\subsection{Organization of Report}

This report is divided into five chapters. Chapter 1 has presented the background information, problem statement, and project objectives. The second chapter summarizes the results of a comprehensive literature review. Chapter 3 describes the methodology used to carry out the project objectives. Chapter 4 summarizes the data collected and presents the trip generation characteristics of rural clinics in West Virginia. The final chapter contains project conclusions and recommendations to users and researchers. 


\section{Chapter 2 Literature Review}

\section{$2.1 \quad$ Introduction}

A literature review was performed to develop an understanding of the role of rural clinics in the health care system and to determine the trip generation characteristics of health care facilities generally. The objectives of the literature review were:

- To understand the role of rural clinics in the health care system

- To explore relevant health care trip generation characteristics

- To understand methodological issues for a trip generation study including sample size, analysis methods, and trip rates.

\subsection{Health Care Facilities}

\subsubsection{Facility Types}

There are a number of health care related facilities including hospitals, physician offices, urgent care centers, clinics, nursing homes, and pharmacies. Each of these entities performs a different role in the health care system. Knowledge of the role and function of each is important in understanding their trip generation characteristics.

General hospitals are the most comprehensive facilities in the health care system. These include, but are not limited to, university, surgical, general, private, and public hospitals. These facilities are capable of handling both major and minor medical needs of patients through general care, inpatient and outpatient procedures, specialized treatment, and emergency medicine. These general hospitals are typically found in urbanized areas. 
One smaller type of hospital is known as Critical Access Hospitals [CAH] designated by the US Center for Medicare and Medicaid Services [CMS], formerly the Health Care Financing Administration [HCFA]. CAHs provide many medical services to rural areas on a smaller scale than general hospitals. CAHs are required to be only in rural locations and are limited in services and accommodations. A CAH is required to have 24-hour emergency services and EMS transportation and an agreement with a non-CAH hospital for referrals (ORHP, 2002). The most common mode of transportation used to access hospitals is private automobile.

Three types of pharmacies are identified by the West Virginia Board of Pharmacy (2003). "Inpatient pharmacies" are those located within another health care facility such as a hospital, nursing home, or clinic. "Outpatient pharmacies" are those located in commercial businesses such as neighborhood drugstores, large grocery stores, and retail super centers. For these first two types of pharmacies, automobile traffic is significant. "Mail order pharmacies" are those which send the majority of their drugs via postal or courier services; for mail order pharmacies, walk-in and drive-up traffic is negligible.

Many types of private physician practices exist, including, surgeons, family practitioners, radiologists, and dentists. West Virginia alone has approximately 1800 physicians and 350 dentists working in private practice offices, and nationally there are about 270,000 physicians and 77,000 dentists in private practice (HRSA, 2003). These practices can commonly be found in stand-alone facilities and medical complexes.

Medicare (2003) identifies 138 nursing homes within the state of West Virginia and over 17,000 nationwide. The facilities are charged with the task of caring for elderly 
patients who are unable to care for themselves. The patients live in the facility. Although the residents are usually not able to drive, staff members and visitors typically access these facilities by private automobiles.

The National Rural Health Association [NRHA] (2003) notes the lack of a uniform definition for rural health clinics. Lack of a uniform definition apparently results from lack of agreement over "access to care." Clinics are certified according to a "designation of need" for an area, and the debate is over whether the clinics should serve those outside the area. While those definitions may be relevant for health care professionals, they do not help transportation engineers understand the nature and operation of such facilities.

The California State Rural Health Association (2003) requirements to obtain the designation of Rural Health Clinic provide additional insight into their nature and operation. Requirements include:

- Designated by Bureau of Census as non-urban and by Health and Human Services as underserved area or health professional shortage area

- Must employ a half-time mid-level practitioner: physician assistant, mid-wife, or nurse practioner

- Must provide out-patient primary care

- Under guidance of a physician who is on-site once every two weeks

- Must provide basic lab tests on-site

Johnston (1977) describes a rural clinic as a relatively "unsophisticated" facility that provides primary care to small towns and rural communities. Primary care is defined as care for common ailments, by general physicians, pediatricians, interns, 
mental health specialists, and related practitioners. Rural health clinics are equipped to handle typical needs with respect to ailments and diseases prevalent within that geographic area. Typical patient services include X-ray, pharmacy, prenatal care, immunization, geriatric medicine, and limited laboratory services to patients. Rural clinics are exclusively outpatient facilities that are not equipped for specialized care such as surgery, long-term care, or chemotherapy. Various names are used to describe this type of facility; these include clinic, ambulatory care facility, and primary care center.

Farley (2003) examined rural health clinics [RHC] on a national basis. In 1992, there were 1,072 rural clinics nationwide; this value increased to 3,749 by 1998 . This is nearly a $250 \%$ increase. The significant increase in number of rural clinics is not surprising given the decrease in number of hospitals in rural areas. It appears that there is an unmet need which the clinics are serving

Farley (2003) used full-time equivalents [FTE] when examining rural clinic staffing characteristics. A physician working 20 hours per week, at a clinic, equals 0.5 staff FTE. In 1998, average staffing at a rural health clinic was as follows.

- Physicians: 1.3 FTE

- Nurse Practitioners: 0.5 FTE

- Physician Assistants: 0.5 FTE

- Total Staff: 5.6 FTE

However, Farley's (2003) paper did not include information on the size of the survey sample or the range in numbers of the employees in each category. Information on facility size was likewise not included. 


\subsubsection{Trip Generation}

Trip generation is a modeling and planning technique that relates trips attracted by and to a land use by time period with land use characteristics. These rates predict the values of trip ends per hour and day of the week by a socio-economic variable (Wright, 1996).

A characteristic with a direct relationship to trip end data must be determined for calculating trip rates; this factor is commonly referred to as a socio-economic variable [SEV]. ITE (1997) refers to the SEV as simply an independent variable defined as a physical, measurable, and predictable unit quantifying the study site or generator. Examples of common independent variables include building size, acreage, employees, beds, and seats.

Trip generation data have been collected for a number of health-care-related land uses. Whitlock (1982) examined the travel characteristics of hospitals, dividing them into four categories: medical centers, general hospitals, extended care facilities, and specialty hospitals. He further noted that there are two basic types for evaluating parking, these being medical centers and general hospitals. General hospitals are classified as those that provide acute care, inpatient clinical and surgical services and outpatient services. Medical centers provide services similar to general hospitals as well as teaching and research activities and office space for private physicians. Interestingly, even at the time of his work (late 1970's) Whitlock (1982) noted a trend toward more clinical services, such as ambulatory care centers and services administered to outpatients. 
Whitlock (1982) divided the daily population of the hospitals into two categories: staff and visitors, based on length of stay and frequency. With some exceptions, staff typically remains at the facility for the day. Exceptions include attending physicians, volunteers and clergy. Population distribution, including composition and activity, is detailed in Table 2-1 from Whitlock (1982). From the table, it is apparent that visitors comprise the majority of the daily population for both facilities. Staff members typically comprise less than half of the total daily population.

Table 2- 1 Daily Population Distribution for General Hospitals and Medical Centers (Whitlock, 1982)

\begin{tabular}{|c|c|c|c|c|}
\hline Population Segment & \begin{tabular}{|l|} 
General \\
Percent of Sub- \\
Population
\end{tabular} & \begin{tabular}{l||} 
Hospitals \\
Percent of Total
\end{tabular} & \begin{tabular}{|l} 
Medical \\
Percent of Sub- \\
Population
\end{tabular} & $\begin{array}{l}\text { Centers } \\
\text { Percent of Total }\end{array}$ \\
\hline Staff & & & & \\
\hline Employees & 83 & 31 & | 87 & 36 \\
\hline Interns/Residents & 1 & 1 & 4 & 1 \\
\hline Attending Physicians & 8 & 2 & |2 & 1 \\
\hline Students & 3 & 1 & 6 & 2 \\
\hline Volunteers/Clergy & 5 & 2 & 1 & 1 \\
\hline Total/Subtotal & 100 & 37 & 100 & 41 \\
\hline Visitors & & & & \\
\hline Inpatients Visitors & 78 & 49 & 71 & 40 \\
\hline Buisness Visitors & 3 & 1 & 4 & 3 \\
\hline $\begin{array}{l}\text { Emergency Room Visitor } \\
\text { Outpatient/Private }\end{array}$ & 9 & 5 & | 9 & 5 \\
\hline Physician Visits & 10 & 8 & ||16 & 11 \\
\hline Total/Subtotal & 100 & 63 & 100 & 59 \\
\hline
\end{tabular}

Table 2-2 presents a summary of daily population activity at hospitals and medical centers on the basis of patient bed capacity. Note that there are significantly more staff and visitor per bed at medical centers. Whitlock (1982) attributed this to increased outpatient business and the broader spectrum of services typically provided at medical centers. He concludes that because of varying generation factors, "it is 
unwise to plan parking facilities at medical institution solely on a per bed ratio, as in years past."

Table 2- 2 Daily Population Activity at General Hospitals and Medical Centers (Whitlock, 1982)

\begin{tabular}{|lccc|}
\hline & $\begin{array}{c}\text { Number of } \\
\text { Study } \\
\text { Centers }\end{array}$ & \multicolumn{2}{c|}{$\begin{array}{c}\text { Number of Daily } \\
\text { Persons per Bed }\end{array}$} \\
\cline { 3 - 4 } & Staff & Visitors \\
\hline \hline $\begin{array}{c}\text { Medical Centers } \\
\text { Average }\end{array}$ & 15 & & \\
Range & & 2.5 & 5.0 \\
\hline $\begin{array}{c}\text { General Hospitals } \\
\text { Average }\end{array}$ & 15 & 3.16 .0 & $2.7-8.5$ \\
\hline Range & & $2.0-6.5$ & $4.4-9.5$ \\
\hline
\end{tabular}

Whitlock (1982) also examined seasonal and hourly variations in hospital activity. With regards to seasonal variations it was noted that fall and winter months were above average for admissions and length of stay of inpatients. Hourly variations in activity were determined by observing the percentage of parking spaces occupied, therefore trip rates were unavailable; however, a morning peak at $9 \mathrm{AM}$ denoted the largest increase in parking usage as outpatients and visitors arrive. The largest decrease in parking usage occurred between 4 and $5 \mathrm{pm}$.

ITE (1997) provides trip generation data for five basic health care related land uses. Hospitals, nursing homes, and clinics are listed under the "Medical" category, medical/dental offices are listed under "Office," and pharmacies/drugstores with drive through window and without drive through window are listed under the "Retail" heading.

ITE (1997) defines a hospital as "any institution where medical or surgical care and overnight accommodations are provided to non-ambulatory and ambulatory patients." ITE (1997) presents three SEVs: employees, gross floor area, and beds. Weekday peak hours were found to be between 8:00 AM and 10:00 AM and between 
1:00 PM and 5:00 PM. ITE (1997) trip generation values are presented in Table 2-3.

The column, "Avg. Number of SEV," represents the average size of the independent variable for the hospitals included in the database. Also presented is the standard deviation and sample size for each of the rates.

Table 2- 3 ITE (1997) Trip Generation Data for Hospitals

\begin{tabular}{|c|c|c|c|c|c|}
\hline SEV & Time Period & Avg. Rate & $\begin{array}{l}\text { Standara } \\
\text { Deviation }\end{array}$ & $\begin{array}{l}\text { Number } \\
\text { of Sites }\end{array}$ & $\begin{array}{l}\text { Avg. Number } \\
\text { of SEV }\end{array}$ \\
\hline \multirow[t]{7}{*}{ Employees } & Weekday & \begin{tabular}{|r|}
5.17 \\
\end{tabular} & 2.90 & 19 & 888 \\
\hline & AM Peak on Adjacent Street & 0.31 & 0.57 & 8 & 1410 \\
\hline & PM Peak on Adjacent Street & 0.29 & 0.54 & 7 & 1526 \\
\hline & Weekday AM Peak & 0.35 & 0.60 & 7 & 1294 \\
\hline & Weekday PM Peak & 0.46 & 0.71 & 15 & 876 \\
\hline & Saturday & 3.72 & 2.21 & 15 & 826 \\
\hline & Sunday Peak Hour & 0.55 & 0.76 & 6 & 491 \\
\hline \multirow{9}{*}{$\begin{array}{l}1000 \text { Sq. Ft. } \\
\text { GFA }\end{array}$} & Weekday & 16.78 & 8.91 & 14 & 301 \\
\hline & AM Peak on Adjacent Street & 0.97 & 1.03 & 5 & 497 \\
\hline & PM Peak on Adjacent Street & 0.92 & 0.99 & 5 & 497 \\
\hline & Weekday AM Peak & 1.20 & 1.10 & 4 & 400 \\
\hline & Weekday PM Peak & 1.46 & 1.34 & 9 & 309 \\
\hline & Saturday & 11.07 & 6.54 & 13 & 315 \\
\hline & Saturday Peak Hour & 1.16 & & 2 & 176 \\
\hline & Sunday & 9.91 & 6.03 & 13 & 315 \\
\hline & Sunday Peak Hour & 1.75 & 1.38 & 5 & 180 \\
\hline \multirow[t]{9}{*}{ Beds } & Weekday & 11.77 & $\overline{7.14}$ & 20 & 392 \\
\hline & Weekday AM Peak & 1.07 & 1.10 & 7 & 507 \\
\hline & AM Peak on Adjacent Street & 1.22 & 1.17 & 7 & 507 \\
\hline & Weekday AM Peak & 1.18 & 1.16 & 6 & 508 \\
\hline & Weekday PM Peak & 1.41 & 1.29 & 14 & 332 \\
\hline & Saturday & 8.03 & 4.73 & 15 & 403 \\
\hline & Saturday Peak Hour & 0.69 & 0.89 & 3 & 336 \\
\hline & Sunday & 7.19 & 4.49 & 15 & 403 \\
\hline & Sunday Peak Hour & 1.03 & 1.10 & 7 & 279 \\
\hline
\end{tabular}

Various characteristics of the hospitals included in the ITE (1997) database can be noted by examining the average values of the socio-economic variables. The hospitals have staffs ranging from about 500 to over 1500 employees, and average 170 to 500 thousand square feet in size with 300 to 500 beds. Rates of 5.17 trips per employee, 16.78 trips per 1000 gross floor area, and 11.77 trips per bed on a weekday illustrates the traffic activity at the hospitals studied. 
ITE (1997) defines a nursing home as "any facility whose primary function is to care for persons who are unable to care for themselves, for example rest homes and chronic care and convalescent homes." The residents rarely drive, therefore, the majority of the traffic is generated by employees, visitors, and deliveries. The trip generation rates are with respect to four SEVs: employees, occupied beds, beds, and gross floor area. ITE (1997) trip generation values for nursing homes are presented in Table 2-4.

Table 2- 4 ITE (1997) Trip Generation Data for Nursing Homes

\begin{tabular}{|c|c|c|c|c|c|}
\hline SEV & Time Period & Avg. Rate & $\begin{array}{l}\text { Standard } \\
\text { Deviation }\end{array}$ & $\begin{array}{l}\text { Number 01 } \\
\text { Sites }\end{array}$ & $\begin{array}{l}\text { AVg. Number } \\
\text { of SEV }\end{array}$ \\
\hline \multirow[t]{7}{*}{ Employees } & Weekday & 4.03 & 2.51 & 18 & 72 \\
\hline & Weekday AM Peak & 0.33 & & 2 & 159 \\
\hline & Weekday PM Peak & 0.48 & - & 2 & 171 \\
\hline & Saturday & 3.39 & 2.46 & 17 & 71 \\
\hline & Saturday Peak Hour & 0.58 & 0.81 & 17 & 71 \\
\hline & Sunday & 3.72 & 2.53 & 17 & 71 \\
\hline & Sunday Peak Hour & 0.67 & 0.87 & 18 & 71 \\
\hline \multirow{9}{*}{$\begin{array}{l}\text { Occupied } \\
\text { Beds }\end{array}$} & Weekday & 3.24 & - & 1 & 176 \\
\hline & AM Peak on Adjacent Street & 0.19 & 0.44 & 11 & 193 \\
\hline & PM Peak on Adjacent Street & 0.17 & 0.42 & 11 & 193 \\
\hline & Weekday AM Peak & 0.20 & 0.46 & 11 & 193 \\
\hline & Weekday PM Peak & 0.27 & 0.53 & 11 & 193 \\
\hline & Saturday & 1.52 & 1.41 & 3 & 254 \\
\hline & Saturday Peak Hour & 0.26 & 0.52 & 3 & 254 \\
\hline & Sunday & 1.98 & 1.59 & 3 & 254 \\
\hline & Sunday Peak Hour & 0.33 & 0.59 & 3 & 254 \\
\hline \multirow[t]{9}{*}{ Beds } & Weekday & 2.61 & 1.68 & 20 & 110 \\
\hline & AM Peak on Adjacent Street & 0.17 & - & 2 & 90 \\
\hline & PM Peak on Adjacent Street & 0.20 & 0.44 & 3 & 92 \\
\hline & Weekday AM Peak & 0.12 & 0.36 & 3 & 128 \\
\hline & Weekday PM Peak & 0.36 & 0.60 & 4 & 97 \\
\hline & Saturday & 2.15 & 1.55 & 17 & 112 \\
\hline & Saturday Peak Hour & 0.37 & 0.61 & 17 & 112 \\
\hline & Sunday & 2.36 & 1.62 & 17 & 112 \\
\hline & Sunday Peak Hour & 0.41 & 0.64 & 19 & 116 \\
\hline \multirow{4}{*}{$\begin{array}{l}1000 \text { Sq. Ft. } \\
\text { GFA }\end{array}$} & AM Peak on Adjacent Street & 0.40 & 0.63 & 4 & 110 \\
\hline & PM Peak on Adjacent Street & 0.36 & 0.63 & 4 & 110 \\
\hline & Weekday AM Peak & 0.40 & 0.64 & 4 & 110 \\
\hline & Weekday PM Peak & 0.58 & 0.77 & 4 & 97 \\
\hline
\end{tabular}


Various characteristics of the nursing homes included in the ITE (1997) database can be noted by examining the trip rates and average socio-economic variables. The nursing homes have staffs ranging from approximately 70 to 170 employees and floor areas on the order of 100 thousand square feet. Therefore, these facilities are much smaller than the hospitals included in the ITE database. Trip rates per employee are similar to those for hospitals. Rates per bed are much smaller than those for hospitals, as was expected.

ITE (2003) defines a medical-dental office building as "a facility that provides diagnosis and out-patient care on a routine basis but is unable to provide prolonged inhouse medical and surgical care. This type of facility is generally operated by one or more private physicians or dentists." Only two SEVs are presented for medical-dental office buildings, employees and gross floor area. ITE (1997) trip generation values are presented in Table 2-5.

Table 2- 5 ITE (1997) Trip Generation Data for Medical-Dental Office Building

\begin{tabular}{|c|c|c|c|c|c|}
\hline SEV & Time Period & Avg. Rate & $\begin{array}{l}\text { Standara } \\
\text { Deviation }\end{array}$ & $\begin{array}{l}\text { Number } \\
\text { of Sites }\end{array}$ & $\begin{array}{l}\text { AVg. Number } \\
\text { of SEV }\end{array}$ \\
\hline \multirow[t]{9}{*}{ Employees } & Weekday & 8.91 & 3.95 & 5 & 127 \\
\hline & AM Peak on Adjacent Street & 0.53 & $\overline{0.76}$ & 10 & 120 \\
\hline & PM Peak on Adjacent Street & 1.06 & 1.08 & 15 & 88 \\
\hline & Weekday AM Peak & 0.80 & 0.98 & 11 & 209 \\
\hline & Weekday PM Peak & 0.97 & 1.06 & 16 & 151 \\
\hline & Saturday & 4.02 & 2.41 & 4 & 116 \\
\hline & Saturday Peak Hour & 0.88 & 0.95 & 3 & 116 \\
\hline & Sunday & 0.64 & 0.88 & 3 & 116 \\
\hline & Sunday Peak Hour & 0.10 & & 2 & 142 \\
\hline 1000 Sq. Ft. & Weekday & 36.13 & 10.18 & 10 & 45 \\
\hline \multirow[t]{8}{*}{ GFA } & AM Peak on Adjacent Street & 2.43 & 1.92 & 20 & 40 \\
\hline & PM Peak on Adjacent Street & 3.66 & 2.46 & 40 & 30 \\
\hline & Weekday AM Peak & 3.60 & 2.40 & 15 & 41 \\
\hline & Weekday PM Peak & 4.36 & 2.46 & 20 & 32 \\
\hline & Saturday & 8.96 & 9.17 & 5 & 44 \\
\hline & Saturday Peak Hour & 3.63 & 1.93 & 3 & 28 \\
\hline & Sunday & 1.55 & 1.80 & 4 & 49 \\
\hline & Sunday Peak Hour & 0.40 & & 2 & 34 \\
\hline
\end{tabular}


Various characteristics of the medical-dental office buildings included in the ITE (1997) database can be noted by examining the trip rates and average socio-economic variables. The medical-dental office buildings average about 120 employees, similar to nursing homes. However, they are much smaller in size than hospitals or nursing homes. Employee rates are similar to those previously mentioned, while gross floor area rates are much higher for medical-dental office buildings compared to hospitals and nursing homes.

ITE (1997) defines a pharmacy/drugstore as "a retail facility that sells prescription and nonprescription drugs. These facilities may also sell cosmetics, toiletries, medications, stationery, personal care products, limited food products, and general merchandise." Gross floor area is the only SEV used for pharmacies. From a traffic generation standpoint, ITE (1997) separates pharmacies into two distinct types: those with drive-through windows and those without. The ITE (1997) trip generation values for both categories are presented in Table 2-6.

Table 2- 6 ITE (1997) Trip Generation Data for Pharmacies/Drugstores

(a) without Drive-Through Window

\begin{tabular}{|l|l||r|r|r|r|}
\hline \multirow{2}{*}{ SEV } & Time Period & Avg. Rate & $\begin{array}{l}\text { Standarara } \\
\text { Deviation }\end{array}$ & $\begin{array}{l}\text { Number } \\
\text { of Sites }\end{array}$ & $\begin{array}{l}\text { Avg. Number } \\
\text { of SEV }\end{array}$ \\
\hline \hline \multirow{2}{*}{$\begin{array}{l}\text { GFo Sq. Ft. } \\
\text { GFA }\end{array}$} & PM Peak on Adjacent Street & 7.63 & 3.26 & 6 & 11 \\
\cline { 2 - 6 } & Weekday AM Peak Hour & 7.64 & 2.84 & 6 & 11 \\
\cline { 2 - 6 } & Weekday PM Peak Hour & 8.62 & 3.15 & 6 & 11 \\
\hline
\end{tabular}

(b) with Drive-Through Window

\begin{tabular}{|l|l||r|r|r|r|}
\hline \multirow{3}{*}{ SEV } & Time Period & Avg. Rate & $\begin{array}{l}\text { Standarard } \\
\text { Deviation }\end{array}$ & $\begin{array}{l}\text { Number } \\
\text { of Sites }\end{array}$ & $\begin{array}{l}\text { Avg. Number } \\
\text { of SEV }\end{array}$ \\
\hline \multirow{3}{*}{$\begin{array}{l}\text { 1000 Sq. Ft. } \\
\text { GFA }\end{array}$} & Weekday & 88.16 & 14.37 & 3 & 14 \\
\cline { 2 - 6 } & AM Peak on Adjacent Street & 2.66 & 1.80 & 3 & 14 \\
\cline { 2 - 6 } & PM Peak on Adjacent Street & 10.40 & 5.41 & 5 & 14 \\
\cline { 2 - 6 } & Weekday AM Peak Hour & 6.71 & 2.63 & 3 & 14 \\
\cline { 2 - 6 } & Weekday PM Peak Hour & 9.18 & 4.09 & 4 & 14 \\
\hline
\end{tabular}


Various characteristics of the pharmacies included in the ITE (1997) database can be noted by examining the trip rates and average socio-economic variables. The pharmacy buildings average 11 to 14 thousand square feet, smaller than the previously mentioned land uses. The trip rates appear to be much higher than the rates presented for hospitals, medical-dental office buildings, and nursing homes. This is not surprising since modern pharmacies serve a variety of retail needs beyond prescription drugs. Trip generation rates for the two classifications of pharmacies were similar; however, pharmacies with drive-through windows had slightly higher rates. This is an expected consequence, because the convenience of the window is an appeal to some customers.

The definition of a "rural" clinic is not directly addressed by ITE (1997). Clinic is defined as a "facility that provides diagnostic and outpatient care, but which is not equipped to provide prolonged in-house medical/surgical care." The publication also notes the vagueness of the definition in that a wide range of facilities use the name clinic. While the ITE definition could certainly apply to rural clinics, it is not clear if rural clinics are included in the ITE database.

ITE (1997) identifies the use of three different clinic SEV's: employees, number of full-time doctors, and gross floor area. Doctors is a SEV that does not appear in any of the other health care land uses, while employees and gross floor area are typical SEVs. Employees and full-time doctors are simply defined as a quantity. Gross floor area is defined as the sum in square feet, of the area at each floor level within the exterior faces of the building. The clinic trip generation rates and sample sizes included in the ITE Trip Generation handbook (1997) are presented in Table 2-7. 
Table 2- 7 Clinic Trip Generation Rates as Presented in ITE Trip Generation Handbook (ITE 1997)

\begin{tabular}{|c|c|c|c|c|c|}
\hline SEV & Time Period & Avg. Rate & $\begin{array}{l}\text { Standara } \\
\text { Deviation }\end{array}$ & $\begin{array}{l}\text { Number } \\
\text { of Sites }\end{array}$ & $\begin{array}{l}\text { AVg. Number } \\
\text { of SEV }\end{array}$ \\
\hline \multirow[t]{6}{*}{ Employees } & Weekday & 7.75 & & 2 & 457 \\
\hline & PM Peak on Adjacent Street & 1.23 & 1.11 & 3 & 114 \\
\hline & Weekday AM Peak & 0.90 & - & 1 & 20 \\
\hline & Weekday PM Peak & 1.31 & - & 2 & 39 \\
\hline & Saturday & 3.35 & - & 1 & 650 \\
\hline & Sunday & 5.97 & - & 1 & 650 \\
\hline \multirow{3}{*}{$\begin{array}{l}\text { Full-Time } \\
\text { Doctors }\end{array}$} & Weekday & 3.60 & - & 1 & 5 \\
\hline & PM Peak on Adjacent Street & 3.78 & - & 2 & 12 \\
\hline & Weekday PM Peak & 4.43 & - & 2 & 12 \\
\hline \multirow{4}{*}{$\begin{array}{l}1000 \text { Sq. Ft. } \\
\text { GFA }\end{array}$} & Weekday & 31.45 & & 2 & 112 \\
\hline & PM Peak on Adjacent Street & 5.18 & & 1 & 64 \\
\hline & Saturday & 13.54 & - & 1 & 161 \\
\hline & Sunday & 24.10 & - & 1 & 161 \\
\hline
\end{tabular}

A noteworthy finding from Table $2-5$ is that all but one of the rates shown were based on only one or two sites. The rates for other health care related facilities presented earlier in this chapter were based on significantly larger sample sizes. This raises concerns about the applicability, to clinics generally, of rates that are based on only one site.

Compounding the problem is the lack of specific information about the nature and characteristics of the one or two clinics studied. However, review of the limited information available suggests that these one or two clinics were not rural clinics. For example, Saturday and Sunday rates are included, implying that these clinics were open on weekends. The researcher's experience in West Virginia indicates that rural clinics are typically closed on weekends.

ITE (1987) states that one of the first two clinics in the database functioned primarily as a hospital with 650 employees, 240 beds, and 161,000 square feet of gross floor area. This site could adversely affect rates that represent not only rural clinics but clinics generally. 
It can be concluded that, for rural clinics generally, the available trip generation data are extremely limited. No published information could be located relative to trip generation characteristics of rural clinics.

\subsection{Methodological Issues}

ITE (1997) suggests a standard technique for collecting and analyzing the data needed to develop trip generation rates; failure to follow the accepted procedures may lead to invalid results. Rates could be calculated that are considered unreliable or nontransferable. For example, the sample size on which rates are based could be too small or the variance of the data could be greater than accepted practice recommends.

Adherence to the procedure is important throughout the process, including initial planning. The study plan or experimental design should address sample size, types of average trip rates, and analysis techniques.

\subsubsection{Sample Size}

Sample size is an important factor in a trip generation study, since it directly influences the standard deviation, variance, and reliability of the results. An equation was offered in Neumann and Deshpande's (1974) traffic generator report based on the student's t distribution. The equation requires an estimated standard deviation. This is a limitation when trying to determine sample size for a land use for which there are no published trip generation data.

French, Eck, and Balmer's (2000) review of trip generation literature identified that most study sample sizes were under ten observations per land use. ITE's database includes larger sample sizes, yet these are due to the fact the database is a collection of many sources. 
ITE (1997) does not offer much guidance relative to sample size determination. The only mention is with regards to performing regression analysis on collected trip data. ITE (1997) states that trip generation data must be a collection of four or more sites before regression analysis is applicable.

\subsubsection{Average Trip Rate}

Count data collected during a trip generation study is compiled into a dataset which produces two mean values computed by dividing the sum of the results in the dataset by the total number of observations. These average rates are:

- Weighted average trip ends per unit time (peak hour, day, etc.)

- Weighted average trip ends per land-use-specific SEV (trip rate) Equation 2-1.

$$
\begin{aligned}
& R_{a w}= \frac{\sum V_{i}}{\sum S E V_{i}} \\
& \text { where: } \\
& \mathrm{R}_{\mathrm{aw}}=\text { average weighted trip rate } \\
& \quad \mathrm{V}_{\mathrm{i}=\text { trip ends per unit time }} \\
& \mathrm{SEV} \mathrm{V}_{\mathrm{i}}=\text { individual socioeconomic variables }
\end{aligned}
$$

Weighted average trip ends per time are used rather than average trip ends per time in order to reduce variance occurring between sites. Average daily trip ends for a location are the total number of trip ends over the period of time in days. The weighted average daily trip rates, used by ITE (1997), are weighted to the number of sites. So, if two or more studies of the same land use had different numbers of observations, the rate would be calculated by summing the total trip ends over the total number of locations, rather than just averaging the rates. 
As in the trip ends per time, the trip rate is calculated using the weighted average method. The trip rate is expressed as a linear equation with a positive slope equal to the rate, intercepting the origin. According to Buttke (1990), this method should be used only with low standard deviations, although a bound is not specifically identified. This technique is designed to eliminate any controversy in interpolating data. However, it is noted that a low standard deviation is not always applicable, therefore it is stated that a scatter plot should be used when the standard deviation is high.

\subsubsection{Analysis Techniques}

Roess, McShane, and Prassas (1998) note that the standard deviation is the most commonly used technique for evaluating a spread of data around the mean. When data is scarce, Equation 2-2 should be used. The equation squares the difference between a point in the dataset and the mean, then divides it by one less than the total number of observations. The subtraction of one from the observations is due to losing one degree of freedom by using the mean in the calculation. Due to the fact that data is collected in bulk, a more convenient equation is illustrated as Equation 2-3. This equation combines like observations and reduces the length of calculations.

$$
\begin{aligned}
& \mathrm{s}=\sqrt{\frac{\sum\left(x_{i}-\bar{x}\right)^{2}}{N-1}} \\
& \mathrm{~s}=\sqrt{\frac{\sum n_{i} x_{i}^{2}-N \bar{x}^{2}}{N-1}} \\
& \text { Where } \quad \mathrm{s}=\text { Standard Deviation } \\
& \mathrm{n}_{\mathrm{i}}=\text { Number of readings } \mathrm{x}_{\mathrm{i}}
\end{aligned}
$$




$$
\begin{aligned}
& \mathrm{x}_{\mathrm{i}}=\text { Value in dataset } \\
& \mathrm{N}=\text { Total number of observations } \\
& \bar{x}=\text { Mean of dataset }
\end{aligned}
$$

The most elementary method of displaying data is through the use of a scatter plot where each studied site is represented by a coordinate on the plot. ITE (1997) uses the technique of placing the dependent variable trip ends on the vertical (y) axis. The independent variable or SEV is then placed on the horizontal $(x)$ axis. When the data forms a near-linear relationship on the plot, predictions can be made by interpolating between coordinates. However, it is common for the points to not appear linear. In this case, regression analysis is used to compute predicted values of trip ends (Buttke, 1990).

The standard deviation and coefficient of determination $\left[R^{2}\right]$ are also very important in determining the appropriate methods for displaying and selecting a trip generation rate. $R^{2}$ is the "percent of variance in the number of the trips associated with the variance in the sample size" of the SEV. ITE (1997) classifies weighted average trip generation rates with a standard-deviation-to-mean ratio, or consistency, of less than $110 \%$ as "good". Use of equations and plotted curves as a representation of the rate is considered "good" if the $R^{2}$ is calculated to be greater than 0.75 . Even though not classified as "good," an equation and plotted curve are shown in the Trip Generation handbook (1997), if they meet three criteria:

- $\mathrm{R}^{2}$ is greater or equal to 0.40 (0.35 may be considered).

- Sample size of greater than 4 sites.

- Trips increase as the size of the variable increases. 
In most instances, the relationship between data in a set is too complicated to describe, however this relationship can often be approximated through the use of regression analysis. When the relation is simplified to a single variable affecting the response variable, it is labeled as single variable regression analysis. When multiple variables are used to represent the relationship, it is called multi-variable regression.

Single variable regression analysis attempts to minimize the difference between the function and data coordinates through the least squares method. The results of the analysis form an equation, which can be used as a prediction tool for future development of similar land uses. In the process of creating a regression equation, three assumptions must be made (Hogg and Ledolter, 1987):

- Means of the dependent variable lie in a straight line

- $Y$ values are independently and normally distributed for each $x$ value

- Variance is constant among $x$ and $y$ values

Least square equations can be adapted to any basic type of equation; however, ITE (1997) accepts two types: linear (equation 2-4) and logarithmic (equation 2-5). Linear equation have no submission limitations, however, limitations are imposed for logarithmic. ITE (1997) requires that there must be at least 4 observations and a positive slope. Equations 2-6 and 2-7 define the calculations for the constants $a$ and b, respectively (ITE, 1997).

$$
\begin{aligned}
& \mathrm{T}=\mathrm{ax}+\mathrm{b} \\
& \operatorname{Ln}(\mathrm{T})=\mathrm{aLn}(\mathrm{x})+\operatorname{Ln}(\mathrm{b}) \\
& \mathrm{a}=\frac{1}{n} \sum_{i=1}^{n} T_{I}-\frac{b}{n} \sum_{i=1}^{n} x_{i}=\bar{T}-b \bar{x}
\end{aligned}
$$


$\mathrm{b}=\frac{\sum_{i=1}^{n} x_{i} T_{i}-\frac{1}{n}\left(\sum_{i=1}^{n} x_{i}\right)\left(\sum_{i=1}^{n} T_{i}\right)}{\sum_{i=1}^{n} x_{i}^{2}-\frac{1}{n}\left(\sum_{i=1}^{n} x_{i}\right)}$

Where: $\quad \mathrm{T}=$ dependent variable (trip ends)

$\mathrm{X}=$ independent variable $(\mathrm{SEV})$

$\mathrm{a}=$ slope

$b=y$-intercept

$\mathrm{n}=$ number of observations (sites)

\subsubsection{Displaying Results}

The results of a trip generation study should be presented in a format that can be used by multiple people and agencies. Therefore, it was determined that the format provided by the Institute of Transportation Engineers would be best suited due to its wide acceptance in the traffic engineering and planning communities. The ITE (1997) format requires that the information listed below be presented on a single page. A sample page is included as Appendix A. It should be noted that each of the following items must be present on the form.

- Number of sites included

- Average SEV for the sample

- Average weighted trip rate

- Trip rate range

- Standard deviation

- Data plot including

- Scatter Plot of data 
- Average weighted rate

- Regression curve

- Regression Equation

- $\mathrm{R}^{2}$ value

The results should include a data sheet for each of the SEV's used for each of the relevant time periods including:

- Weekday

- Weekday AM peak hour trips

- Weekday PM peak hour trips

- Weekday peak hour trips

- Peak hour of adjacent street traffic, one hour between 8 and 10 AM

- Peak hour of adjacent street traffic, one hour between 4 and 6 PM

- Saturday

- Saturday peak hour

- Sunday

- Sunday peak hour

Figure 2-1 is a sample of the manner in which this information is presented in the ITE Trip Generation manual (1997). The excerpt comes from section 630 "Clinics." The page illustrates the trip generation information available for the weekday pm peak hour on an adjacent street relative to the SEV, employees. Weighted average trip generation rates are always presented. For this data, the standard-deviation-to-mean ratio would be $1.11 / 1.23=0.90$. Since this is less than 1.10 , according to the ITE criteria, the rate 


\section{Average Vehicle Trip Ends vs: Employees \\ On a: Average Weekday}

Number of Studies: 3

Average Number of Variable: 114

Directional Distribution: $\quad 41 \%$ entering, 59\% exiting

\section{Trip Generation per Employee}

\begin{tabular}{|ccc|}
\hline Average Rate & Range of Rates & Standard Deviation \\
\hline 1.23 & $1.10-1.26$ & 1.11 \\
\hline
\end{tabular}

\section{Data Plot and Equation}

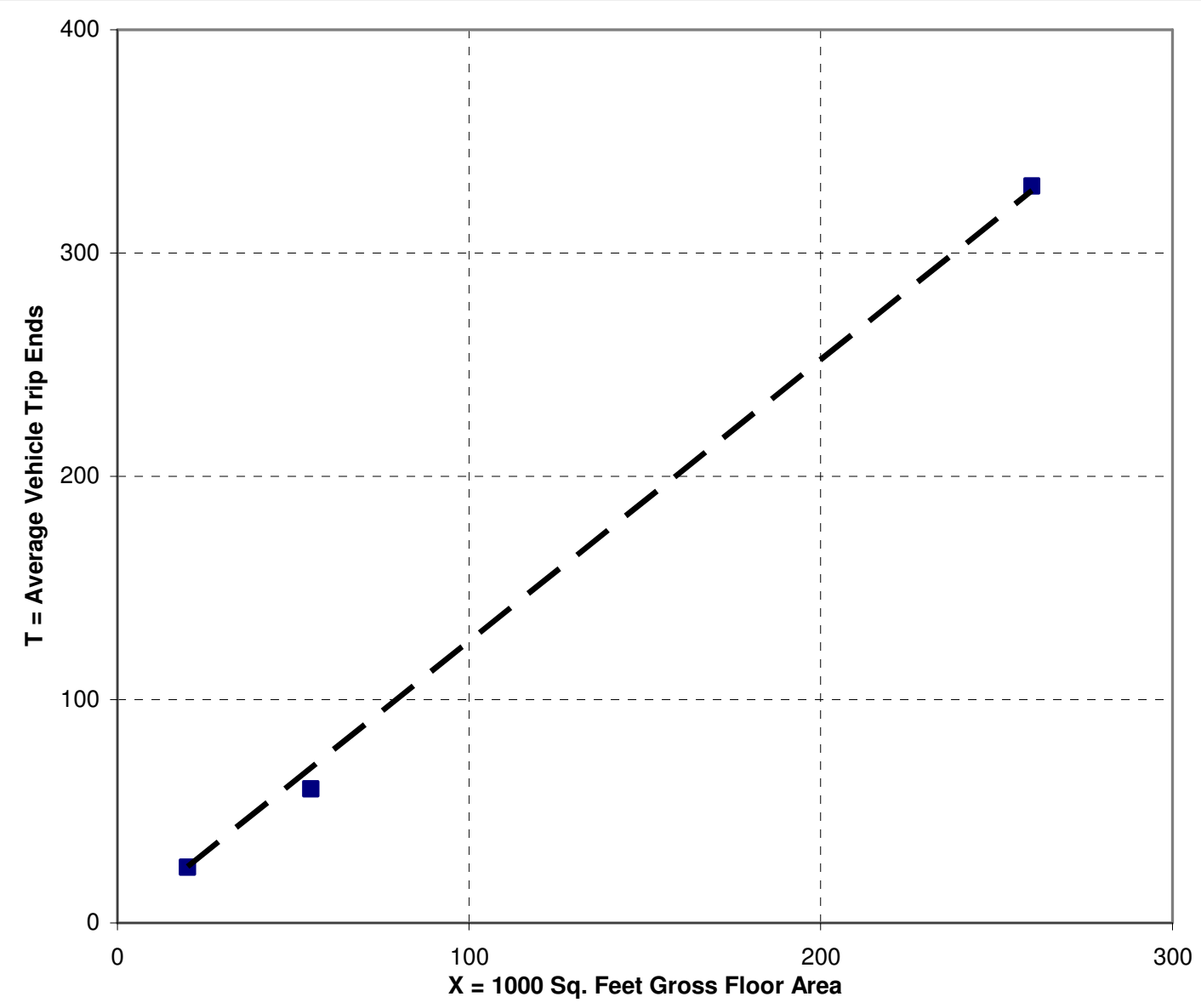

Actual Data Points

Fitted Curve

Average Rate

Fitted Curve Equation: $\mathrm{T}=$

Figure 2-1 ITE (1997) Trip Rate Form for Clinics (Trips per Employees on Average Weekday) 
would be classified as "good." However, an equation and plotted curve were not shown since the ITE criterion of a minimum sample size of 4 sites was not met (only 3 sites were involved). Since the minimum sample size criterion was not met, a $R^{2}$ value was not computed. The trip ends increase as the number of employees increase, i.e., a positive slope. Therefore, this criterion was met.

\subsection{Concluding Remarks}

Rural clinics are primary care facilities serving small towns and rural communities. While they tend to be small in size and have only one or two physicians on staff, they fill a healthcare need in geographic areas where hospitals and/or physician's offices are difficult to reach. During the 1990's, the number of rural clinics in the United States grew rapidly. This growth is expected to continue, as the number of hospitals, particularly those serving rural areas, declines.

From the literature review, it was determined that trip generation data are available for a variety of health care related facilities, including hospitals, physician offices, pharmacies, and nursing homes. The ITE trip generation database includes very limited data (one or two sites) for "clinics." However, it appears that these clinics are not rural clinics since their physical and staff size suggest they are more like small hospitals. Thus, there is a need to acquire trip generation data for rural clinics. The ITE literature presents a standard methodology for conducting such studies. 


\section{Chapter 3 Methodology}

\subsection{Introduction}

The methodology recommended by ITE's Trip Generation (1997) was used in this research due to its acceptance within the discipline. ITE (1997) identifies four basic steps:

- Site selection

- Data collection

- Analysis and computation

- Presentation of results

Each of these steps was followed in conducting this study. Each step will be described in this chapter.

\subsection{Site Selection}

\subsubsection{Site Selection Criteria}

A careful selection of sites must be undertaken to attempt to eliminate the collection of problematic or unreliable data. ITE (1997) suggests six general criteria for selecting a site. These are identified below and discussed in the context of the current study.

Sites need to be freestanding and have single facility parking. If the clinic shared office space or parking facilities with other entities, then determining specific trip destinations would be difficult, and any rates developed would reflect higher than actual values. Therefore, it was determined that clinics that were not freestanding or which shared parking with another entity would not be suitable as a study site for the project. 
A site must provide adequate parking so that patrons and employees are not required to park off site. Insufficient on-site parking could result in patrons and employees parking on local streets and other parking areas. Such trip ends would be difficult to quantify, since they would be outside the count location. The researcher determined this visually during the site visit as well as through discussion with facility managers.

Sites must not have the potential for cut-through traffic. Cut-through traffic involves vehicles trying to avoid delays on the roadway by diverting through driveways or other access points. The concern was that although the clinic did not share parking with other land uses, traffic may use the access drives as shortcuts to an adjacent parking area or, at corner facilities, as a route to avoid intersection queues. Cut-through traffic leads to inflated trip generation rates, due to the additional, but unrelated, traffic crossing the counters.

Site socio-economic data must be available to the researchers so that appropriate independent variables can be determined. Without this data, computed rates would have little meaning, because comparison and transfer of the data would be extremely difficult.

A site should contain no unique characteristics that might cause it to not reflect a typical situation. An example would be clinics that offer uncommon services on site such as health-oriented classes.

Characteristics of the facility's access drives are a prime concern in site selection. In order for traffic counting equipment to operate properly, certain criteria had 
to be established. All of the criteria discussed below were adopted for this study so the traffic counting equipment would function properly.

The principal criteria are number of access points, driveway length, and driveway width. The number of access points relates directly to the number of traffic counters required for the site. In this case, two drives were determined to be the maximum acceptable number. The driveway must be long enough to handle any queuing that may occur due to parking movements, waiting for spots to open, and passenger dropoffs. Driveway width was a concern in combination with its length. The driveway configuration had to be such that the vehicle would cross the pneumatic tube at a ninety degree angle so that each axle would register only a single count.

When portable pneumatic tube counters are used, as was the case in this study, other site criteria apply so that the counting equipment operates properly (French, Eck, and Balmer, 2000). These include the following. The driveway surface had to be concrete or asphalt rather than stone or earth so that pneumatic tubes could be well secured and function properly. The driveway must offer a counter location where vehicle queues will not stop on the tube. Finally, the site must include a fixed object (such as a sign support or utility pole) to which the counter could be secured, to reduce the risk of theft or vandalism.

\subsubsection{Identification of Clinics}

As noted previously, the West Virginia Office of Community and Rural Health Services Division of Primary Care (2002) supports 75 clinics throughout the state. Their website includes a list of all primary care centers, satellite clinics, and free clinics operating in West Virginia. 
From the list, 11 sites were selected as possible study locations. Study sites were limited to the northern half of the state to maintain reasonable travel times from Morgantown. This list was further narrowed based on the personal knowledge of the researcher and colleagues in the area of community medicine.

Each location was then visited and assessed relative to the identified criteria. The sites and their relevant characteristics are shown in Table 3-1. It was determined from the field visits that six of the sites were not appropriate since they did not meet one or more of the established criteria. The five sites meeting the criteria were selected for the study. These were: Eglon Clinic, Good Samaritan Clinic, Inc., Rowlesburg Clinic, Shinnston Medical Center, and St. George Medical Center.

Table 3- 1 Characteristics of Rural Clinics Identified as Possible Study Locations

\begin{tabular}{|c|c|c|c|c|c|c|c|c|c|}
\hline Name & Location & 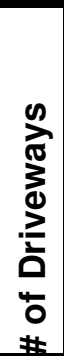 & 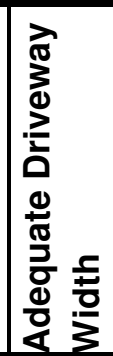 & 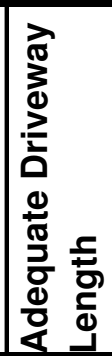 & 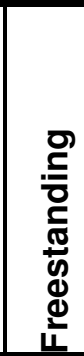 & 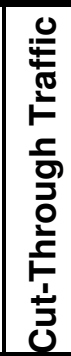 & 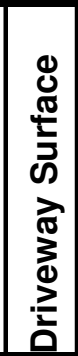 & 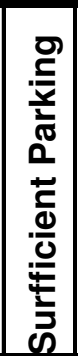 & 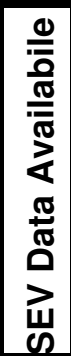 \\
\hline Clay-Battelle Health Services Assoc. & Blacksville & 1 & Yes & Yes & No & No & Asp & No & - \\
\hline Eglon Clinic & Eglon & 1 & Yes & Yes & Yes & No & Asp & Yes & Yes \\
\hline Good Samaritan Clinic, Inc. & Parkersburg & 1 & Yes & Yes & Yes & No & Asp & Yes & Yes \\
\hline Medical Center of Taylor County & Grafton & 1 & No & No & Yes & No & Asp & Yes & - \\
\hline Mountaintop Health Center & Davis & 1 & No & No & No & Yes & Asp & Yes & - \\
\hline Newburg Clinic & Newburg & 3 & No & No & No & No & Asp & No & - \\
\hline Ritchie County Primary Care Assoc., Inc. & Harrisville & 2 & Yes & No & No & No & Asp & Yes & - \\
\hline Rowlesburg Clinic & Rowlesburg & 2 & Yes & Yes & Yes & No & Asp & Yes & Yes \\
\hline Shinnston Medical Center & Shinnston & 2 & Yes & Yes & Yes & No & Asp & Yes & Yes \\
\hline St. George Medical Clinic, Inc. & St. George & 2 & Yes & Yes & Yes* & No & Asp & Yes & Yes \\
\hline Wirt County Health Services Assoc. & Elizabeth & 2 & Yes & Yes & No & No & Asp & Yes & - \\
\hline
\end{tabular}

* includes on-site fitness area

The manager/administrator of each facility selected was contacted via telephone in order to explain the purpose of the study and to seek permission to conduct a oneweek machine traffic count. At a later time, each manager was asked to complete a 
survey form, described in the next section, either over the phone, in person, or via facsimile transmission, seeking information on site characteristics and relevant socioeconomic variables.

The survey form was created to attempt to collect site characteristic data for each of the facilities. Contact information was requested along with staffing and infrastructure data. The survey form is included in Appendix B and will be discussed in more detail in the next section.

\subsection{Data Collection}

Data collection consisted of two parts. First, the survey forms were completed by the facility managers, allowing site characteristics and independent variables to be compiled. Next, traffic counts were performed at each of the sites to collect trip data. Each of these is discussed below.

\subsubsection{Site Characteristics}

To facilitate the collection of site characteristic and socio-economic data, the previously mentioned survey form (included as Appendix B) was developed. The form was divided into 6 sections for the purpose of data collection. Each section represented a different type of data.

The first section contained contact information for future reference. Information requested included site name, address, phone number, and name of person interviewed.

During the interview, information was also sought on the socio-economic variables of interest in the study. These variables were: 
- total number of employees

- number of doctors

- number of nurses

- number of examination rooms

Information was also sought on commercial vehicle traffic serving rural clinics. The portable traffic counters used were axle counters and were not able to classify traffic. Due to the relatively low volumes of traffic generated by rural clinics, it was felt not to be productive to collect truck data manually. Consequently, it was decided to collect the information from facility managers. The form included space to record the maximum size vehicle serving the facility, the number of axles on this vehicle, and the frequency with which it served the site.

Hours of operation for each day of the week were requested. These were collected for the purpose of categorizing facilities and explaining differences in hourly and daily variations in traffic. The form divided the seven days of the week into three periods (morning, afternoon, evening) since it was recognized that not all clinics operated all day, every day.

Information about site characteristics (for potential use as socio-economic variables) was also sought. In most cases, this was collected by the researcher. Questions about numbers of driveways and pavement surface type were used in determining the number of counters and type of fasteners required. When not available from the facility manager, a 200-foot tape and measuring wheel were used to acquire certain exterior building and site measurements. These dimensions were: 
- Gross Floor Area (GFA) - sum (in square feet) of the area at each floor level of the facility

- Acreage - measurement in acres of the plot of land that the facility occupies. Where property lines were not apparent to the researcher, they were pointed out by the facility manager.

The last section on the first page of the form included a note area where the manager was asked to include information about the facility, not otherwise requested, e.g., services offered by the clinic.

The second page was essentially left blank to allow for a sketch of the facility. The sketch was prepared by the researcher to show surrounding land uses, adjacent streets, and a layout of the site including the building, parking, and other features such as helipad or outdoor fitness area.

\subsubsection{Pass-By Trips}

ITE (1997) notes that the traffic generated by a land use is usually more than the volume of traffic it adds to the street system. This "phenomenon" can be explained by examining categories of trips. One category is "primary trips;" a primary trip is a trip whose destination is the trip generator. Another category is "pass-by trips" where an intermediate stop is made between the trip origin and primary destination. For example,

on a trip from work to home, the motorist stops at a fast-food establishment to make a purchase.

The phenomenon of pass-by trips means that for certain land uses, the trip counts will not represent the additional traffic volume on the roadway attributable to that land use. Therefore, it is necessary to adjust the count data to reflect pass-by trips. 
This is usually done by quantifying the percentage of pass-by trips associated with a particular land use. The percentage is computed by dividing the number of pass-by trips by the total number of trips to the land use. Determination of pass-by trips is accomplished through surveys at the land use.

In the researcher's judgment, rural clinics would be the primary trip end for patrons and employees, rather than an impulse or convenience stop such as a fast-food restaurant or service station. Using this reasoning, it can be inferred that the number of pass-by trips would be negligible for rural clinics. Therefore, pass-by data was not collected in this study.

\subsubsection{Machine Counts}

Portable pneumatic tube traffic counters were used to collect trip counts at the sites. Tubes were laid across the driveway throats and fastened with masonry nails and nylon straps to keep them in place. The closed ends of the tubes were then attached to ten-inch steel stakes and driven into the ground to anchor them in place. The open end of the tube was then attached to the traffic counter. Counters were set to count at 60minute intervals, and left in place for a period of one week. The counters could not measure vehicle direction; thus, the directional distribution was assumed to be $50 \%$ entering and 50\%exiting.

The counters were set up during what the clinic administrators considered typical weeks of operation. The intent was to avoid weeks which included a holiday or when staff were on vacation so that results would be representative. The counts were performed during the last three weeks in September, 2002. 
The researcher was aware that from time-to-time there would be specialized activities at some of the sites. For example, one of the clinics indicated that occasionally a mobile MRI unit would be on-site for a short period of time. It is important to note that none of these special activities took place during the counting period for the study.

\subsection{Data Analysis and Computations}

Data analysis was performed in accordance with the procedures listed in Trip Generation (ITE, 1997). The data analysis is outlined below.

\subsubsection{Preliminary Analysis}

The first step in the procedure was to plot the traffic count data versus time so the hourly and daily variation could be examined to look for peaks and patterns. Of particular interest here was relating the variation in traffic flow to the hours of operation of the facility.

The largest vehicle serving any of the clinics was reported to be a two-axle delivery truck. Since each truck would contact the pneumatic tube the same number of times as a typical passenger vehicle (i.e., twice), it was not necessary to correct the counts for trucks.

In accordance with adopted procedures, a number of rates were computed. Weekday rates were averaged over a Monday to Friday period. Saturday and Sunday counts had been collected, however, it was decided not to report these values, since the clinics studied were closed for business on weekends. The following flow were reported: 
- Average Vehicles per Weekday

- Average Vehicles per Peak Hour

- Average Vehicles per AM Peak Hour (7 - 9am)

- Average Vehicles per PM Peak Hour (4 - 6pm)

\subsubsection{Independent Variable Selection}

Before trip rate calculations were performed, the list of socio-economic variables needed to be specified. Determination of appropriate SEVs was accomplished by looking at the SEVs recorded for each of the sites in conjunction with the results of the literature review.

As described above, potential independent variables had been obtained from the survey form. Those collected were:

- Number of Employees

- Number of Doctors

- Number of Nurses

- Number of Examination Rooms

- Gross Floor Area (Sq. Feet)

- Acres

It was realized that the each of the facilities operated differently in terms of health care professional staff. Some clinics were operated by a single physician, others by multiple full-time or part-time physicians; one was operated by nurse practitioners. Therefore, number of nurses was eliminated due to the small number and significant variation in types. 
The total number of examination rooms at a clinic was eliminated as an independent variable. It was noted that the number of examination rooms was not necessarily a measure of the number of patients the clinic could serve.

Acreage was also dismissed as an independent variable in the study. Different sites have different land use intensities, i.e., percent of land occupied by the structure and parking. Some clinics were on large lots that are essentially vacant or occupied by a fitness trail. In other cases, the clinic structure and parking occupied nearly the entire lot.

Therefore, three socio-economic variables were selected for trip generation calculations. Gross floor area and total number of employees were selected to be used for the five sites. The Good Samaritan Clinic was operated by a nurse practitioner rather than a physician, i.e., the denominator in the rate calculation would be zero. Thus, for the four sites operated by a physician, doctors was used as an SEV.

\subsubsection{Trip Rates}

According to Trip Generation (1997), multiple trip rate formats should be prepared after collecting site data. The three most common formats are individual site rates, average weighted rate, and regression plots for those that qualify.

\subsubsection{Trip Rates for Individual Sites}

Individual site rates are a relationship between traffic volume and socioeconomic variables. Given the four volumes listed in section 3.4.1, four rates are possible for each variable.

After computing the rates, a standard deviation was determined for each site. The standard-deviation-to-mean ratio is then used as a measure of "consistency" 
between the sites. A ratio of zero would be a perfectly consistent ratio and indicate that all values in the sample are the same. As the value increases, the sample becomes more inconsistent. A high ratio, however, is not necessarily an indicator of an error or problem. All computed rates with a ratio less than the value of 1.1, the limit listed in ITE (1997), were retained as part of the study.

\subsubsection{Average Weighted Trip Rate}

An average weighted rate was computed using the method described mentioned in Chapter 2. Twenty separate rates were calculated in this study.

\subsubsection{Regression Trip Rate Plot}

Regression analysis was performed in Microsoft Excel 97. The individual site trip rates were entered into a spreadsheet and plotted. Then Excel's LINEST tool was used to compute a linear regression of the variables forced through zero. Next, the LOGEST tool was used to compute logarithmic regression. Therefore, each trip rate had both linear and logarithmic regression equations.

\subsection{Presentation of Results}

The results were presented in accordance with the techniques described in section 2.4, i.e., the ITE format shown in Appendix A. Those rates that met the requirements stated in Chapter 2 for equation and plotted curve were included on the data sheets. 


\section{Chapter 4 Results}

\subsection{Introduction}

This chapter presents the results of the data collection effort to determine trip generation rates for rural clinics. Study sites are described and the data collected are summarized and analyzed. The chapter will follow the format outlined in Chapter 3 , sections 3.4 and 3.5 .

\subsection{Sites Studied}

This section offers a description of each of the study sites. The location, ownership, facility characteristics, and services are listed for each. Any noteworthy features, observed during data collection, are also noted. Completed survey forms for each site are included in Appendix C. Photographs of the actual sites are also included in Appendix C. Figure 4-1, shows the locations of the clinics studied.

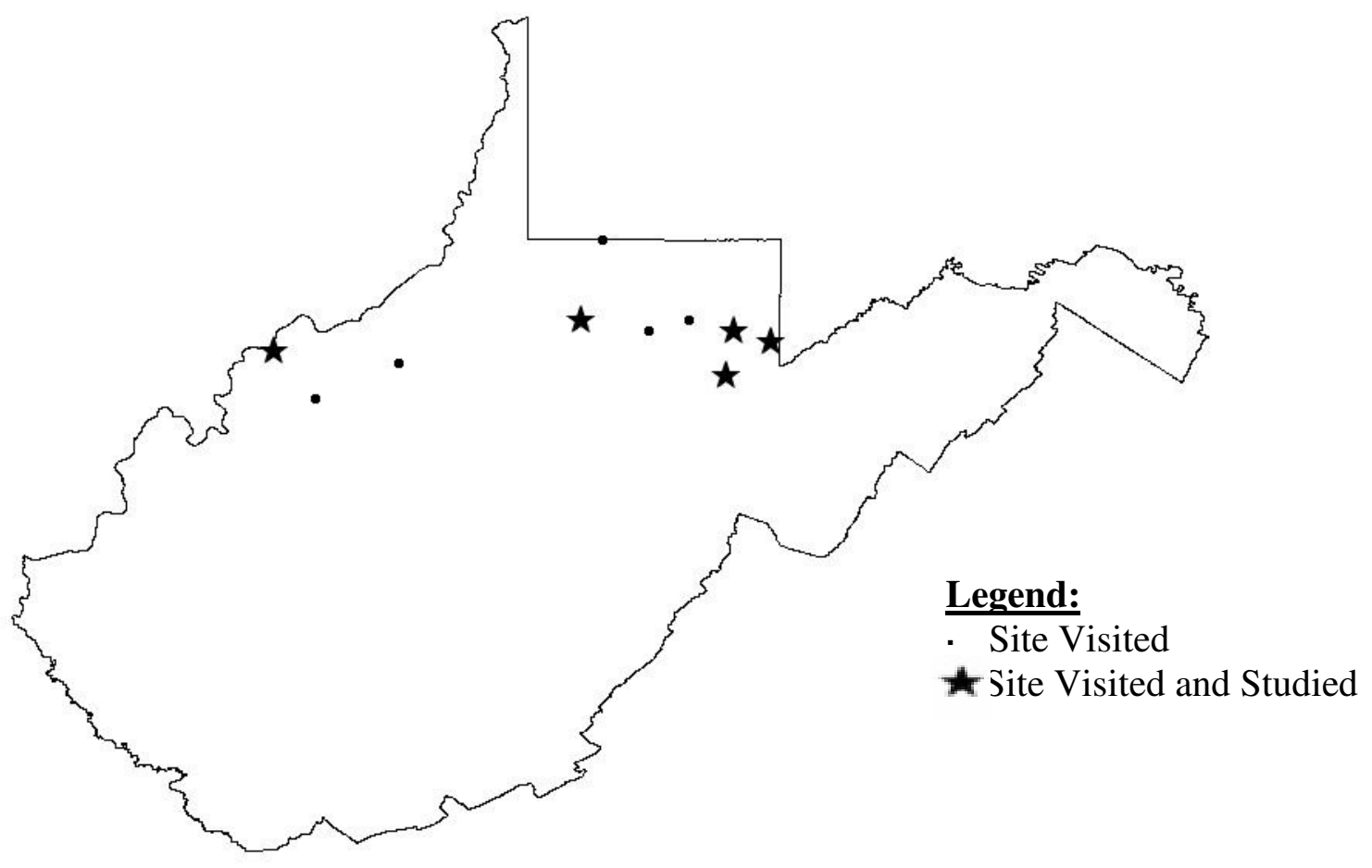

Figure 4- 1 Locations of Clinics Visited and Studied 


\subsubsection{Eglon Clinic}

The Eglon Clinic is situated at the intersection of State Route 24 and Star Route 24 in a rural area of Preston County near the unincorporated community of Eglon. It is part of Preston-Taylor Community Health Centers, Inc, a network of five health care centers in Preston and Taylor counties. The clinic offers a wide variety of primary care services: handling acute and chronic illnesses, preventative care, sports medicine, physicals, laboratory testing, diagnostic screening, EKG, immunization, and a basic needs pharmacy. The Eglon Clinic was the smallest clinic in the study in terms of gross floor area.

\subsubsection{Good Samaritan Clinic, Inc.}

The Good Samaritan Clinic, Inc. is located in a residential area within Parkersburg city limits on Emerson Avenue near the intersection with Garfield Avenue. The clinic is a private, non-profit, state-funded, free clinic offering services to those without insurance and incomes below the poverty level. The clinic offers pharmaceuticals, screenings by a nurse practitioner and social worker, dental exams, and x-rays. This is the only clinic located in an urbanized area of over 2,000 population. Perhaps as a consequence, it had the smallest lot size of all clinics studied.

\subsubsection{Rowlesburg Clinic}

The Rowlesburg Clinic is situated adjacent to a residential area in the town of Rowlesburg, Preston County. The clinic is also part of Preston-Taylor Community Health Centers, Inc., and has basically the same capabilities as the Eglon Clinic. The Rowlesburg clinic is, however, the only site with a helipad for life-flight service. 


\subsubsection{Shinnston Medical Center}

The clinic in Shinnston is located on State Route 19 in a residential area of Shinnston, with the parking lot entrance on Route 19 and exiting onto Columbia Rd. The clinic is a satellite facility of Monongahela Valley Association of Health Centers, Inc., a regional set of facilities based in Fairmont, West Virginia. The clinic's mission is to serve the primary care needs of the local community.

\subsubsection{St. George Medical Clinic, Inc.}

The clinic at St. George is located in a rural area on Tucker County Rt. 1. It is a community-owned, non-profit center with a focus on prevention. The clinic offers typical primary care services such as prenatal care, child wellness exams, preventative exams, physicals, treatment of acute and chronic illnesses, and a well-stocked pharmacy. The clinic also offers some atypical services to its customers such as family planning, cancer screening, and assault screenings.

The St. George Clinic was unique in several ways. It was the largest clinic included in the study in terms of number of employees, acreage, number of examination rooms and gross floor area. It was also the only clinic in the study with an on-site fitness area.

\subsubsection{Comparison of Sites}

Table 4-1 presents a summary of the physical characteristics of the five clinics studied. There is considerable variation in the size of the facilities. Lot size ranges from one-quarter acre to 1.50 acres; gross floor area varies from $1500 \mathrm{ft}^{2}$ to over $3300 \mathrm{ft}^{2}$. The greatest variation is in number of examination rooms, ranging from one at the Good Samaritan Clinic to six at St. George. 
Table 4- 1 Physical Facility Characteristics of the Five Clinics

\begin{tabular}{|l|c|c|c|c|}
\hline Site & $\begin{array}{c}\text { Examination } \\
\text { Rooms }\end{array}$ & Parking Stalls & $\begin{array}{c}\text { Gross Floor } \\
\left.\text { Area (ft }{ }^{\wedge} \mathbf{2}\right)\end{array}$ & Acreage \\
\hline \hline Eglon Clinic & 3 & 9 & 1500 & 0.28 \\
\hline Good Samaritan Clinic, Inc. & 1 & 9 & 3008 & 0.25 \\
\hline Rowlesburg Clinic & 3 & 14 & 2400 & 1 \\
\hline Shinnston Medical Health Center & 4 & 17 & 2800 & 0.52 \\
\hline St. George Medical Clinic, Inc. & 6 & 19 & 3375 & 1.5 \\
\hline \hline Mean & 3.4 & 13.6 & 2617 & 0.83 \\
\hline
\end{tabular}

As shown in Table 4-2, there is also considerable variation in the number of employees. The Rowlesburg and St. George clinics have ten or more employees, while the Good Samaritan Clinic has only three employees.

Table 4- 2 Staffing Characteristics of the Five Clinics.

\begin{tabular}{|c|c|c|c|c|}
\hline Site & Support Staff & Doctors & Nurses & $\begin{array}{l}\text { Total Number } \\
\text { of Employees }\end{array}$ \\
\hline Eglon Clinic & 4 & 1 & 1 & 6 \\
\hline Good Samaritan Clinic, Inc. & 2 & 0 & 1 & 3 \\
\hline Rowlesburg Clinic & 5 & 3 & 2 & 10 \\
\hline Shinnston Medical Health Center & 3 & 2 & 3 & 8 \\
\hline St. George Medical Clinic, Inc. & 7 & 2 & 3 & 12 \\
\hline Mean & 4.2 & $\overline{1.6}$ & $=$ & 7.8 \\
\hline
\end{tabular}

However, when viewed on a per unit basis, as shown in Table 4-3, the sites are rather consistent. There is generally 0.3 to 0.5 examination rooms per employee. Except for Good Samaritan Clinic, there are about 1.25 to 2.0 exam rooms per $1000 \mathrm{ft}^{2}$ of floor area. Furthermore, there are about 3 to 5 parking spaces per exam room for all but the Good Samaritan Clinic. The uniformity of some of the unit values suggest that certain rules of thumb are used in the planning/design of rural clinics.

Table 4- 3 Facility Characteristics on a Per Unit Basis

\begin{tabular}{|l|c|c|c|c|c|}
\hline Site & $\begin{array}{c}\text { Exam Rooms } \\
\text { per Employee }\end{array}$ & $\begin{array}{c}\text { Exam Rooms } \\
\text { per 1000 Sq. Ft. } \\
\text { GFA }\end{array}$ & $\begin{array}{c}\text { Parking Stalls } \\
\text { per } \\
\text { Employees }\end{array}$ & $\begin{array}{c}\text { Parking Stalls } \\
\text { per 1000 Sq. Ft. } \\
\text { GFA }\end{array}$ & $\begin{array}{c}\text { Parking Stalls } \\
\text { per Exam } \\
\text { Room }\end{array}$ \\
\hline \hline Eglon & 0.5 & 2.0 & 1.5 & 6.0 & 3.0 \\
\hline Good Samaritan & 0.3 & 0.3 & 3.0 & 3.0 & 9.0 \\
\hline Rowlesburg & 0.3 & 1.3 & 1.4 & 5.8 & 4.7 \\
\hline Shinnston & 0.5 & 1.4 & 2.1 & 6.1 & 4.3 \\
\hline St. George & 0.5 & 1.8 & 1.6 & 5.6 & 3.2 \\
\hline \hline Mean & & 0.4 & & 1.4 & \\
\hline
\end{tabular}


Note that each of the sites studied was open daily during the week. All sites were closed on the weekends. Hours of operation for each of the study sites are shown in Table 4-4. Note that the St. George Clinic (two evenings), Rowlesburg (one evening), and Eglon (one evening) facilities were open beyond normal working hours at least one day per week. Shinnston had fairly uniform hours of operation, essentially 8 AM to 4 PM daily. Good Samaritan Clinic was open only one-half day during two days of the week.

Table 4- 4 Hours of Operation for the Five Clinics Studied

\begin{tabular}{|c|c|c|c|c|c|c|c|c|c|c|}
\hline \multirow[b]{2}{*}{ Site } & \multicolumn{2}{|c|}{ Monday } & \multicolumn{2}{|c|}{ Tuesday } & \multicolumn{2}{|c|}{ Wednesday } & \multicolumn{2}{|c|}{ Thursday } & \multicolumn{2}{|c|}{ Friday } \\
\hline & \multicolumn{2}{|c|}{ From -To } & \multicolumn{2}{|c|}{ From -To } & \multicolumn{2}{|c|}{ From -To } & \multicolumn{2}{|c|}{ From -To } & \multicolumn{2}{|c|}{ From -To } \\
\hline & $11 \mathrm{AM}$ & $2 \mathrm{PM}$ & $8 \mathrm{AM}$ & $12 \mathrm{PM}$ & $8 \mathrm{AM}$ & $12 \mathrm{PM}$ & $8 \mathrm{AM}$ & $12 \mathrm{PM}$ & $8 \mathrm{AM}$ & $\overline{12 \mathrm{PM}}$ \\
\hline Eglon Clinic & $3 \mathrm{PM}$ & $7 \mathrm{PM}$ & $1 \mathrm{PM}$ & 5 PM & $1 \mathrm{PM}$ & 5 PM & $1 \mathrm{PM}$ & 5 PM & $1 \mathrm{PM}$ & 5 PM \\
\hline Good Samaritan & $8 \mathrm{AM}$ & $12 \mathrm{PM}$ & $8 \mathrm{AM}$ & $12 \mathrm{PM}$ & $8 \mathrm{AM}$ & $12 \mathrm{PM}$ & $8 \mathrm{AM}$ & $12 \mathrm{PM}$ & $8 \mathrm{AM}$ & $12 \mathrm{PM}$ \\
\hline Clinic, Inc. & $1 \mathrm{PM}$ & $4 \mathrm{PM}$ & $1 \mathrm{PM}$ & $4 \mathrm{PM}$ & $1 \mathrm{PM}$ & $4 \mathrm{PM}$ & -- & -- & -- & -- \\
\hline Rowlesburg Clinic & $\begin{array}{c}10: 30 \\
\text { AM }\end{array}$ & $7 \mathrm{PM}$ & $8 \mathrm{AM}$ & $5 \mathrm{PM}$ & $\begin{array}{c}8: 30 \\
\text { AM }\end{array}$ & $5 \mathrm{PM}$ & $\begin{array}{c}8: 30 \\
\text { AM }\end{array}$ & $5 \mathrm{PM}$ & $8 \mathrm{AM}$ & $4 \mathrm{PM}$ \\
\hline $\begin{array}{l}\text { Shinnston Medical } \\
\text { Center }\end{array}$ & $8 \mathrm{AM}$ & $4 \mathrm{PM}$ & $8 \mathrm{AM}$ & $4 \mathrm{PM}$ & $8 \mathrm{AM}$ & $4 \mathrm{PM}$ & $8 \mathrm{AM}$ & $4 \mathrm{PM}$ & $8 \mathrm{AM}$ & $3 \mathrm{PM}$ \\
\hline $\begin{array}{l}\text { St. George Medical } \\
\text { Clinic, Inc. }\end{array}$ & $8 \mathrm{AM}$ & $5 \mathrm{PM}$ & $8 \mathrm{AM}$ & $5 \mathrm{PM}$ & $8 \mathrm{AM}$ & $\begin{array}{l}7: 30 \\
P M\end{array}$ & $8 \mathrm{AM}$ & $\begin{array}{l}7: 30 \\
P M\end{array}$ & $8 \mathrm{AM}$ & $4 \mathrm{PM}$ \\
\hline
\end{tabular}

\subsection{Daily and Hourly Variation in Trips}

As described in Chapter 3, a trip plot was created for each of the five clinics. The number of trips per hour was scaled on the $y$-axis, with time on the $x$-axis. A separate line was drawn for each day of the week. The plots for the five sites are presented in Figures 4-2 through 4-6.

Figure 4-2 presents the hourly and daily variations for the Eglon Clinic. Three weekday peaks are apparent; one around noon, one in the late afternoon, and one in the evening. Note that while the noon and afternoon peaks occur each weekday, the evening peak occurs only on Monday which is when the facility has evening hours. 


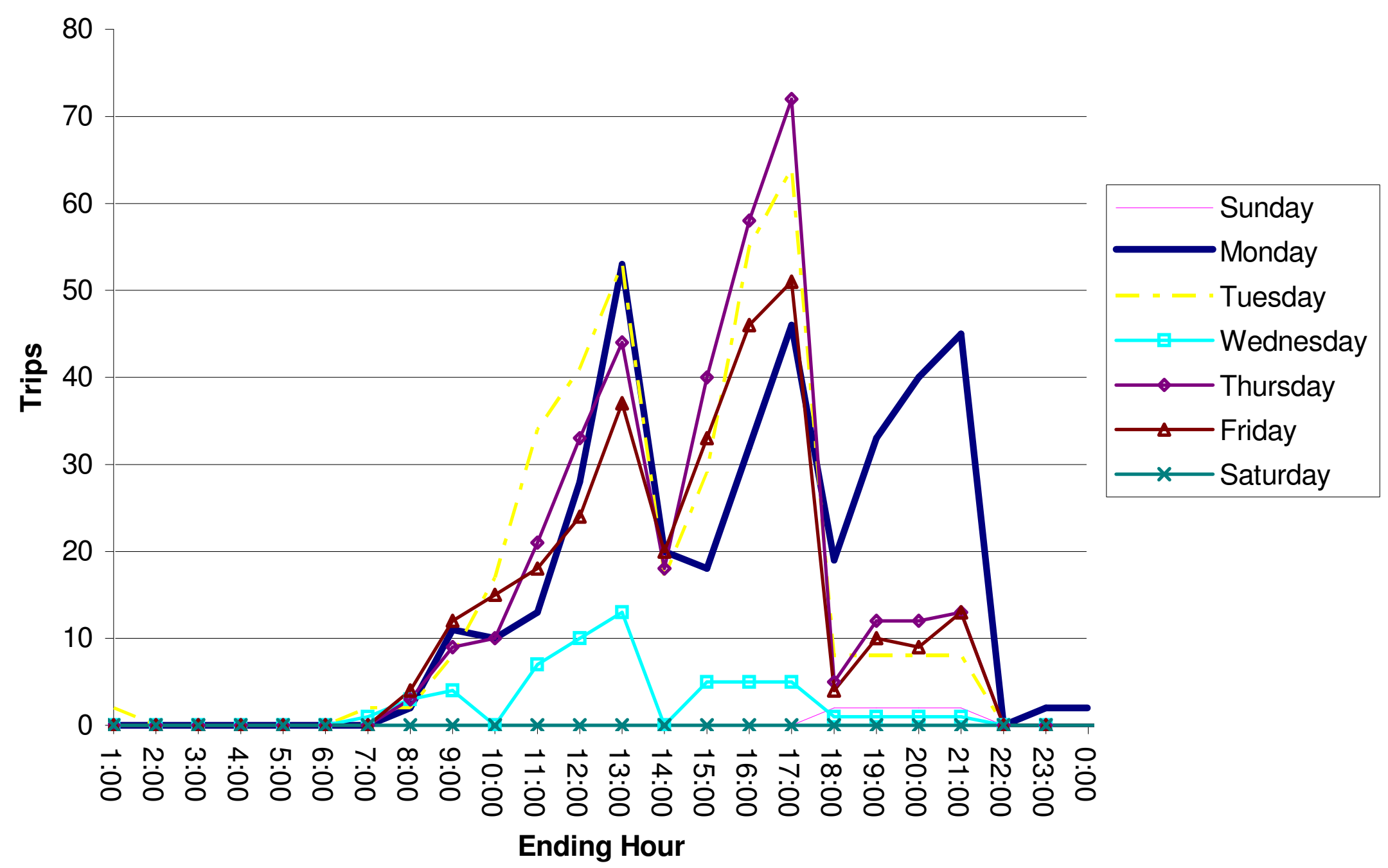

Figure 4- 2 Hourly and Daily Variation in Trips for Eglon Clinic (September 15 to 22, 2002) 


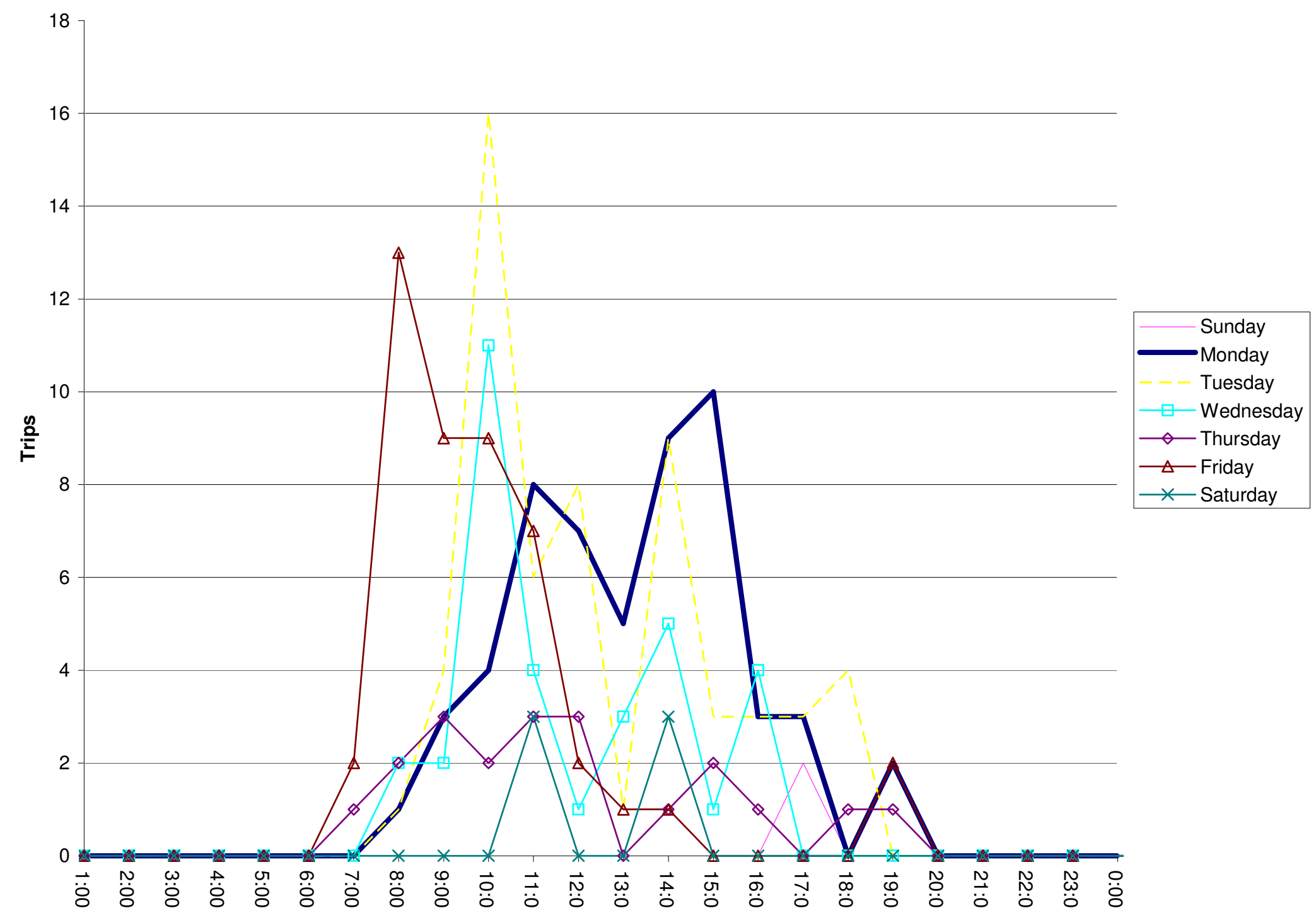

Figure 4- 3 Hourly and Daily Variation in Trips for Good Samaritan Clinic (September 22 to 29, 2002) 


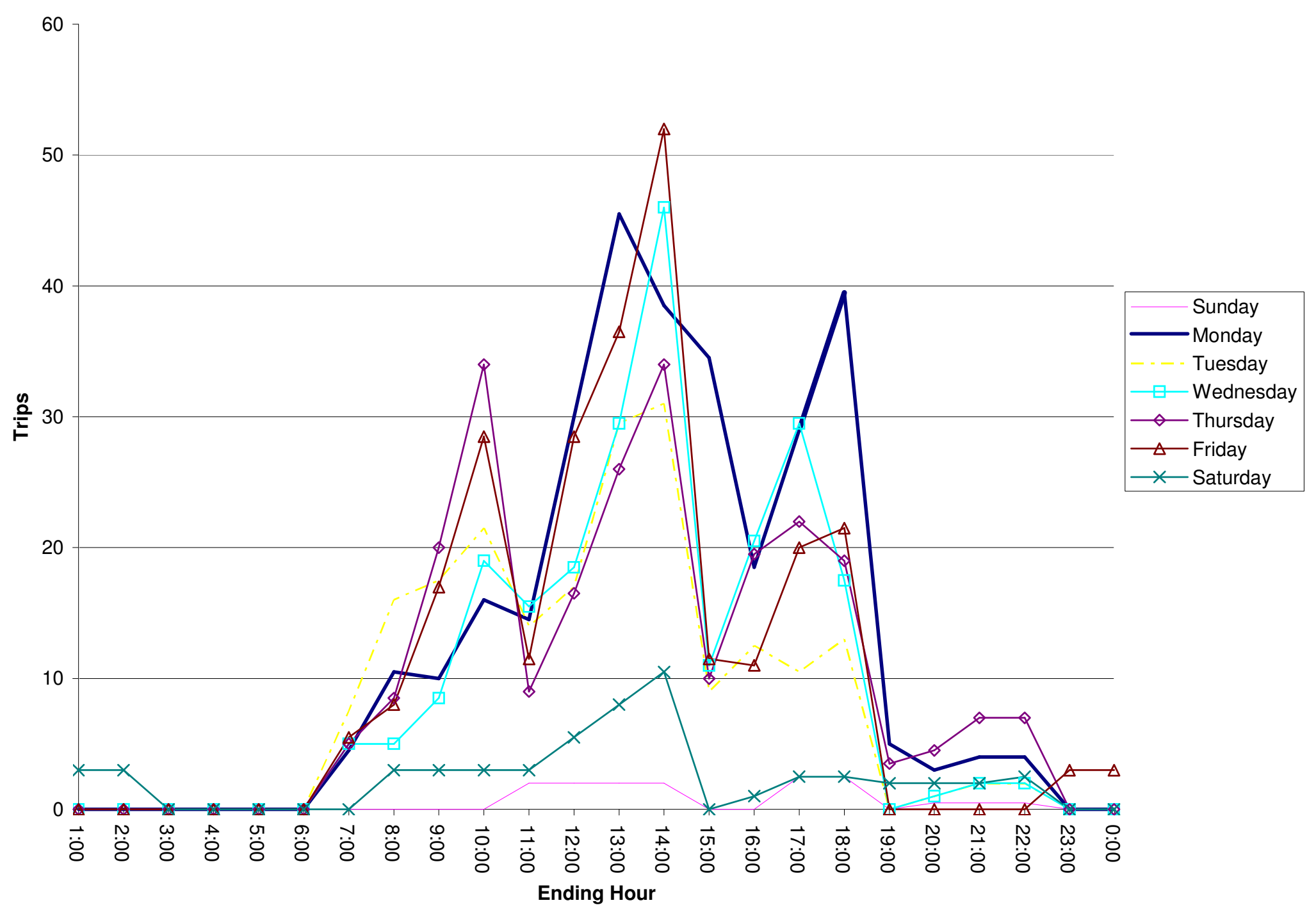

Figure 4- 4 Hourly and Daily Variation in Trips for Rowlesburg Clinic (September 15 to 22, 2002) 


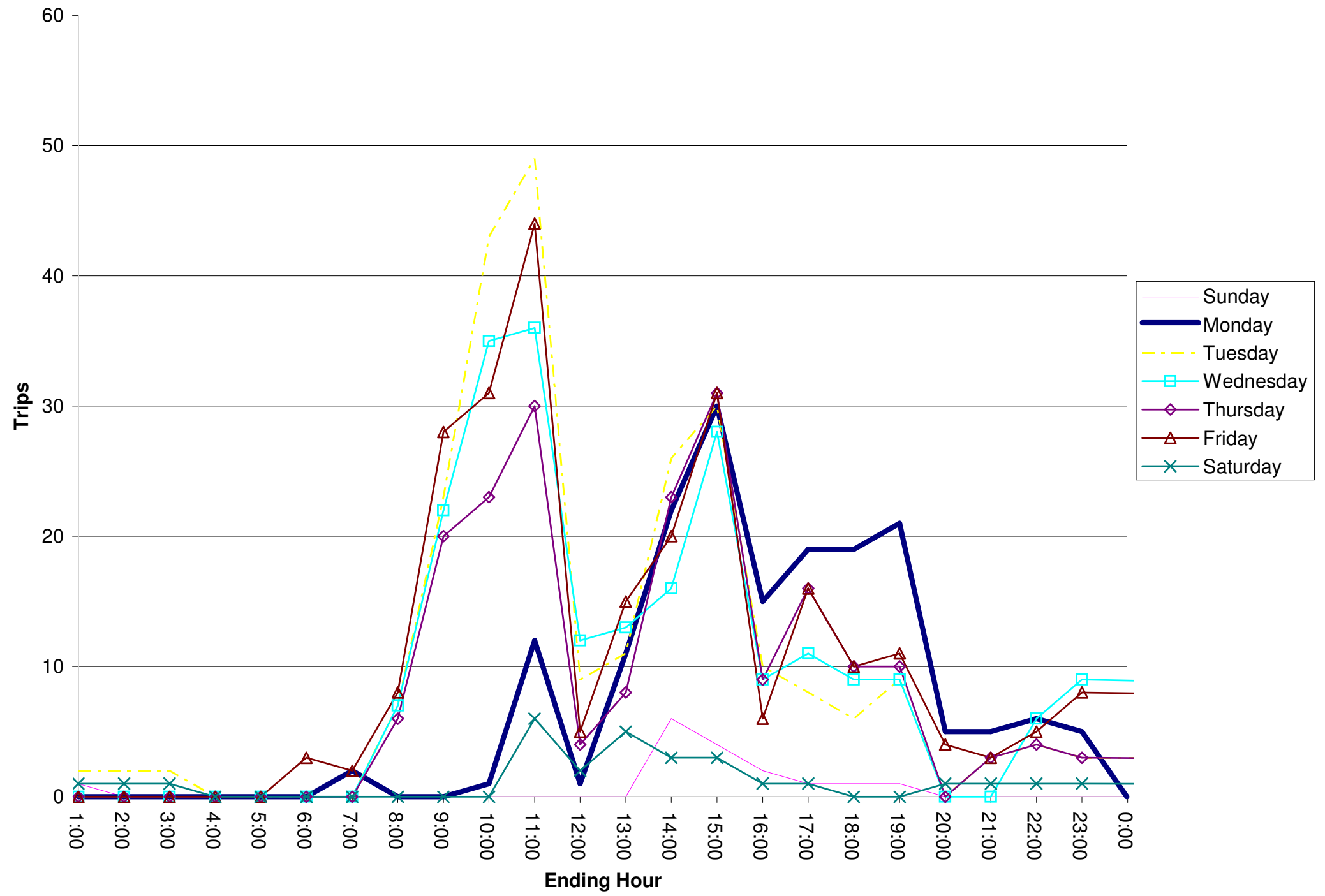

Figure 4- 5 Hourly and Daily Variation in Trips for Shinnston Medical Center (September 22 to 29, 2002)

48 


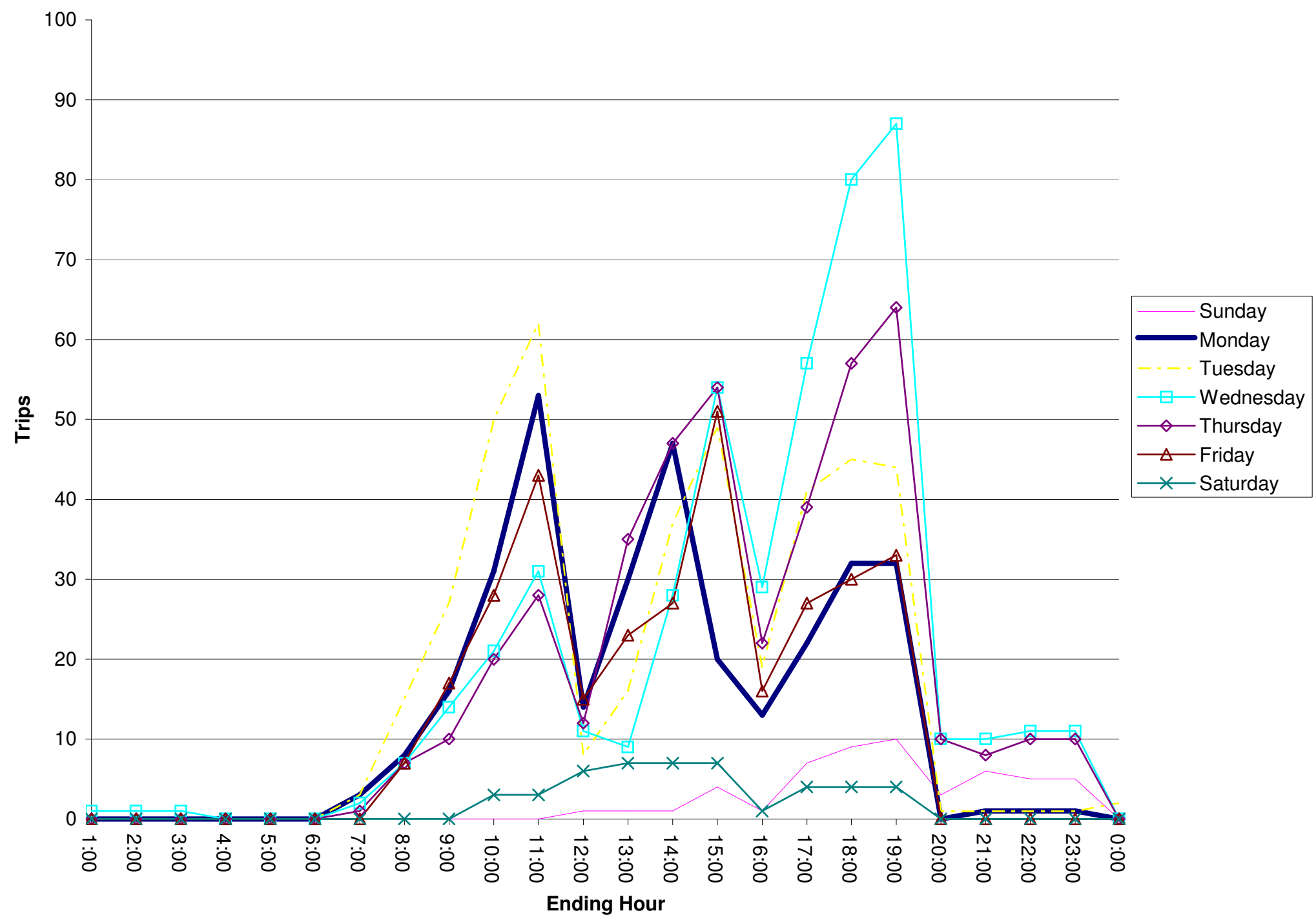

Figure 4- 6 Hourly and Daily Variation in Trips for St. George Clinic (September 8 to 15, 2002) 
Wednesday appears to be much lower; this is due to no doctors seeing patients on Wednesdays at the clinic.

The Good Samaritan Clinic trip variations are presented in Figure 4-3. The magnitude of the values is much lower than Eglon and there is considerably more variability in the data. The clinic shows two peaks at different hours from Eglon; one relatively early in the morning and one in mid-afternoon. As expected, Thursday and Friday afternoon volumes were low since the clinic was not open.

The hourly and daily variations for the Rowlesburg Clinic are shown in Figure 4-4. The pattern of the data is very similar to the Eglon Clinic. Rowlesburg also has 3 distinct peaks, but they appear to occur earlier in the morning and afternoon than those at Eglon. In both cases, the evening volumes are greater than the morning volumes.

Hourly and daily variations for the Shinnston Clinic are illustrated in Figure 4-5. With a few exceptions, the data are quite uniform. Two peaks are evident on the plot, one in the morning around $9 \mathrm{AM}$ and one in the afternoon around 3 PM. Like the Good Samaritan Clinic, the morning peak was greater than the afternoon peak. There was a Monday afternoon peak around 7 PM. This could have been due to a special late afternoon activity.

Finally, trip variations for the St. George Clinic are presented in Figure 4-6. Three peaks are present on the plot; a morning peak around $10 \mathrm{AM}$, and afternoon peak around $2 \mathrm{PM}$, and an evening peak at $5 \mathrm{PM}$. The evening peak is highest on Wednesday and Thursday, corresponding to the evenings the clinic is open, although a noticeable peak was present each weekday. This is different from the other two sites with evening hours, where the evening hours were lower than those during the day. 
One possible explanation is the existence of the outdoor fitness area at the St. George Clinic. Due to the lack of independent parking for this area, those who make use of the outdoor exercise facilities park their vehicle in the same lot as patrons of the clinic itself. According to AccuWeather.com ${ }^{\circledR}$ (2003), during the week count period, weather conditions were favorable with average temperatures ranging from $60^{\circ}$ to $74^{\circ}$ Fahrenheit, and only 0.10 inches of precipitation on Saturday. Therefore, it is likely that local residents used the fitness trail in early evening. This would account for the higher volumes during this time period.

\subsection{Average Rates}

Table 4-5 presents trip ends per employee for the five study sites. All four of the rates meet the consistency (standard-deviation-to-mean ratio) requirement for good of less than 1.10. The weekday rates had the largest range, with a low of 14.13 for Good Samaritan and high of 47.77 for Eglon.. The AM peak rates are the most consistent of the rates at 0.23 .

Table 4- 5 Trip Ends per Employee for the 5 Study Sites

\begin{tabular}{|c|c|c|c|c|c|}
\hline \multicolumn{2}{|c|}{ Site } & \multicolumn{4}{|c|}{ Average Trip Ends per Employees } \\
\hline Name & Employees & W e ekday & $\begin{array}{l}\text { Weekday } \\
\text { Peak }\end{array}$ & AM Peak & PM Peak \\
\hline Eglon & 6 & 47.77 & 8.50 & 1.47 & 5.70 \\
\hline Good Samaritan & 3 & 14.13 & 3.33 & 1.67 & 0.47 \\
\hline Rowlesburg & 10 & 24.89 & 4.04 & 1.47 & 2.66 \\
\hline Shinnston & 8 & 22.38 & 4.40 & 2.33 & 1.63 \\
\hline St. George & 12 & 32.87 & 5.32 & 1.40 & 4.57 \\
\hline \multicolumn{2}{|c|}{ Weighted Average } & 29.52 & 5.14 & 1.64 & 3.33 \\
\hline \multicolumn{2}{|c|}{ Standard Deviation } & 12.72 & 2.02 & 0.38 & 2.13 \\
\hline \multicolumn{2}{|c|}{ Std.Dev:Mean Ratio } & 0.43 & 0.39 & 0.23 & 0.64 \\
\hline
\end{tabular}

Table 4-6 presents trip ends per $1000 \mathrm{ft}^{2}$ of gross floor area for the five study sites. The data indicated that a sizable variation occurred among the sites, with some sites well above the average and other sites substantially below. The PM peak is the most inconsistent with a ratio of 0.90 , however, it is still classified as good by ITE. The 
weekday rates showed the largest range, varying from only 14 at Good Samaritan to 191 at Eglon.

Table 4- 6 Trip Ends per 1000 Sq. Feet Gross Floor Area for the 5 Study Sites

\begin{tabular}{|c|c|c|c|c|c|}
\hline \multicolumn{2}{|c|}{ Site } & \multicolumn{4}{|c|}{ Average Trip Ends per 1,000 sq. ft. GFA } \\
\hline Name & $\begin{array}{l}1000 \text { sq. ft. } \\
\text { GFA }\end{array}$ & Weekday & $\begin{array}{l}\text { Weekday } \\
\text { Peak }\end{array}$ & AM Peak & PM Peak \\
\hline Eglon & 1.5 & 191.07 & 34.00 & 5.87 & 22.80 \\
\hline Good Samaritan & 3.008 & 14.10 & 3.32 & 1.66 & 0.47 \\
\hline Rowlesburg & 2.4 & 103.71 & 16.83 & 6.13 & 11.08 \\
\hline Shinnston & 2.8 & 63.93 & 12.57 & 6.64 & 4.64 \\
\hline St. George & 3.375 & 116.86 & 18.90 & 4.98 & 16.24 \\
\hline \multicolumn{2}{|c|}{$\begin{array}{r}\text { Weighted Average } \\
\end{array}$} & 88.00 & 15.32 & 4.88 & 9.94 \\
\hline \multicolumn{2}{|c|}{ Standard Deviation } & 65.67 & 11.17 & 1.99 & 8.92 \\
\hline \multicolumn{2}{|c|}{ Std.Dev:Mean Ratio } & 0.75 & 0.73 & 0.41 & 0.90 \\
\hline
\end{tabular}

Some of the eight rates presented for the five sites have rather high standarddeviation-to-mean ratios, and therefore, are not as consistent as some of the others. However, all of the rates meet the criterion set forth by ITE (1997) for classification as "good;" therefore, they are all recommended for use.

As can be inferred from previous discussions, the Good Samaritan Clinic in Parkersburg in some respects was much different from the other four sites. Good Samaritan was the only clinic located in an urbanized area of over 2,000 population. Similarly, it was the only clinic which did not have a physician on staff. In addition, with a staff of only three people, it had, by far, the lowest number of employees. Consequently, it was decided to compute new rates based on the other four sites, i.e., leaving out the Good Samaritan Clinic. These results are shown in Tables 4-7 and 4-8. By considering the four "rural" sites, three of the four consistency values improved for the employee rates. The AM peak hour was the only one not to improve. However, its 
change was not significant. All of the rates for gross floor area improved by at least $30 \%$ when the Good Samaritan Clinic was eliminated from the analysis.

The rates presented for four and five sites had "good" consistencies according to the ITE (1997) criteria. Since the rates for employees did not change considerably by removing the Good Samaritan Clinic, one set of rates is not recommended over the other. However, since the consistencies for gross floor area did noticeably improve when considering only rural sites, the rates based on four sites are recommended.

Table 4- 7 Trip Ends per Employee for the 4 Study Sites (all but Good Samaritan)

\begin{tabular}{|c|c|c|c|c|c|}
\hline \multicolumn{2}{|c|}{ Site } & \multicolumn{4}{|c|}{ Average Trip Ends per Employees } \\
\hline Name & Employees & Weekday & $\begin{array}{l}\text { Weekday } \\
\text { Peak }\end{array}$ & AM Peak & PM Peak \\
\hline Eglon & 6 & 477.77 & 8.50 & \begin{tabular}{|r|}
1.47 \\
\end{tabular} & $\begin{array}{r}.70 \\
\end{array}$ \\
\hline Rowlesburg & 10 & 24.89 & 4.04 & 1.47 & 2.66 \\
\hline Shinnston & 8 & 22.38 & 4.40 & 2.33 & 1.63 \\
\hline St. George & 12 & 32.87 & 5.32 & 1.40 & 4.57 \\
\hline \multicolumn{2}{|c|}{ Weighted Average } & 30.80 & 5.29 & 1.64 & 3.57 \\
\hline \multicolumn{2}{|c|}{ Standard Deviation } & 11.44 & 2.03 & 0.44 & 1.84 \\
\hline \multicolumn{2}{|c|}{ Std.Dev:Mean Ratio } & 0.37 & 0.38 & 0.27 & 0.51 \\
\hline
\end{tabular}

Table 4- 8 Trip Ends per 1000 Sq. Feet Gross Floor Area for the 4 Study Sites (all but Good Samaritan)

\begin{tabular}{|c|c|c|c|c|c|}
\hline \multicolumn{2}{|c|}{ Site } & \multicolumn{4}{|c|}{ Average Trip Ends per 1,000 sq. ft. GFA } \\
\hline Name & $\begin{array}{l}1000 \text { sq. ft. } \\
\text { GFA }\end{array}$ & Weekday & $\begin{array}{l}\text { Weekday } \\
\text { Peak }\end{array}$ & AM Peak & PM Peak \\
\hline Eglon & 1.5 & 191.07 & 34.00 & 5.87 & 22.80 \\
\hline Rowlesburg & 2.4 & 103.71 & 16.83 & 6.13 & 11.08 \\
\hline Shinnston & 2.8 & 63.93 & 12.57 & 6.64 & 4.64 \\
\hline St. George & 3.375 & 116.86 & 18.90 & 4.98 & 16.24 \\
\hline \multicolumn{2}{|c|}{ Weighted Average } & 110.06 & 18.90 & 5.85 & 12.76 \\
\hline \multicolumn{2}{|c|}{ Standard Deviation } & 53.12 & 9.33 & 0.70 & 7.71 \\
\hline \multicolumn{2}{|c|}{ Std.Dev:Mean Ratio } & 0.48 & 0.49 & 0.12 & 0.60 \\
\hline
\end{tabular}

Since the four sites discussed above each have a non-zero number of physicians on staff, it is possible to compute a trip end per doctor rate for these sites. Results are shown in Table 4-9. The AM peak standard-deviation-to-mean ratio shows a highly 
consistent sample. While the other values are not as low, they are still considered "good" by ITE.

Table 4- 9 Trip Ends per Doctors for the 4 Study Sites

\begin{tabular}{|c|c|c|c|c|c|}
\hline \multicolumn{2}{|c|}{ Site } & \multicolumn{4}{|c|}{ Average Trip Ends per Doctors } \\
\hline Name & Doctors & Weekday & $\begin{array}{l}\text { Weekday } \\
\text { Peak }\end{array}$ & AM Peak & PM Peak \\
\hline Eglon & 1 & 286.60 & 51.00 & 8.80 & 34.20 \\
\hline Rowlesburg & 3 & 82.97 & 13.47 & 4.90 & 8.87 \\
\hline Shinnston & 2 & 89.50 & 17.60 & 9.30 & 6.50 \\
\hline St. George & 2 & 197.20 & 31.90 & 8.40 & 27.40 \\
\hline \multicolumn{2}{|c|}{ Weighted Average } & 138.61 & 23.80 & 7.36 & 16.08 \\
\hline \multicolumn{2}{|c|}{ Standard Deviation } & 97.04 & 16.96 & 2.00 & 13.67 \\
\hline \multicolumn{2}{|c|}{ Std.Dev:Mean Ratio } & 0.70 & 0.71 & 0.27 & 0.85 \\
\hline
\end{tabular}

\subsection{Comparison with Trip Generation Values}

With Trip Generation (1997) being the widely accepted guide for trip generation rates, it is interesting to compare the limited data on clinics in that publication with the results of this study of rural clinics in West Virginia. It is important to note that the published values are for clinics in general, not rural clinics. As has been noted earlier, the clinics included in the ITE (1997) publication appear to be larger than rural clinics. It is also important to note that the published rates are based on smaller sample sizes than the sample size used in this study. Table 4-10 compares the rates for West Virginia rural clinics determined in this study with the rates published by ITE.

Table 4- 10 Comparison of Rates for West Virginia Rural Clinics with ITE (1997) Data.

\begin{tabular}{|c|c|c|c|c|c|c|c|}
\hline \multirow[b]{2}{*}{ Variable } & \multirow[b]{2}{*}{ Time } & \multicolumn{3}{|c|}{ ITE (1997) } & \multicolumn{3}{|c|}{ WV (2002) } \\
\hline & & $\begin{array}{l}\text { Avg. } \\
\text { Rate }\end{array}$ & Sample & $\begin{array}{l}\text { Avg. Size } \\
\text { Variable }\end{array}$ & $\begin{array}{l}\text { Avg. } \\
\text { Rate }\end{array}$ & Sample & $\begin{array}{l}\text { Avg. Size } \\
\text { Variable }\end{array}$ \\
\hline \multirow[t]{5}{*}{ Employees } & Weekday AM Peak Hour & \begin{tabular}{|r|}
0.90 \\
\end{tabular} & $\begin{array}{r}1 \\
\end{array}$ & 20 & \begin{tabular}{|l|}
1.64 \\
\end{tabular} & $\begin{array}{r}5 \\
\end{array}$ & 8 \\
\hline & Saturday & 3.35 & 1 & 650 & $\mathrm{NA}$ & NA & 8 \\
\hline & Sunday & 5.97 & 1 & 650 & NA & NA & 8 \\
\hline & Weekday & 7.75 & 2 & 457 & 29.52 & 5 & 8 \\
\hline & Weekday PM Peak Hour & 1.31 & 2 & 114 & 3.33 & 5 & 8 \\
\hline \multirow[t]{2}{*}{ Doctors } & Weekday AM Peak Hour & 3.60 & 1 & 5 & 7.1 & 4 & 2 \\
\hline & Weekday PM Peak Hour & 4.43 & 2 & 12 & 14.44 & 4 & 2 \\
\hline \multirow{4}{*}{$\begin{array}{c}1000 \mathrm{Sq} . \mathrm{Ft} \\
\text { Gross Floor } \\
\text { Area }\end{array}$} & Weekday & 31.45 & 2 & 112 & 88 & 5 & 2.62 \\
\hline & Weekday PM Peak Hour & 5.18 & 1 & 64 & 9.94 & 5 & 2.62 \\
\hline & Saturday & 13.54 & 1 & 161 & $\mathrm{NA}$ & NA & 2.62 \\
\hline & Sunday & 24.10 & 1 & 161 & $\mathrm{NA}$ & NA & 2.62 \\
\hline
\end{tabular}


The trip generation rates for the rural clinics in West Virginia were found to be considerably different from the values found for clinics in Trip Generation (ITE, 1997). In all cases, the trip generation rates for rural West Virginia clinics were significantly higher than the clinic rates published by ITE. The most likely reason for these differences can be determined by comparing the average sizes for the variables. The data from ITE (1997) appears to represent large facilities with hundreds of employees and hundreds of thousands of square feet of floor area, while rural clinics tend to have staffs of less than ten and facilities of only one to two thousand square feet. Since the denominators in the rate equations are so much smaller for West Virginia rural clinics, the trip rates are consequentially higher. It can be concluded that the ITE (1997) rates are more suitable for small hospitals than a rural clinic.

Truck trip generation rates were not collected. According to the facility managers, the only trucks visiting the site were delivery trucks once daily during the week. Therefore truck traffic at rural clinics was felt to be insignificant and included in the trip generation rates presented. Given that they were two-axle delivery vehicles, it was determined that the AASHTO (2001) single unit (SU) truck is the appropriate design vehicle for rural clinics.

\subsection{Regression Results}

According to Trip Generation (ITE, 1997), as discussed in Chapter 3, trip generation results should also be shown in regression equation format if applicable. The guide notes that the two types of equations applicable are a linear line passing through the origin and a logarithmic line. Either equation is considered applicable for trip generation purposes if its $R^{2}$ value is greater than 0.40 . However, only the equation 
with the better $R^{2}$ is presented if both are applicable. Table 4-11 shows the $R^{2}$ values obtained from the data collected in this study for both linear and logarithmic equations for the rates described in the previous section. In many instances, the data did not fit the requirements for equations since $R^{2}$ was less than 0.40 . Those rates that did not meet the $R^{2}$ criteria were stricken in the table. These values cannot be compared to published values for clinics generally since the sample sizes appearing in Trip Generation (1997) are three or less, which according to the criteria, are too small to warrant regression analysis. Those rates that met the requirements for being plotted are presented as Figures 4-7 through 4-13. The plotted regressions in the following figures are all logarithmic except for the average weekday PM peak hour for employees based on all five sites, which is linear. The plots for the remaining 13 rates, i.e., those not meeting the requirements for equations, are included for information purposes only in Appendix D.

Table 4- $11 \mathbf{R}^{2}$ Values for Regression Analysis Performed on Trip Generation Data

\begin{tabular}{|c|c|c|c|}
\hline Linear/ Logarithmic & 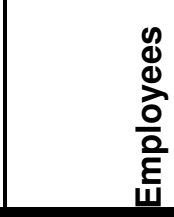 & 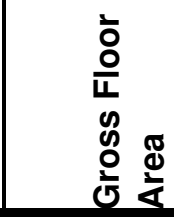 & \\
\hline \multicolumn{4}{|c|}{ All Five Sites } \\
\hline Average Weekday & $.69 / .71$ & .011 .02 & $\overline{\mathrm{INA}}$ \\
\hline Average Weekday Peak Hour & $.64 / .69$ & $.15 / .03$ & NA \\
\hline Average Weekday AM Peak Hour & $.70 / .77$ & .104 .11 & NA \\
\hline Average Weekday PM Peak Hour & $.61 / .57$ & .00407 & NA \\
\hline \multicolumn{4}{|c|}{$\begin{array}{ll} & \text { All But Good Samaritan } \\
\end{array}$} \\
\hline Average Weekday & $\mid 32 / 23$ & $.10 \angle 05$ & $.03 / 03$ \\
\hline Average Weekday Peak Hour & $20 \angle+2$ & .071 .03 & .124 .10 \\
\hline Average Weekday AM Peak Hour & $.38 / .44$ & $.78 / .85$ & $.32 / .49$ \\
\hline Average Weekday PM Peak Hour & .31123 & $.09 / 05$ & $.09 / 03$ \\
\hline
\end{tabular}




\section{West Virginia Rural Clinics}

\section{Average Vehicle Trip Ends vs: Employees \\ On a: Average Weekday}

Number of Studies: 5

Average Number of Variable: 8

Directional Distribution: $\quad 50 \%$ entering, $50 \%$ exiting

\section{Trip Generation per Employee}

\begin{tabular}{|ccc|}
\hline Average Rate & Range of Rates & Standard Deviation \\
\hline 29.52 & $12.72-47.77$ & 12.72 \\
\hline
\end{tabular}

\section{Data Plot and Equation}

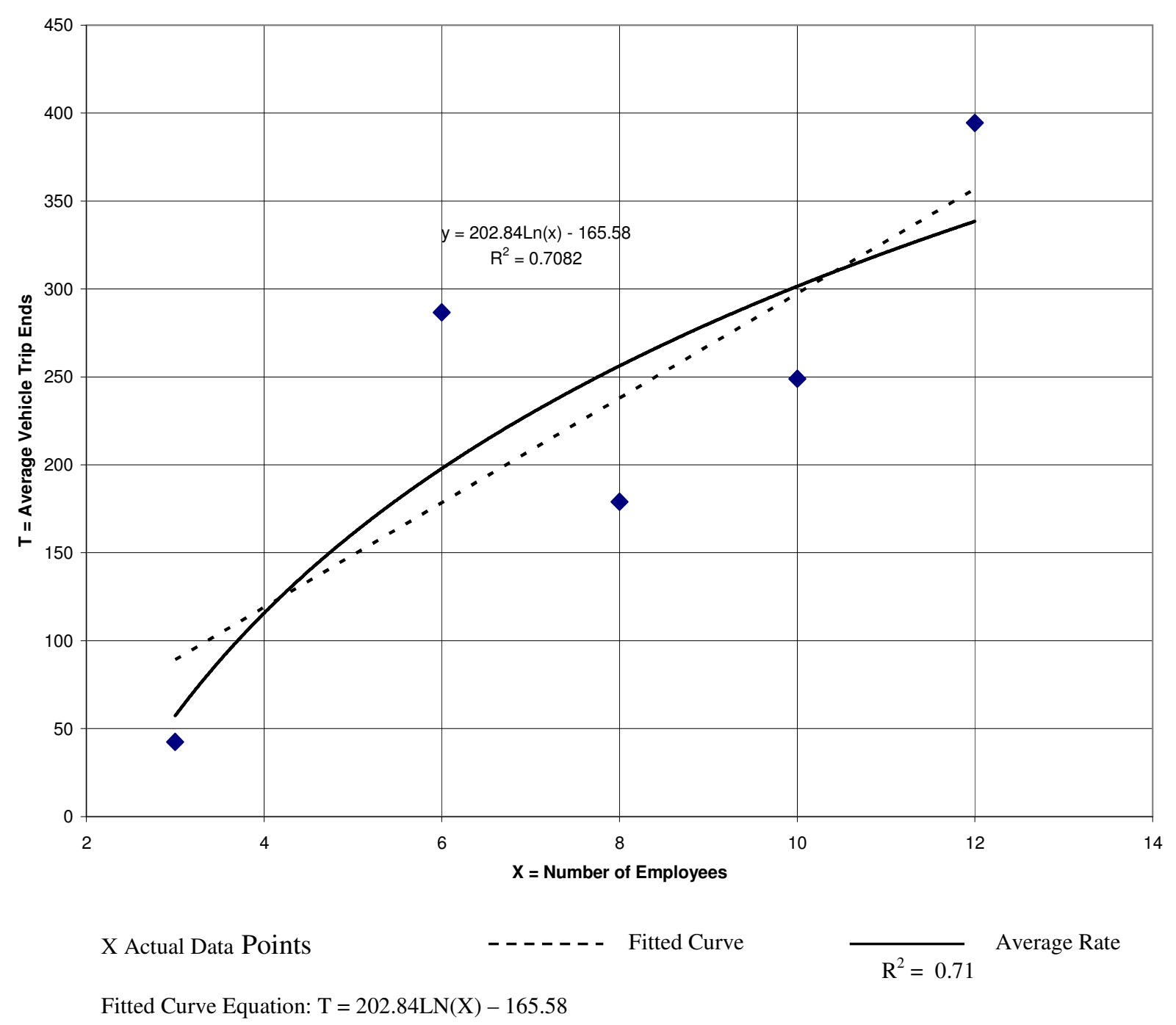




\section{West Virginia Rural Clinics}

\section{Average Vehicle Trip Ends vs: Employees \\ On a: Average Weekday Peak Hour}

Number of Studies: 5

Average Number of Variable: 8

Directional Distribution: $\quad 50 \%$ entering, 50\% exiting

\section{Trip Generation per Employee}

\begin{tabular}{|ccc|}
\hline Average Rate & Range of Rates & Standard Deviation \\
\hline 5.14 & $3.33-8.50$ & 12.72 \\
\hline
\end{tabular}

\section{Data Plot and Equation}

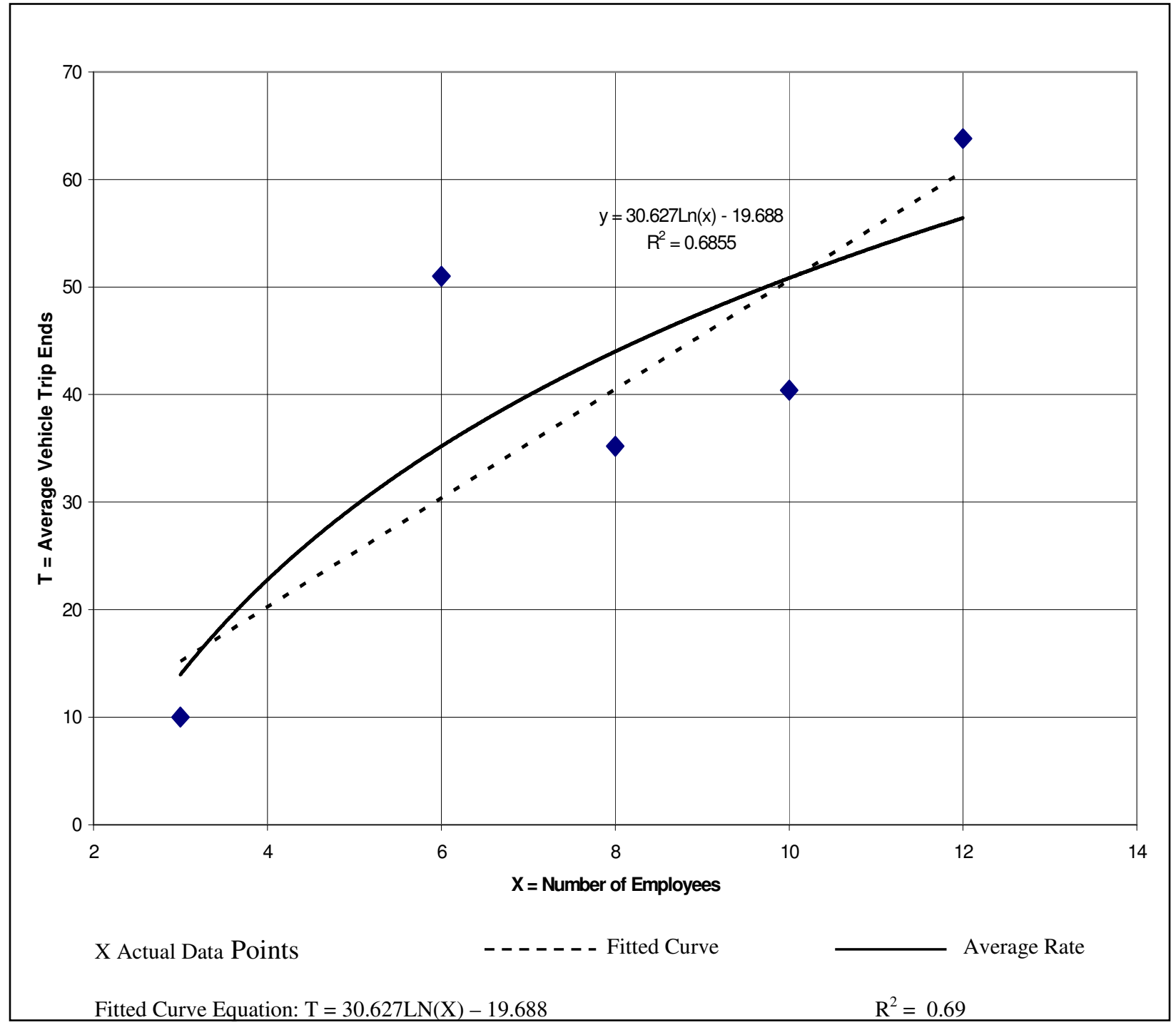




\section{West Virginia Rural Clinics}

\section{Average Vehicle Trip Ends vs: Employees \\ On a: Maximum Weekday AM Peak Hour}

Number of Studies: $\quad 5$

Average Number of Variable: 8

Directional Distribution: $\quad 50 \%$ entering, $50 \%$ exiting

\section{Trip Generation per Employee}

\begin{tabular}{|ccc|}
\hline Average Rate & Range of Rates & Standard Deviation \\
\hline 1.64 & $1.40-2.33$ & 0.38 \\
\hline
\end{tabular}

\section{Data Plot and Equation}

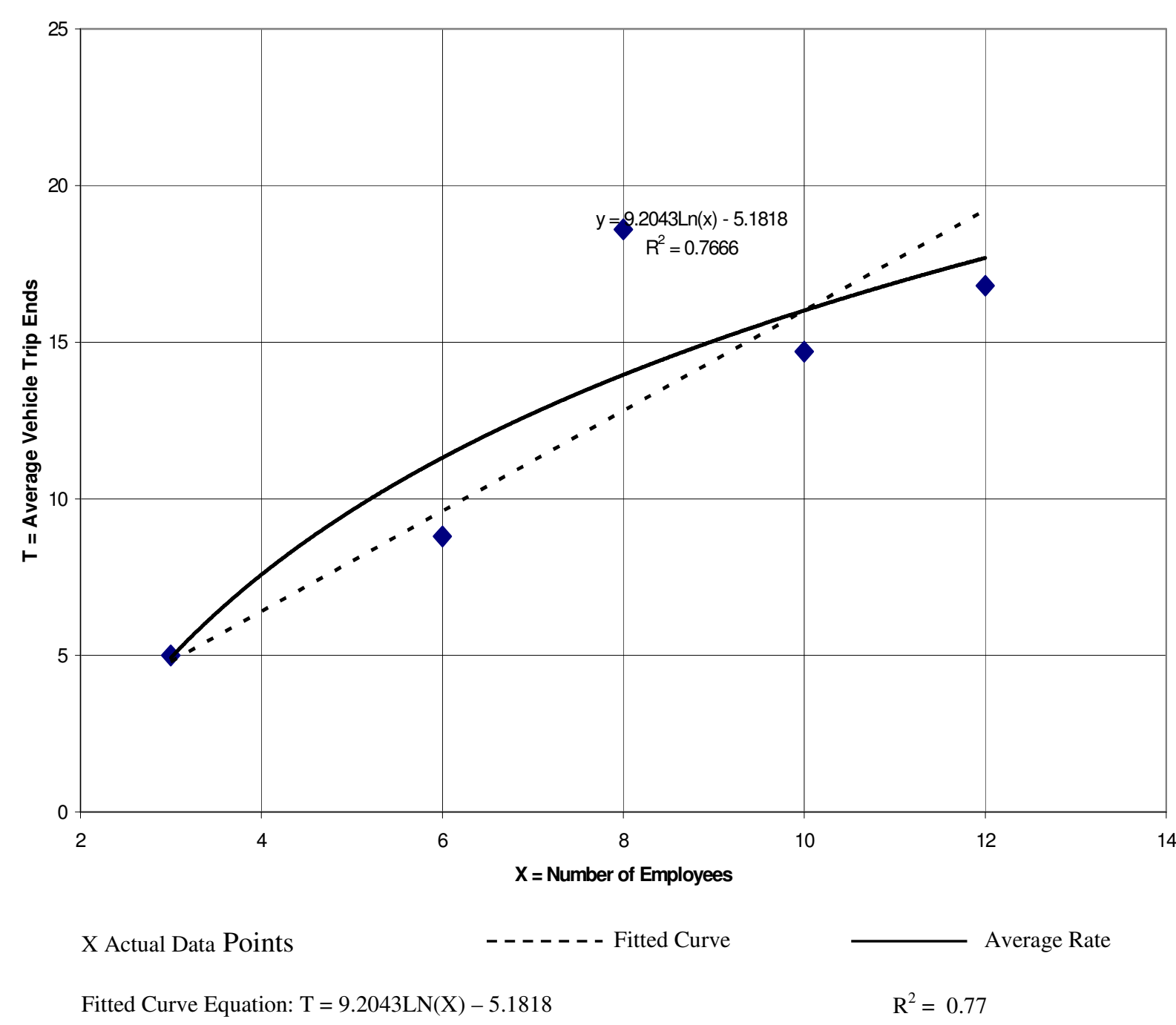




\section{West Virginia Rural Clinics}

\section{Average Vehicle Trip Ends vs: Employees \\ On a: Maximum Weekday PM Peak Hour}

Number of Studies: $\quad 5$

Average Number of Variable: 8

Directional Distribution: $\quad 50 \%$ entering, $50 \%$ exiting

\section{Trip Generation per Employee}

\begin{tabular}{|ccc|}
\hline Average Rate & Range of Rates & Standard Deviation \\
\hline 3.33 & $0.47-5.70$ & 2.13 \\
\hline
\end{tabular}

\section{Data Plot and Equation}

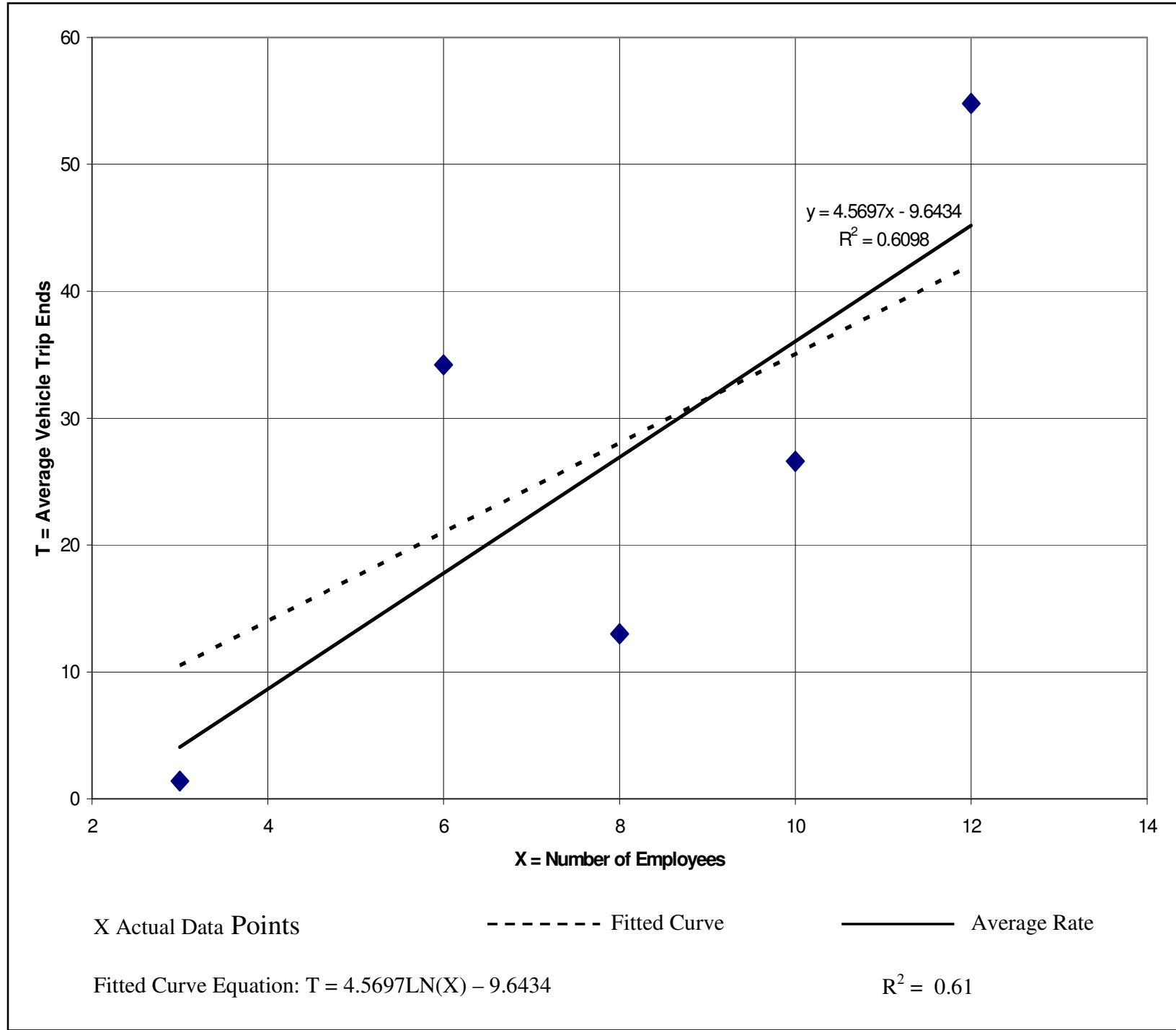




\section{West Virginia Rural Clinics}

\section{Average Vehicle Trip Ends vs: Employees \\ On a: Maximum Weekday AM Peak Hour}

Number of Studies: $\quad 4$

Average Number of Variable: 8

Directional Distribution: $\quad 50 \%$ entering, $50 \%$ exiting

\section{Trip Generation per Employee}

Use Caution - Small Sample Size

\begin{tabular}{|ccc|}
\hline Average Rate & Range of Rates & Standard Deviation \\
\hline 1.64 & $1.40-2.33$ & 0.38 \\
\hline
\end{tabular}

\section{Data Plot and Equation}

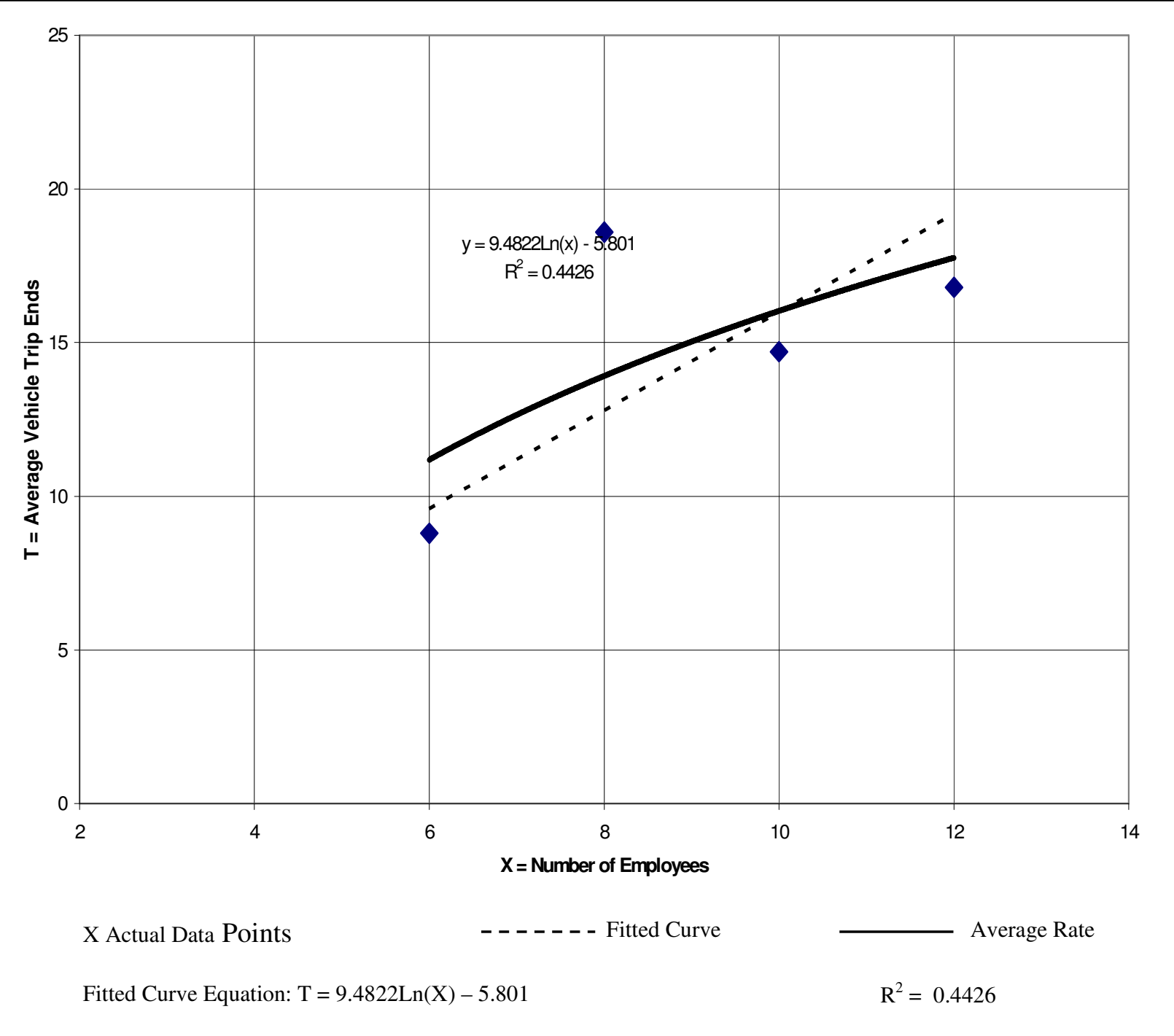

Figure 4-11 Regression Plot and Equation for Four West Virginia Rural Clinics (Maximum AM Weekday Peak Hour Trips per Employee) 


\title{
West Virginia Rural Clinics
}

\section{Average Vehicle Trip Ends vs: 1000 Sq. Ft. Gross Floor Area \\ On a: Maximum Weekday AM Peak Hour}

\author{
Number of Studies: 4 \\ Average Number of Variable: $\quad 2.62$ \\ Directional Distribution: $\quad 50 \%$ entering, $50 \%$ exiting
}

Trip Generation per 1000 Sq. Ft. Gross Floor Area

\begin{tabular}{|ccc|}
\hline Average Rate & Range of Rates & Standard Deviation \\
\hline 4.88 & $1.66-6.64$ & 1.99 \\
\hline
\end{tabular}

Data Plot and Equation

Use Caution - Small Sample Size

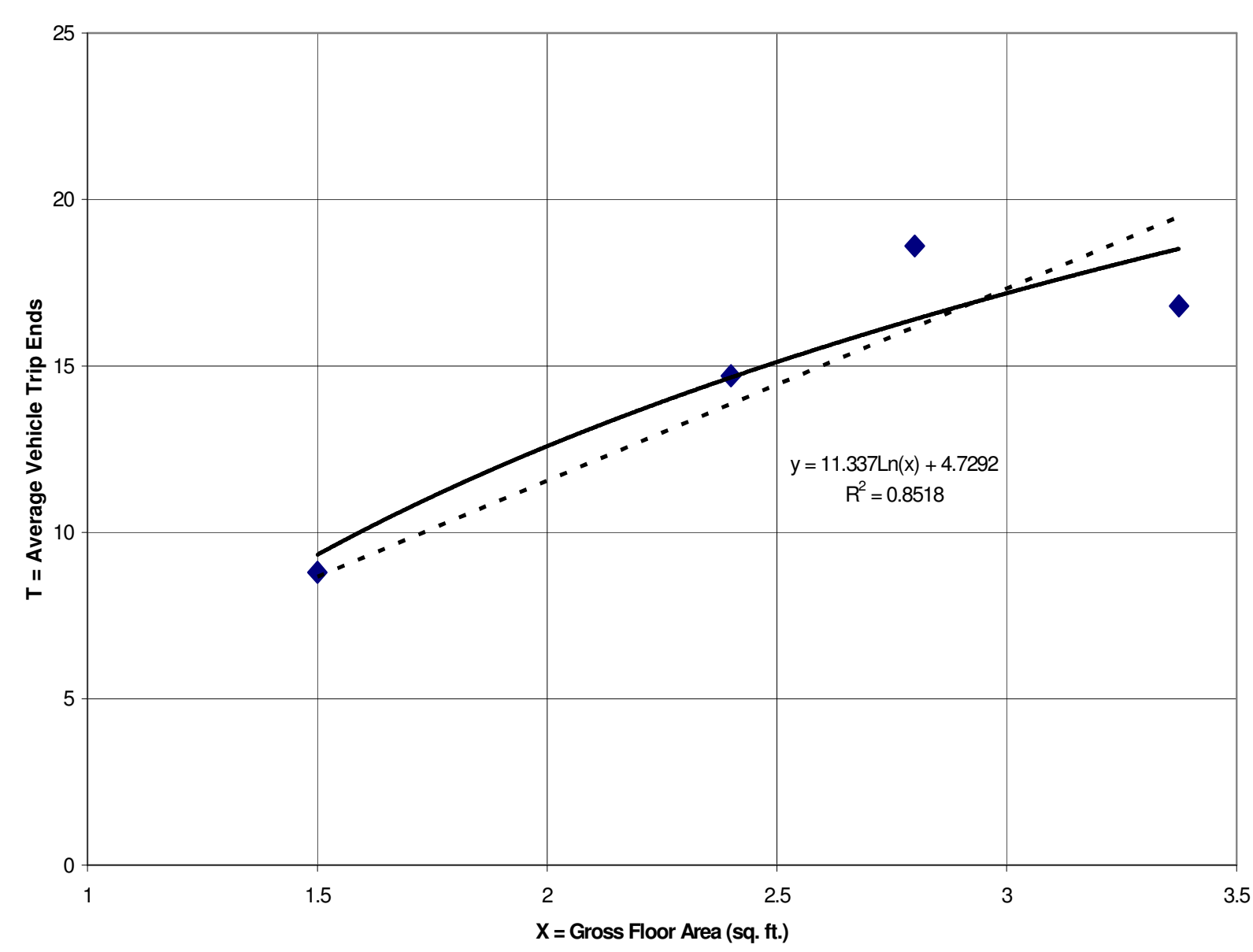

X Actual Data Points 


\title{
West Virginia Rural Clinics
}

\section{Average Vehicle Trip Ends vs: Doctor \\ On a: Maximum Weekday AM Peak Hour}

\author{
Number of Studies: 4 \\ Average Number of Variable: 2 \\ Directional Distribution: $\quad 50 \%$ entering, $50 \%$ exiting
}

Trip Generation per Doctor

\begin{tabular}{|ccc|}
\hline Average Rate & Range of Rates & Standard Deviation \\
\hline 7.36 & $4.90-9.30$ & 2.00 \\
\hline
\end{tabular}

Data Plot and Equation

Use Caution - Small Sample Size

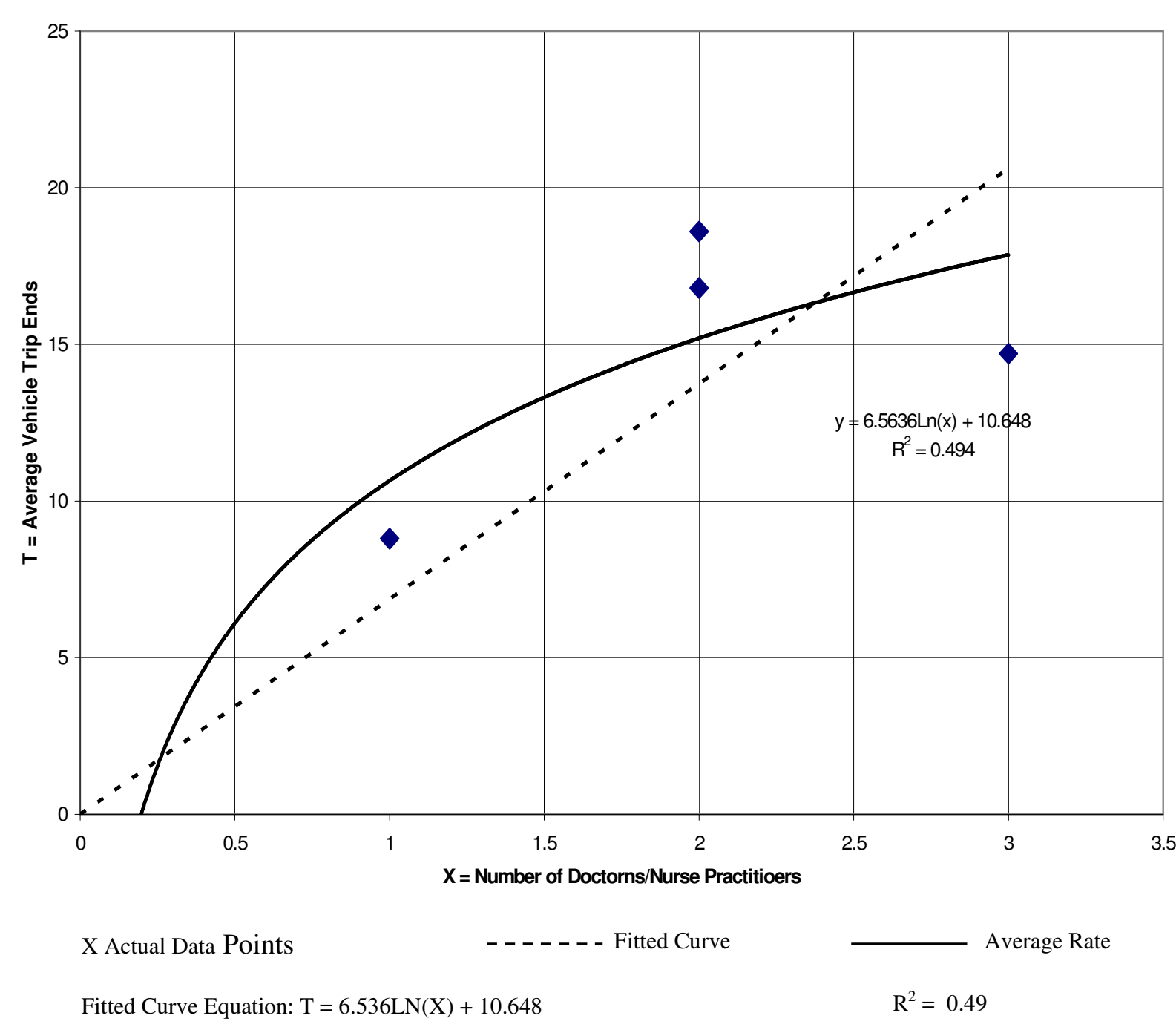

Figure 4-13 Regression Plot and Equation for Four West Virginia Rural Clinics (Maximum AM Weekday Peak Hour Trips per Doctor) 


\section{$5 \quad$ Peaking Characteristics}

The common method for determining a design hour volume is through the use of a peak hour factor, generally called $\mathrm{K}$. This represents the ratio of the highest hourly volume to the average daily traffic [ADT] or average annual daily traffic [AADT](Roess, McShane, and Prassas, 1998). Values for K on highways typically average 8 to $12 \%$ for urban areas and 12 to $18 \%$ for rural areas (AASHTO, 2001). The peak traffic volumes at the clinics studied were not expected to have a significant effect on traffic operations in the rural areas where they are located. However, since traffic volumes for an interval of time shorter than a day more appropriately reflect the operating conditions that should be used for design, $\mathrm{K}$ values were determined for West Virginia rural clinics.

In this study, the daily peak hour volume was divided by the total daily volume to produce peak factors for each day. They were then averaged to compute a $\mathrm{K}$ value for the site. These values are presented in Table 4-12. With the exception of Good Samaritan Clinic, the rural clinics tend to have values consistent with the typical $\mathrm{K}$ values for rural areas. The unusually high value for Good Samaritan is probably due to the fewer hours of operation. The fewer number of hours a facility is open, the higher the factor will be.

Table 4- 12 Weekday "K" Values for the Five Sites Studied

\begin{tabular}{|l||r|r|l|l|l|}
\hline & Eglon Clinic & \multicolumn{2}{|l|}{$\begin{array}{l}\text { Rowlesburg } \\
\text { Clinic }\end{array}$} & $\begin{array}{l}\text { St. George } \\
\text { Clinic }\end{array}$ & \multicolumn{2}{l|}{$\begin{array}{l}\text { Shinnston } \\
\text { Clinic }\end{array}$} & \multicolumn{2}{l|}{$\begin{array}{l}\text { Good Samaritan } \\
\text { Clinic }\end{array}$} \\
\hline \hline Monday & 0.14 & 0.15 & 0.16 & 0.17 & 0.18 \\
\hline Tuesday & 0.18 & 0.15 & 0.15 & 0.20 & 0.28 \\
\hline Wednesday & 0.23 & 0.20 & 0.18 & 0.16 & 0.33 \\
\hline Thursday & 0.21 & 0.14 & 0.15 & 0.16 & 0.15 \\
\hline Friday & 0.18 & 0.18 & 0.17 & 0.12 & 0.22 \\
\hline \hline Average & 0.19 & 0.16 & 0.16 & 0.16 & 0.23 \\
\hline
\end{tabular}




\section{Recommendations for Use}

The results presented in this chapter are based on traffic count data collected at five rural clinics in West Virginia. Each of these sites met the site selection criteria outlined in Chapter 3, yet each was unique in facility location, staff, size, and hours of operation. These clinics are felt to be representative of rural clinics in West Virginia.

Trip generation rates for weekday, weekday peak hour, weekday AM peak hour, and weekday PM peak hour were presented for three SEVs chosen for the study: employees, 1,000 $\mathrm{ft}^{2}$ gross floor area, and doctors. The rates vary in consistency from 0.12 for gross floor area, AM peak hour, for all sites but Good Samaritan to 0.90 for

gross floor area, PM peak hour, for all five sites. It should be noted, however, that all of the consistencies met the ITE (1997) criteria to be considered "good." Therefore, all of these rates are offered as acceptable for trip generation studies.

Regression analysis was performed in accordance with the procedures set forth in Trip Generation (ITE, 1997). Seven of the twenty rates examined had $R^{2}$ values that were acceptable for presenting equations and plotted curves.

- Employees, Weekday, all five sites

- Employees, Weekday Peak Hour, all five sites

- Employees, Weekday AM Peak Hour, all five sites

- Employees, Weekday PM Peak Hour, all five sites

- Employees, Weekday AM Peak Hour, all but Good Samaritan

- Gross Floor Area, Weekday AM Peak Hour, all but Good Samaritan

- Doctors, Weekday AM Peak Hour, all but Good Samaritan 
Although the regression analyses and rates are deemed statistically acceptable according to ITE (1997), it was felt the Good Samaritan clinic was significantly different from the other sites. The results based on the remaining four clinics are recommended for use.

Rates are valid only for rural clinic sites within the range of characteristics examined in this study. Therefore, it is recommended that these rates only be used for facilities with SEVs within the limits presented in Table 4-13.

Table 4- 13 Range of Socio Economic Values for West Virginia Rural Clinics

\begin{tabular}{|l|r|r|}
\hline Variable & Minimum & Maximum \\
\hline Employees & 6 & 12 \\
\hline Gross Floor Area & $1500 \mathrm{ft}^{\wedge} 2$ & $3400 \mathrm{ft}^{\wedge} 2$ \\
\hline Doctors & 1 & 3 \\
\hline
\end{tabular}

Comparing the rates and average variable sizes from this study with those listed in Trip Generation (1997), it is clear that the two sets of rates do not represent the same type of clinic. The rates presented by ITE (1997) represent facilities on the scale of small hospitals rather than rural clinics. Therefore, the rates presented by this study are for a facility type not previously included in ITE documents and are recommended for engineers and planners needing trip generation data for rural clinics.

As mentioned previously, truck trip generation rates were not collected. According to the facility managers, the only trucks visiting the site were delivery trucks once daily during the week. Therefore, these trucks were considered insignificant in terms of the overall volume of traffic and were included in the trip generation rates presented. 


\section{Chapter 5 Conclusions and Recommendations}

\subsection{Introduction}

The overall goal of the project was to determine trip generation characteristics for rural clinics in West Virginia. This chapter presents conclusions drawn from the research, recommendations on applying the results developed herein, and recommendations for follow-on research.

\subsection{Conclusions}

Rural clinics are primary care facilities serving small towns and rural communities. While they tend to be small in size and have only one or two physicians on staff, they fill a health care need in geographic areas where hospitals and/or physician's offices are difficult to reach. During the 1990's, the number of rural clinics in the United States grew rapidly. This growth is expected to continue, as the number of hospitals, particularly those serving rural areas, declines.

Published trip generation rates for clinics apparently involved larger, more urban facilities. They include facilities with up to 650 employees and several hundred thousand square feet of floor area. Thus, they appear to be actually small hospitals. Clinics in the ITE database also tend to have on average 5 to 12 physicians on staff when the typical rural clinic typically employs only a few.

By reviewing available literature and through collection of data from the West Virginia study sites, it can be concluded that the "clinic" trip generation information presented in ITE Trip Generation (1997) does not adequately represent the rural clinics examined in this study. Therefore, the results of the study appear to be the only published data available regarding traffic characteristics of rural clinics. This study 
carefully defined rural clinics, followed a standard method for data collection, and collected data from a sufficient number of sites; therefore, the results are considered valid, reliable, and transferable to other locations. This data is limited to "rural" clinics whose socio-economic variables are within the limits presented in Chapter 4.

All of the rates determined in this study are classified as "good" according to the ITE consistency criteria; therefore they are considered reliable for use. Seven equations and plotted curves within the limits set by ITE (1997) were also presented according to ITE (1997) guidelines. The rates which satisfied equation and curve plot criteria were:

- Employees, Weekday, all five sites

- Employees, Weekday Peak Hour, all five sites

- Employees, Weekday AM Peak Hour, all five sites

- Employees, Weekday PM Peak Hour, all five sites

- Employees, Weekday AM Peak Hour, all but Good Samaritan

- Gross Floor Area, Weekday AM Peak Hour, all but Good Samaritan

- Doctors, Weekday AM Peak Hour, all but Good Samaritan

Proximity to other health care providers may explain some of the differences in trip generation rates. Although seven of the regression equations and all of the rates met the ITE criteria (1997), due to significant differences in organization structure, hours of operation, and the location of the Good Samaritan Clinic, only those rates and regression results based on the remaining four sites are recommended for use. Rates based on gross floor area will be the most widely used. 
Based on interviews with site managers, it was determined that the largest vehicle visiting the clinics was a single unit delivery truck and that there was one such truck per day serving the site. It was decided that a truck trip generation rate was not necessary, because the rate is negligible.

\subsection{Recommendations for Further Research}

A few recommendations are presented for future research of trip characteristics of rural clinics. One would be to study more sites in different geographic areas to obtain more values to refine rates and allow production of more regression curves. Examining rural clinics of different sizes and services would allow planners and engineers to develop a better understanding of clinics (and their characteristics) throughout the country.

Some rural clinics offer special services by bringing mobile units of various types to the facility on a short-term basis. Given that these "events" would be an attraction to clinic clientele and given their short term nature, the peak flow they generate could impact traffic operations in the vicinity of the site. To assist in understanding the phenomenon, trip characteristics and rates associated with such special events should be collected and computed.

Seasonal variations in trip generation occur among hospitals. A similar phenomenon would be expected to occur for rural clinics. However, no data was found on whether this variation occurs, and, if so, what are its characteristics. Data should be collected at rural clinics to characterize any such variation.

In developing the trip generation rates presented in this study, an effort was made to clearly identify the characteristics of rural clinics studied. At the same time, it 
was noted that the characteristics of the "clinics" presented in ITE trip generation publications were not clearly defined. They appeared to be much larger, more urban facilities than the rural clinics in this study. Thus, it is recommended that ITE more clearly define or categorize the clinics contained in its database so that they can be used appropriately by planners and engineers. For example, given their large staffs and 7-day per week operation, it is possible that the ITE clinics are actually urban urgent care facilities. This is another type of health care related land use whose traffic generation characteristics should be compared with those of rural clinic.

Facility managers stated that two-axle delivery trucks visiting once per day were the only trucks arriving at the site. The researcher, however, speculates that solid waste, bio-waste, and other vehicles may visit the site on a more infrequent schedule. Therefore, additional investigation of the numbers and sizes of commercial vehicles serving rural clinics is recommended.

\subsection{Implementation}

These results are now available to engineers, planners, and others involved in traffic evaluation and forecasting and in planning and designing rural clinics. The data will also be submitted to the Institute of Transportation Engineers for inclusion in the trip generation database 


\section{List of References}

AccuWeather.com. "Past Weather Data." www.accuweather.com. 2003.

American Association of State Highway and Transportation Officials. A Policy on Geometric Design of Highways and Streets: Fourth Edition. AASHTO. Washington, DC. 2001.

Buttke, Carol H. and ITE Technical Council Committee 6A-32. "Guidelines for Using Trip Generation Rates or Equations." ITE Journal. August_1990

California State Rural Health Association. "What is a Rural Health Clinic." http://www.csrha.org. 2003.

Farley, Donna O. Trends in Specialized Medicare Payments and Service Utilization for Rural Areas in the 1990s. 2002. http://www.rand.org/publications/MR/MR1595/. 2003.

French III, L.J., Eck, R.W., Balmer, A.M.. Trip Generation Rates, Peaking Characteristics, and Vehicle Mix Characteristics of Special West Virginia Generators. Department of Civil and Environmental Engineering, West Virginia University. Morgantown, WV. 2000.

Health Resources and Service Administration. "HRSA State Health Workforce Profiles:

West Virginia." http://bhpr.hrsa.gov/healthworkforce. 2003

Hogg, Robert V. and Ledolter, Johannes. Applied Statistics for Engineers and Physical Scientists. Macmillan Publishing Company. New York. 1987.

Institute of Transportation Engineers, Trip Generation: $6^{\text {th }}$ Edition, Institute of Transportation Engineers. Washington, DC. 1997. 
Institute of Transportation Engineers, Trip Generation: $4^{\text {th }}$ Edition, Institute of Transportation Engineers. Washington, DC. 1987.

Johnston, David G. Primary Care Centers: Design and Construction. Appalachian Regional Commission. Washington, DC. 1977.

Medicare. "Nursing Home Compare" http://www.medicare.gov. 2003.

National Association of Rural Health Clinics, "Rural Health Clinics - Rules and Guidelines." http://www.narhc.org/guidelines.htm. 2002.

National Rural Health Association. "Rural Health Clinics in Rural America." http://www.nrharural.org. 2003.

Neumann E.S. and G.K. Deshpande. West Virginia Special Traffic Generators Study, Phase I. Department of Civil Engineering, West Virginia University. Morgantown, WV. 1974.

Office of Community and Rural Health Services, "Division of Primary Care." State of West Virginia, Department of Health and Human Resources. http://www.wvprimarycare.org. 2002.

Office of Rural Health Policy, "West Virginia Rural Hospital Flexibility Program." http//www.ruralhealthpolicy.org/projects/rhfp/index.htm. 2002.

Roess, R.P., McShane, W.R., Prassas, E.S.. Traffic Engineering: Second Edition. Prentice Hall. Upper Saddle River, NJ. 1998.

USDA Rural Information Center. http://www.nal.usda.gov/ric/faqs/ruralfaq.htm. 2002.

US Department of Health and Human Resources, "Bureau of Primary Health Care." http://bphc.hrsa.gov/databases/newmua/. 2002. 
West Virginia Board of Pharmacy. "General Rules and Regulations of the Board of Pharmacy." http://wvbop.com. 2003.

Whitlock, Edward M. Parking for Institutions and Special Events. ENO Foundation for Transportation. Westport, CT. 1982.

Wright, Paul H. Highway Engineering: Sixth Edition. John Wiley and Sons, Inc. New York. 1996. 


\section{Appendix A \\ Sample of Method of \\ Presentation Recommended \\ by ITE (1997)}




\section{SAMPLE PAGE}

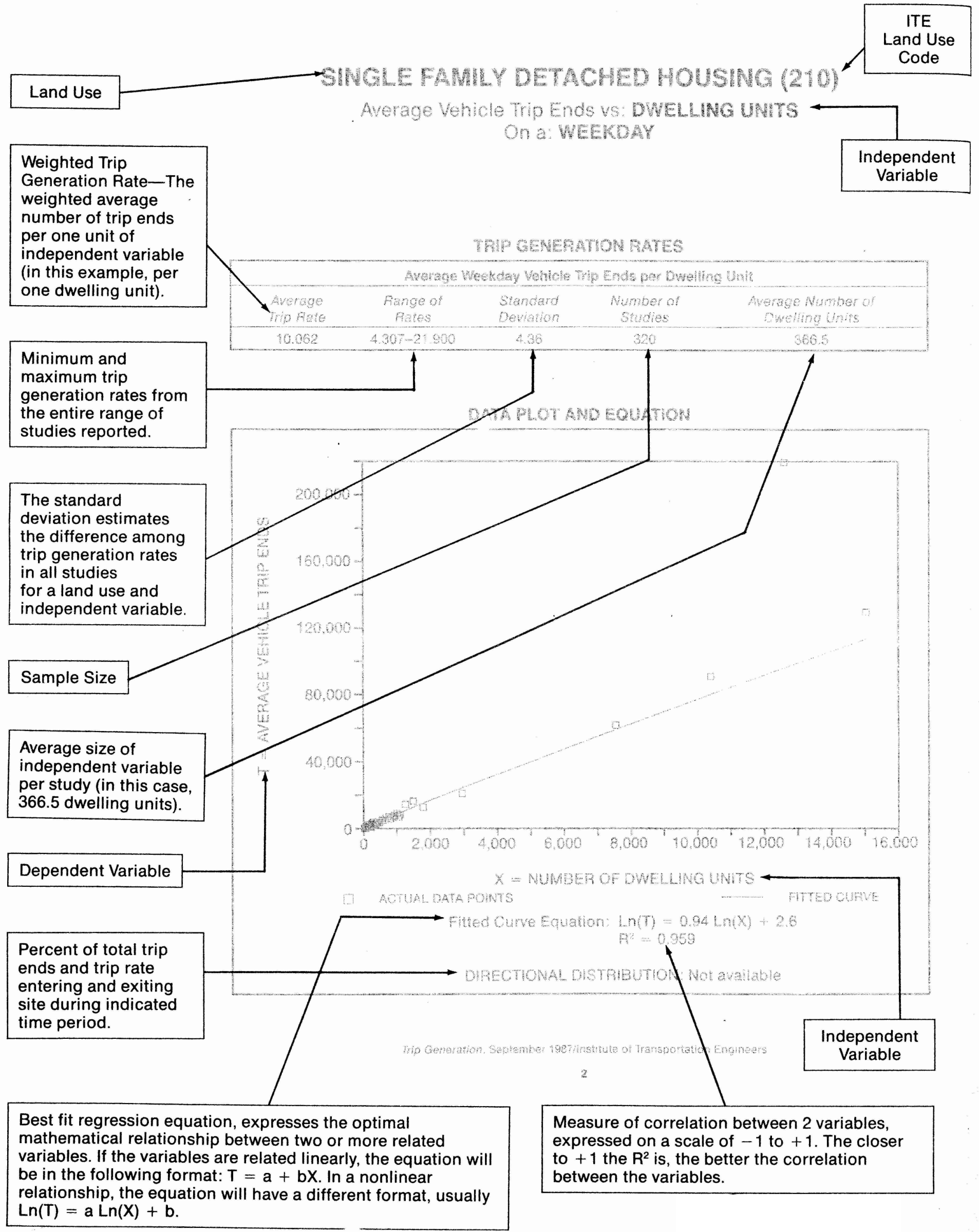


Appendix B

Site Survey Form 
Trip Generation Interview / Site Inspection Form

Site Name

Address

City

Zip

Interviewee

Position

Phone

Date Time

\section{Interview}

\begin{tabular}{|c|c|}
\hline Employees (full/part) & Maximum Size Vehicle \\
\hline Doctors (full/part) & Maximum Size Vehicle (axles) \\
\hline Nurses (full/part) & Frequency Max Vehicle \\
\hline Examination Rooms & \\
\hline
\end{tabular}

Hours of Operation

\begin{tabular}{|l|l|l|l|l|l|l|l|}
\hline \hline & Mon & Tues & Wed & Thurs & Fri & Sat & Sun \\
\hline Morning & & & & & & & \\
\hline Afternoon & & & & & & & \\
\hline Evening & & & & & & & \\
\hline \hline
\end{tabular}

Site Measurements

\begin{tabular}{|c|c|}
\hline \# Parking Stalls (non-handicap) & \# Access Driveways \\
\hline \# Handicap Parking Stalls & Gross Floor Area $\left(\mathrm{ft}^{2}\right)$ \\
\hline Pavement Surface (A/S/C) & Acres \\
\hline
\end{tabular}

Services Provided \& Additional Notes 


\section{West Virginia Rural Clinic}

Trip Generation Interview / Site Inspection Form

Site Sketch 


\section{Appendix C \\ Completed Site Survey Forms for and Photographs of the Five Study Sites}




\section{West Virginia Rural Clinic}

\section{Trip Generation Interview / Site Inspection Form}

I

nterviwee Name Eglon Clinic (Preston-Taylor Community Health Centers, Inc.)

Address Star Route 24, Box 8

City Eglon Zip 26716

Interviewee Linda Shriver

Position Administrator

Phone (304)-265-0312 Date _ August 20, 2002 Time NA

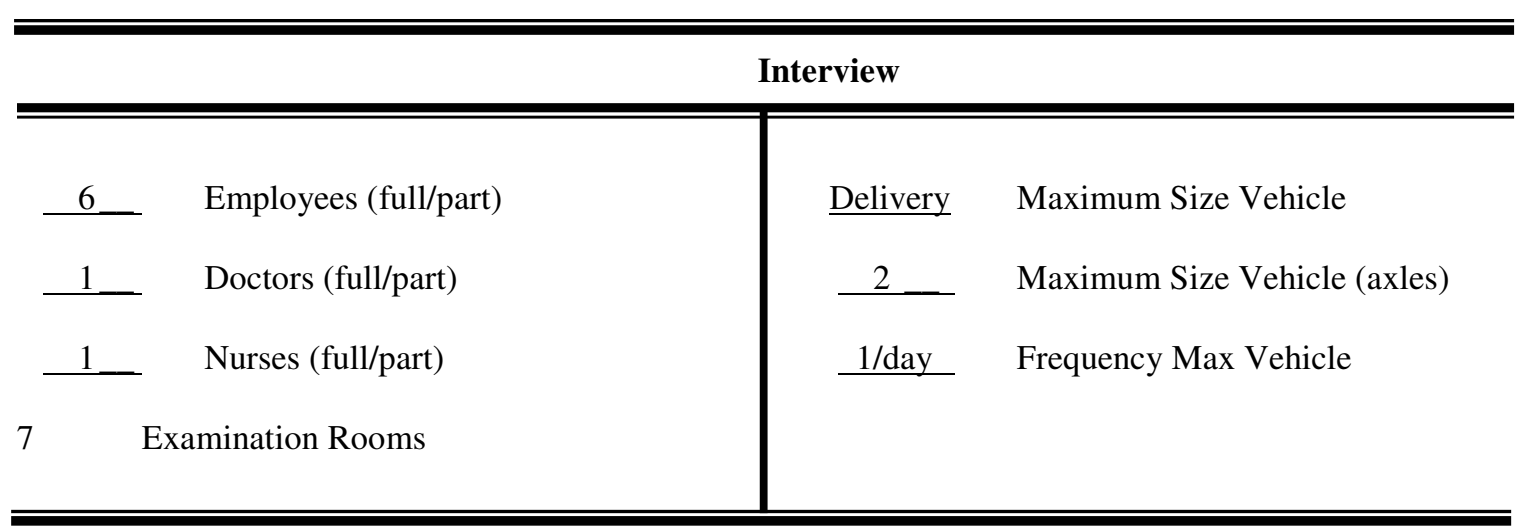

Hours of Operation

\begin{tabular}{|l|l|l|l|l|l|l|l|}
\hline \hline & Mon & Tues & Wed & Thurs & Fri & Sat & Sun \\
\hline Morning & $11-2 \mathrm{PM}$ & $8-12 \mathrm{PM}$ & $8-12 \mathrm{PM}$ & $8-12 \mathrm{PM}$ & $8-12 \mathrm{PM}$ & Closed & Closed \\
\hline Afternoon & & $1-5 \mathrm{PM}$ & $1-5 \mathrm{PM}$ & $1-5 \mathrm{PM}$ & $1-5 \mathrm{PM}$ & Closed & Closed \\
\hline Evening & $3-7 \mathrm{PM}$ & & & & & & \\
\hline \hline
\end{tabular}

Site Measurements

\begin{tabular}{|c|c|c|c|}
\hline 9 & \# Parking Stalls (non-handicap) & 1 & \# Access Driveways \\
\hline 1 & \# Handicap Parking Stalls & 1500 & Gross Floor Area $\left(\mathrm{ft}^{2}\right)$ \\
\hline A & Pavement Surface (A/S/C) & 0.28 & Acres \\
\hline
\end{tabular}

Services Provided \& Additional Notes

$\underline{\text { Handle chronic and acute illnesses, preventative care, sports medicine, physicals, }}$ laboratory tests, diagnostic screening, EKG, immunization, basic pharmacy 


\section{West Virginia Rural Clinic}

Trip Generation Interview / Site Inspection Form

Site Sketch
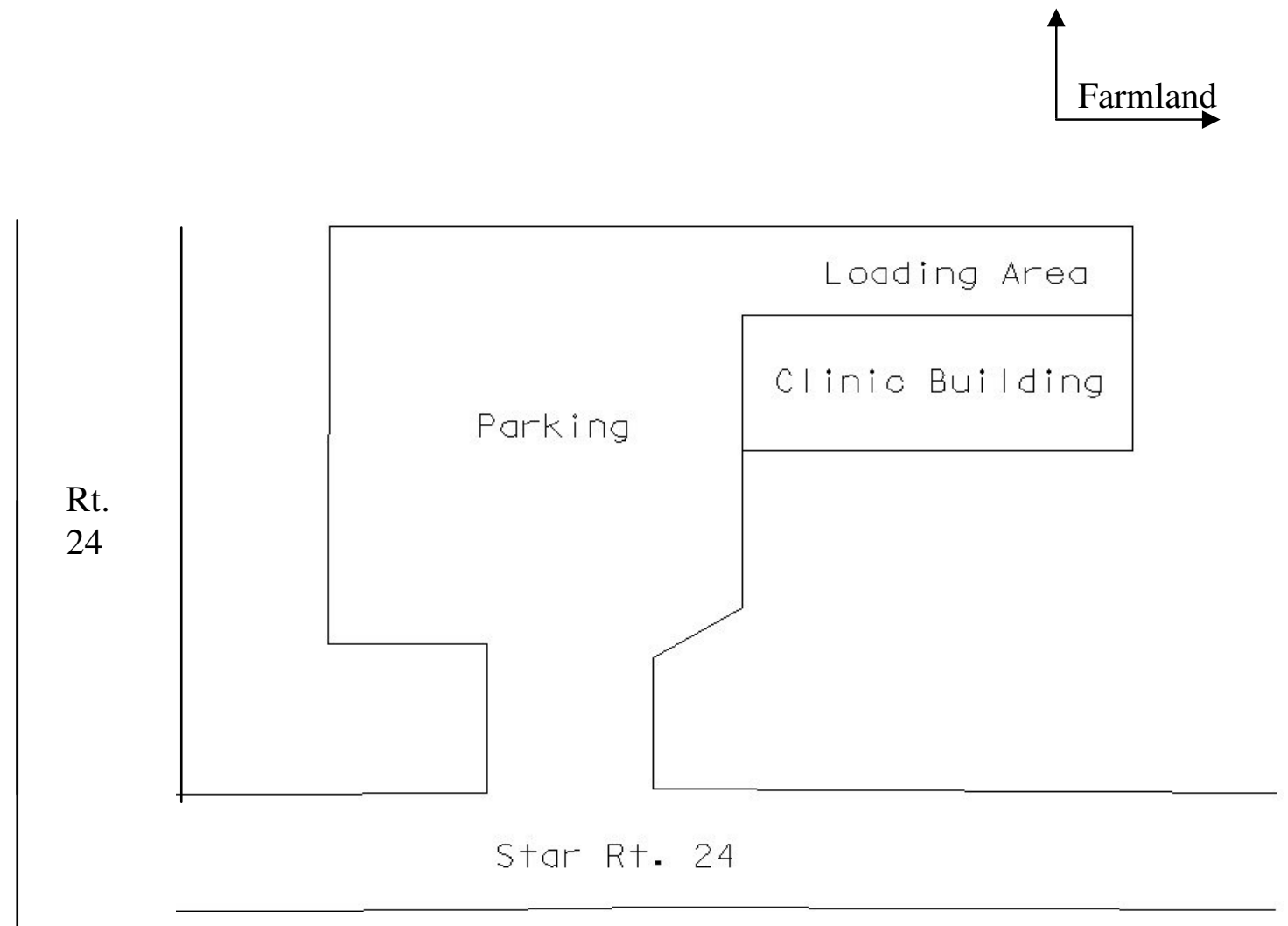

Farmland 


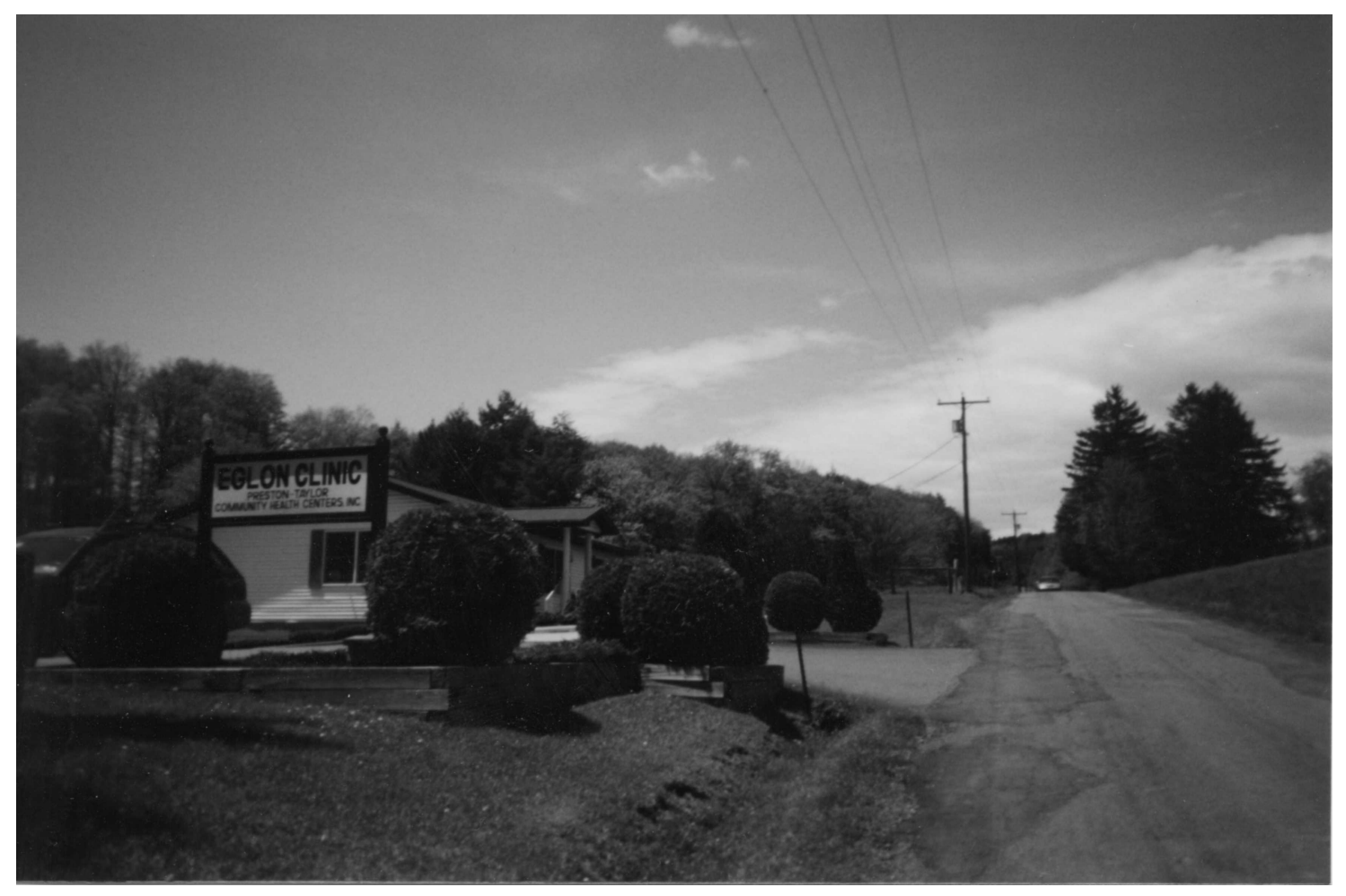




\section{West Virginia Rural Clinic}

\section{Trip Generation Interview / Site Inspection Form}

Site Name Good Samaritan Clinic

Address 911 Emerson Ave.

City Parkersbur Zip 26101

Interviewee ___ Cynthia Moore Position Administrator

Phone (304)-422-7357 Date August 23, 2002 Time NA

\begin{tabular}{|c|c|c|c|}
\hline & \multicolumn{3}{|c|}{ Interview } \\
\hline 3 & Employees (full/part) & Delivery & Maximum Size Vehicle \\
\hline 0 & Doctors (full/part) & 2 & Maximum Size Vehicle (axles) \\
\hline 1 & Nurses (full/part) & 1/day & Frequency Max Vehicle \\
\hline & amination Rooms & & \\
\hline
\end{tabular}

Hours of Operation

\begin{tabular}{|l|l|l|l|l|l|l|l|}
\hline \hline & Mon & Tues & Wed & Thurs & Fri & Sat & Sun \\
\hline Morning & $8-12 \mathrm{PM}$ & $8-12 \mathrm{PM}$ & $8-12 \mathrm{PM}$ & $8-12 \mathrm{PM}$ & $8-12 \mathrm{PM}$ & Closed & Closed \\
\hline Afternoon & $1-4 \mathrm{PM}$ & $1-4 \mathrm{PM}$ & $1-4 \mathrm{PM}$ & & & Closed & Closed \\
\hline Evening & & & & & & & \\
\hline \hline
\end{tabular}

Site Measurements

\begin{tabular}{ll|ll}
\hline \hline 9 & \# Parking Stalls (non-handicap) & $\underline{1}-$ & \# Access Driveways \\
- & \# Handicap Parking Stalls & $\underline{3008}$ & Gross Floor Area $\left(\mathrm{ft}^{2}\right)$ \\
A__ Pavement Surface (A/S/C) & $\underline{0.25}$ & Acres \\
\hline \hline
\end{tabular}

\section{Services Provided \& Additional Notes}

Primary Care 


\section{West Virginia Rural Clinic}

\section{Trip Generation Interview / Site Inspection Form}

Site Sketch

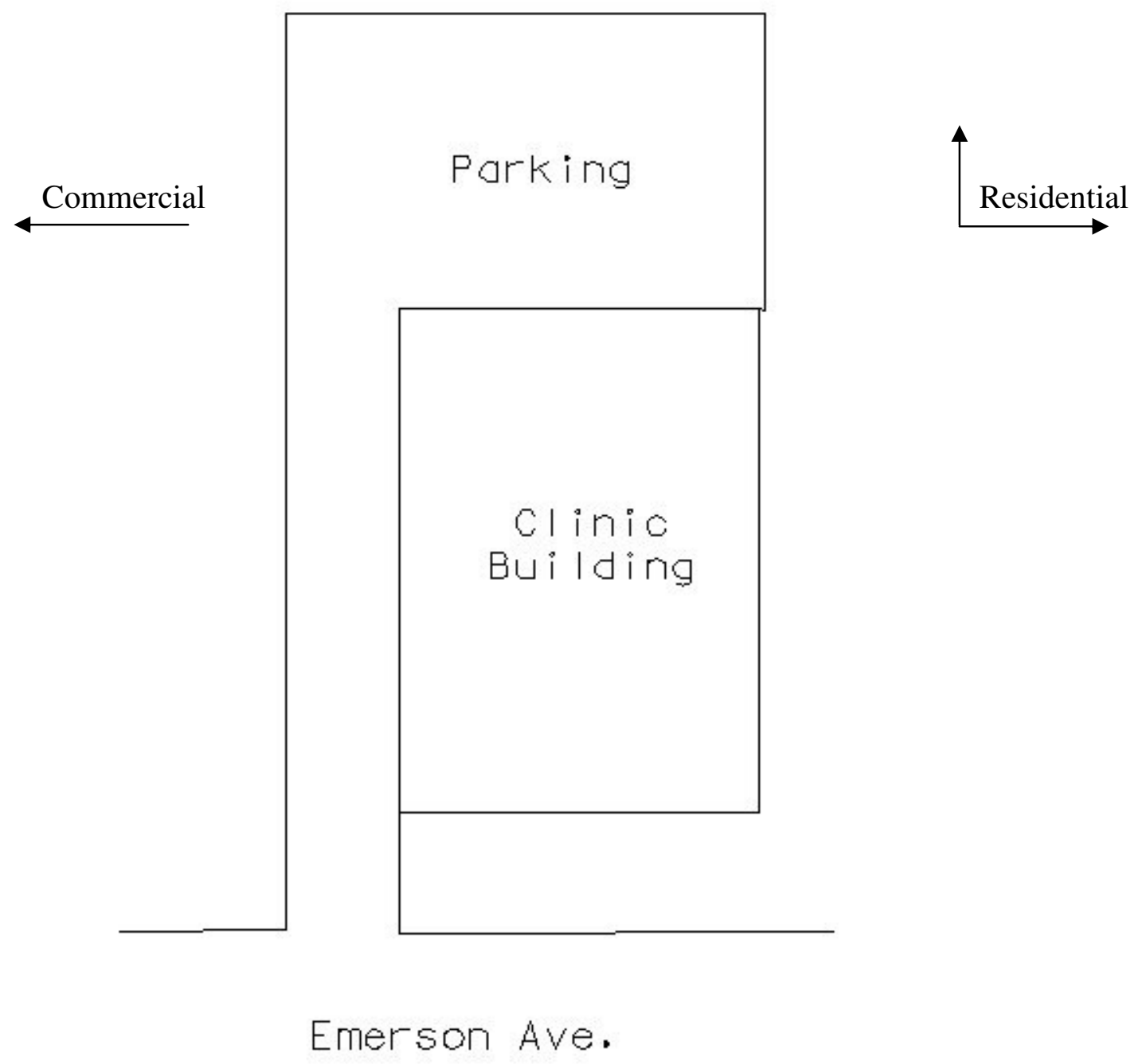

Residential 


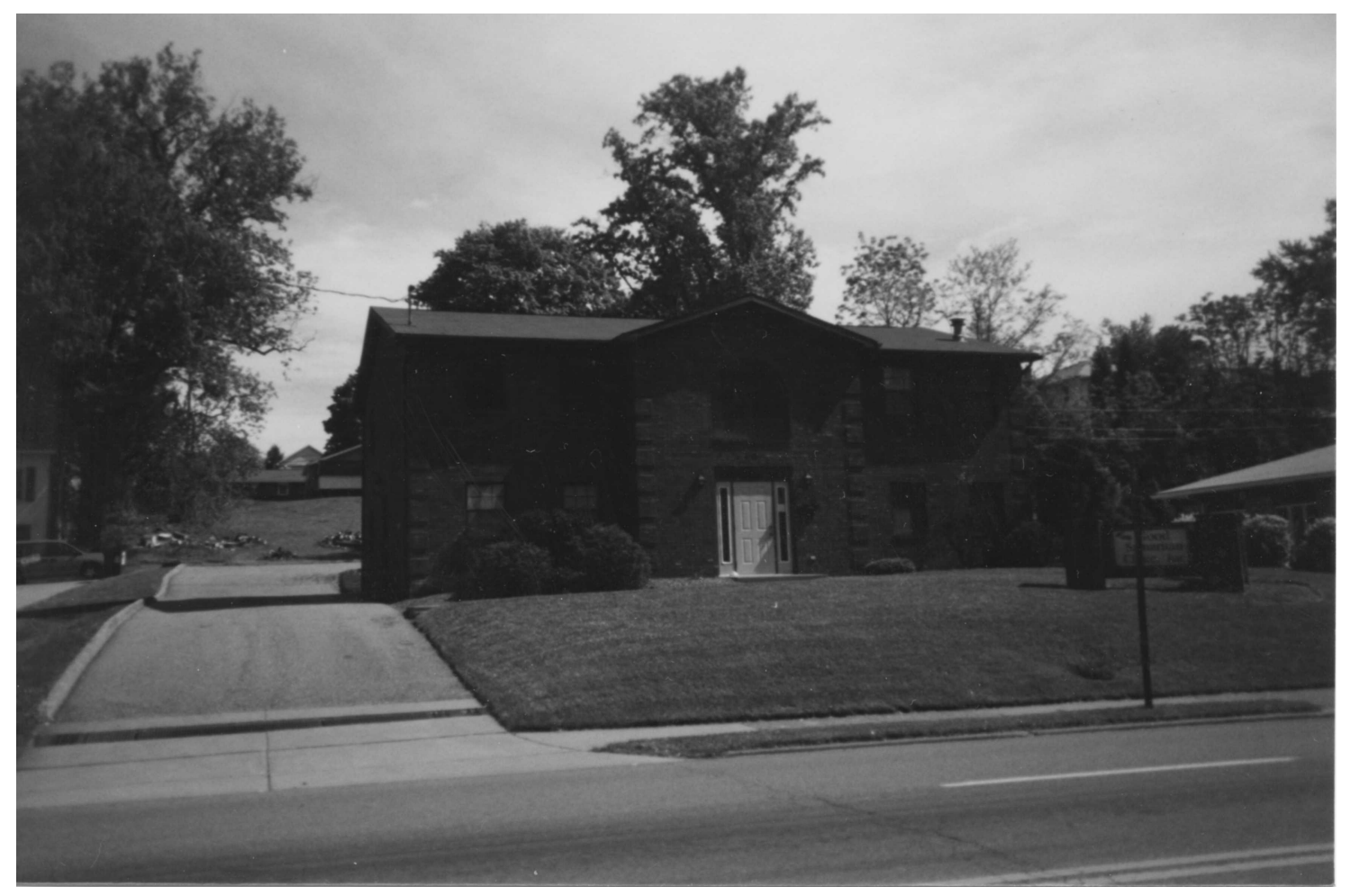




\section{West Virginia Rural Clinic}

\section{Trip Generation Interview / Site Inspection Form}

Site Name _ Rowlesburg Clinic (Preston-Taylor Community Health Centers, Inc.)

Address PO Box 565 City _ Rowlesburg Zip 26245

Interviewee Linda Shriver Position Administrator

Phone (304)-265-0312 Date _ August 20, 2002 Time NA

\begin{tabular}{|c|c|c|c|}
\hline & \multicolumn{3}{|c|}{ Interview } \\
\hline 10 & Employees (full/part) & Delivery & Maximum Size Vehicle \\
\hline 3 & Doctors (full/part) & 2 & Maximum Size Vehicle (axles) \\
\hline 2 & Nurses (full/part) & 1/day & Frequency Max Vehicle \\
\hline & amination Rooms & & \\
\hline
\end{tabular}

Hours of Operation

\begin{tabular}{|l|l|l|l|l|l|l|l|}
\hline \hline & Mon & Tues & Wed & Thurs & Fri & Sat & Sun \\
\hline Morning & $10: 30 \mathrm{AM}$ & $8 \mathrm{AM}$ to & $8: 30 \mathrm{AM}$ & $8: 30 \mathrm{AM}$ & $8 \mathrm{AM}$ to & Closed & Closed \\
\hline Afternoon & to & $5 \mathrm{PM}$ & to 5PM & to 5PM & 4PM & & \\
\hline Evening & $7 \mathrm{PM}$ & & & & & & \\
\hline \hline
\end{tabular}

\section{Site Measurements}

\begin{tabular}{ll|ll}
\hline \hline & & & \\
14 & \# Parking Stalls (non-handicap) & $\underline{2}-$ & \# Access Driveways \\
2 & \# Handicap Parking Stalls & $\underline{2400}$ & Gross Floor Area $\left(\mathrm{ft}^{2}\right)$ \\
A__ & Pavement Surface (A/S/C) & 1.0 & Acres \\
\hline \hline
\end{tabular}

\section{Services Provided \& Additional Notes}

Handle chronic and acute illnesses, preventative care, sports medicine, physicals, laboratory tests, diagnostic screening, EKG, immunization, basic pharmacy 


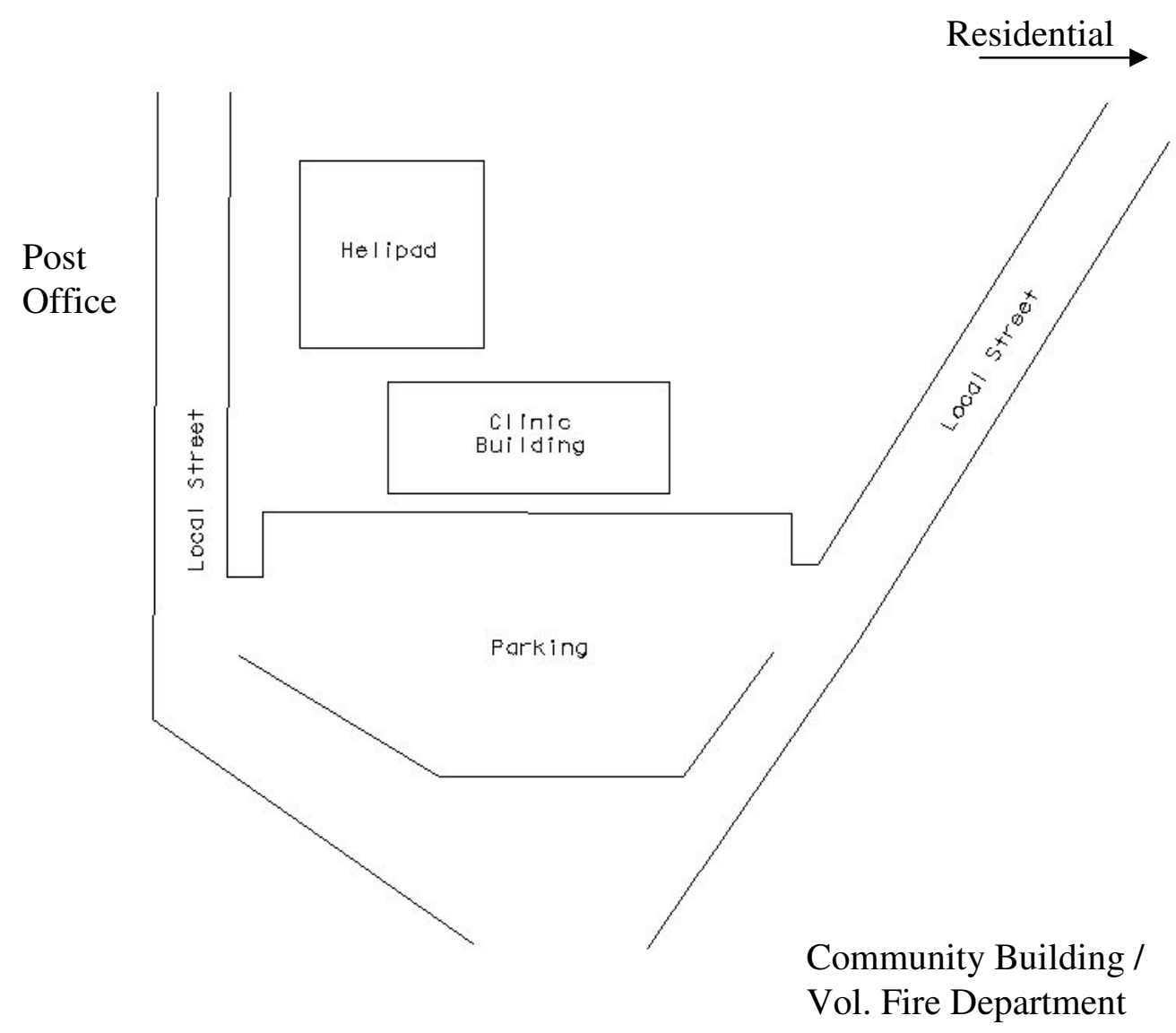



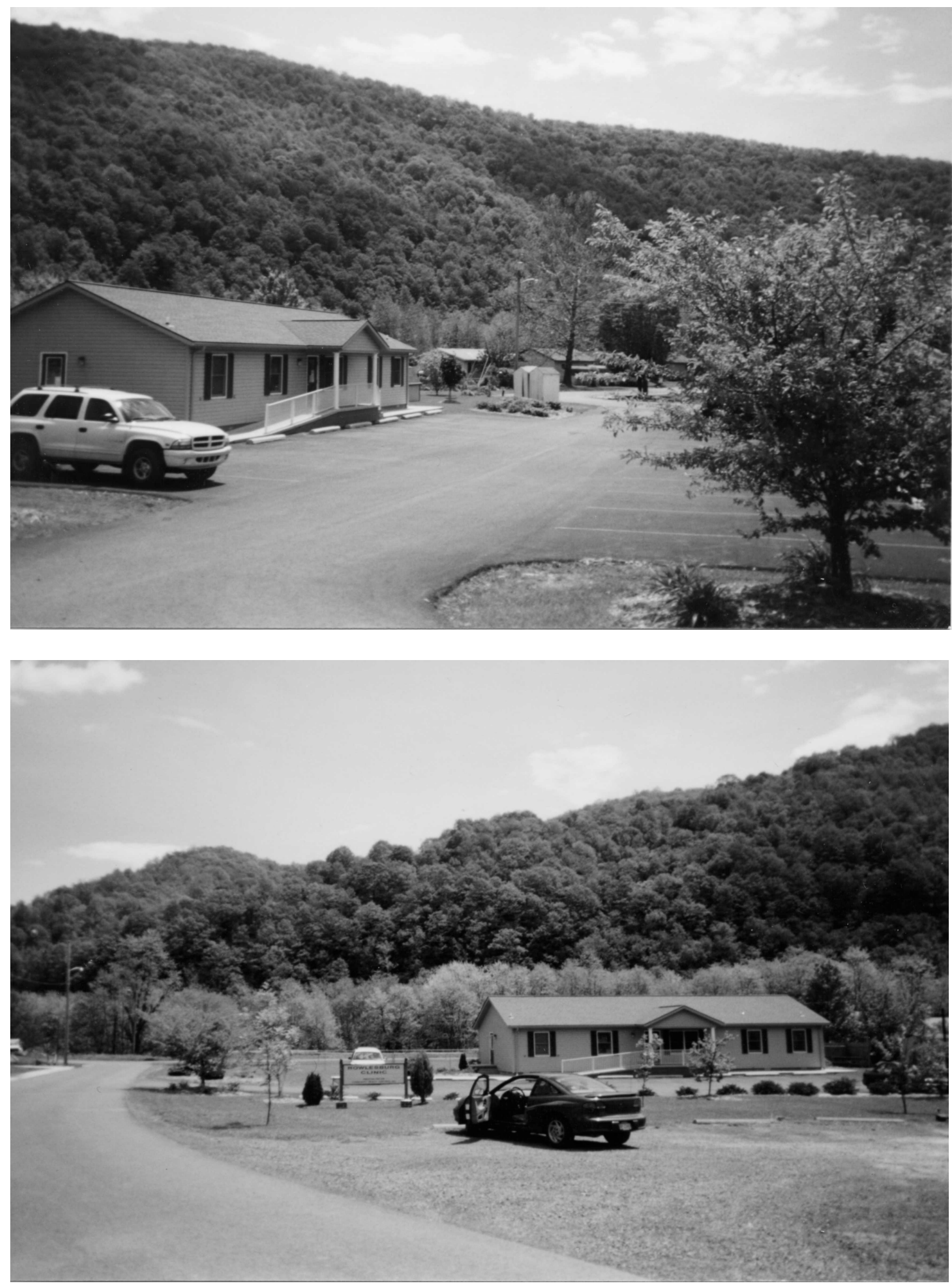


\section{West Virginia Rural Clinic}

\section{Trip Generation Interview / Site Inspection Form}

Site Name Shinnston Medical Center

Address 1 Columbia Rd.

City Shinnston

Zip

26431

Interviewee

Position

Administrative Assistant

Phone (304)-366-0700

Date August 27, 2002

Time NA

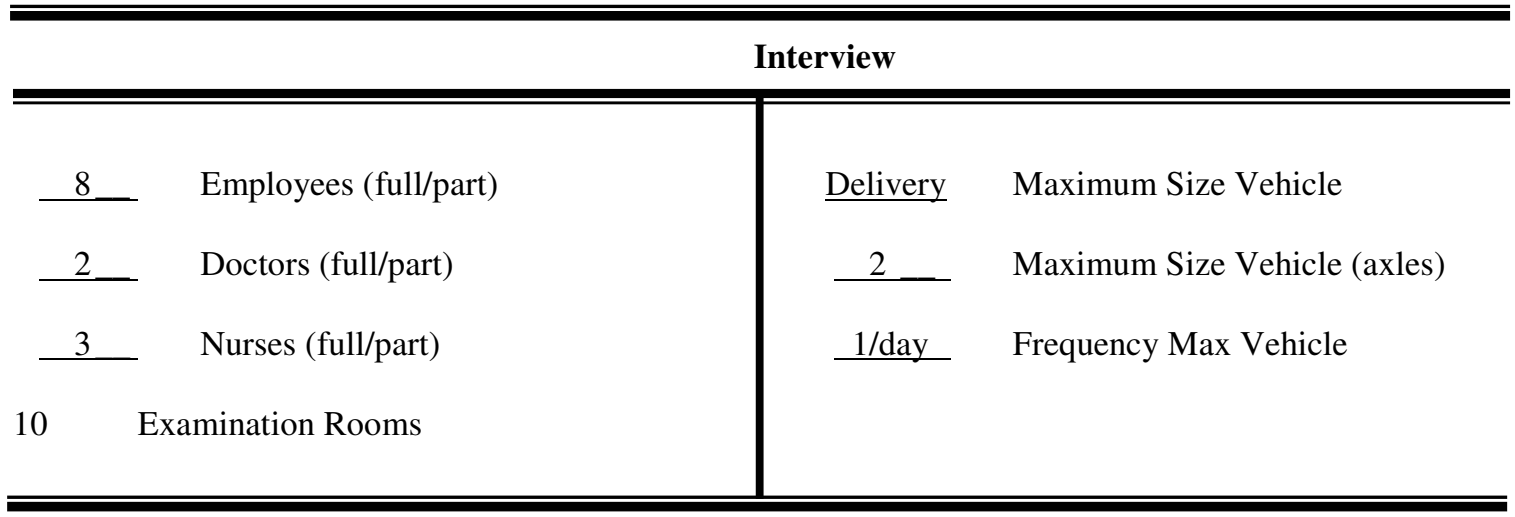

Hours of Operation

\begin{tabular}{|l|l|l|l|l|l|l|l|}
\hline \hline & Mon & Tues & Wed & Thurs & Fri & Sat & Sun \\
\hline Morning & $8 \mathrm{AM}$ to & $8 \mathrm{AM}$ to & $8 \mathrm{AM}$ to & $8 \mathrm{AM}$ to & $8 \mathrm{AM}$ to & Closed & Closed \\
\hline Afternoon & $4 \mathrm{PM}$ & $4 \mathrm{PM}$ & $4 \mathrm{PM}$ & $4 \mathrm{PM}$ & $3 \mathrm{PM}$ & Closed & Closed \\
\hline Evening & & & & & & & \\
\hline \hline
\end{tabular}

Site Measurements

\begin{tabular}{ll|ll}
\hline \hline & & & \\
17 & \# Parking Stalls (non-handicap) & $\underline{2}-$ & \# Access Driveways \\
$\underline{3}-\quad$ \# Handicap Parking Stalls & $\underline{2800}$ & Gross Floor Area $\left(\mathrm{ft}^{2}\right)$ \\
A__ Pavement Surface (A/S/C) & $\underline{0.52}$ & Acres \\
\hline \hline
\end{tabular}

Services Provided \& Additional Notes

Primary Care Services 


\section{West Virginia Rural Clinic}

\section{Trip Generation Interview / Site Inspection Form}

Site Sketch

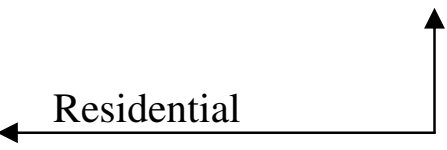

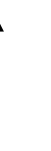

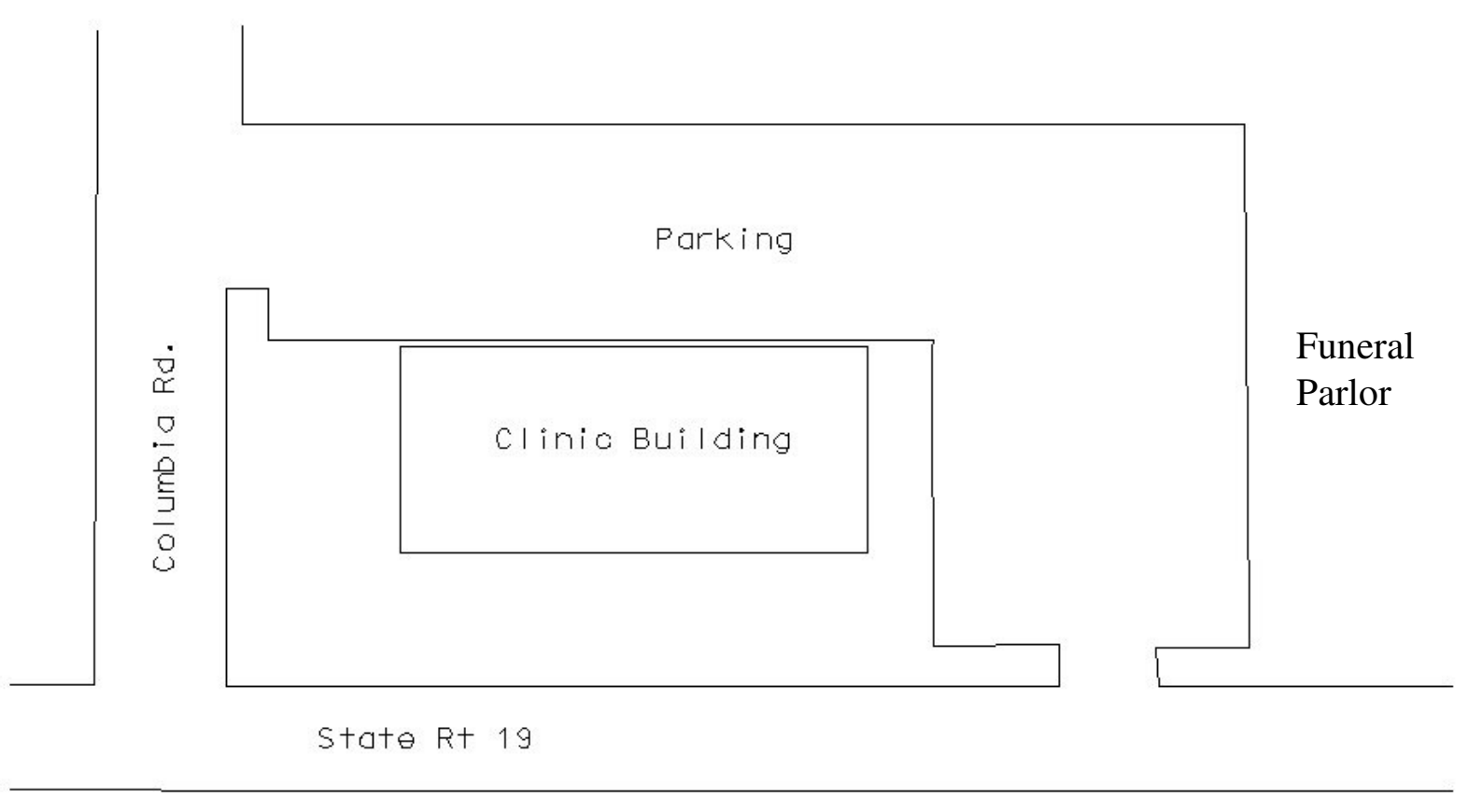

Residential 


\section{West Virginia Rural Clinic}

\section{Trip Generation Interview / Site Inspection Form}

Site Name _ St. George Clinic

Address

Rt. 1 Box 208

City St. George

Zip $\quad 26290$

Interviewee _ Sarah Hunt

Position

Assistant Manager

Phone (304)-478-3339

Date July 29, 2002

Time $12 \mathrm{PM}$

\begin{tabular}{|c|c|c|c|}
\hline \multicolumn{4}{|c|}{ Interview } \\
\hline 12 & Employees (full/part) & Delivery & Maximum Size Vehicle \\
\hline 2 & Doctors (full/part) & 2 & Maximum Size Vehicle (axles) \\
\hline 3 & Nurses (full/part) & 1/day & Frequency Max Vehicle \\
\hline & amination Rooms & & \\
\hline
\end{tabular}

Hours of Operation

\begin{tabular}{|l|l|l|l|l|l|l|l|}
\hline \hline & Mon & Tues & Wed & Thurs & Fri & Sat & Sun \\
\hline Morning & $8 \mathrm{AM}$ to & $8 \mathrm{AM}$ to & $8 \mathrm{AM}$ to & $8 \mathrm{AM}$ to & $8 \mathrm{AM}$ to & Closed & Closed \\
\hline Afternoon & $5 \mathrm{PM}$ & $5 \mathrm{PM}$ & $7: 30 \mathrm{PM}$ & $7: 30 \mathrm{PM}$ & $3 \mathrm{PM}$ & Closed & Closed \\
\hline Evening & & & & & & & \\
\hline \hline
\end{tabular}

Site Measurements

\begin{tabular}{ll|ll}
\hline \hline & & & \\
19 & \# Parking Stalls (non-handicap) & $\underline{2}-$ & \# Access Driveways \\
$\underline{3}-\quad$ \# Handicap Parking Stalls & $\underline{3375}$ & Gross Floor Area $\left(\mathrm{ft}^{2}\right)$ \\
A__ Pavement Surface (A/S/C) & $\underline{1.5}$ & Acres \\
\hline \hline
\end{tabular}

\section{Services Provided \& Additional Notes}

$\underline{\text { Preventative care, child wellness exams, preventative exams, physicals, treatment of acute }}$ and chronic illnesses, pharmacy 


\section{West Virginia Rural Clinic}

\section{Trip Generation Interview / Site Inspection Form}

Site Sketch

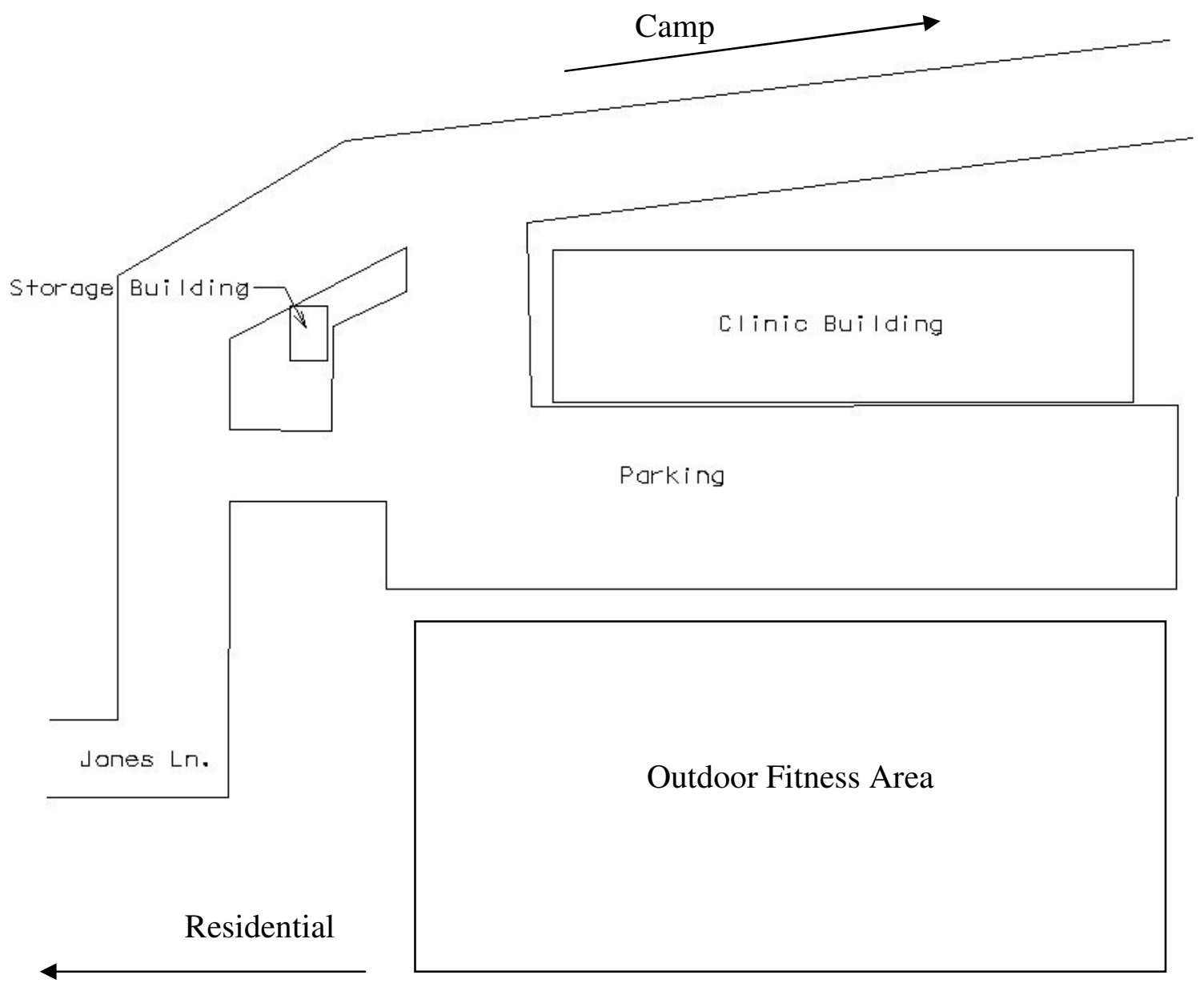




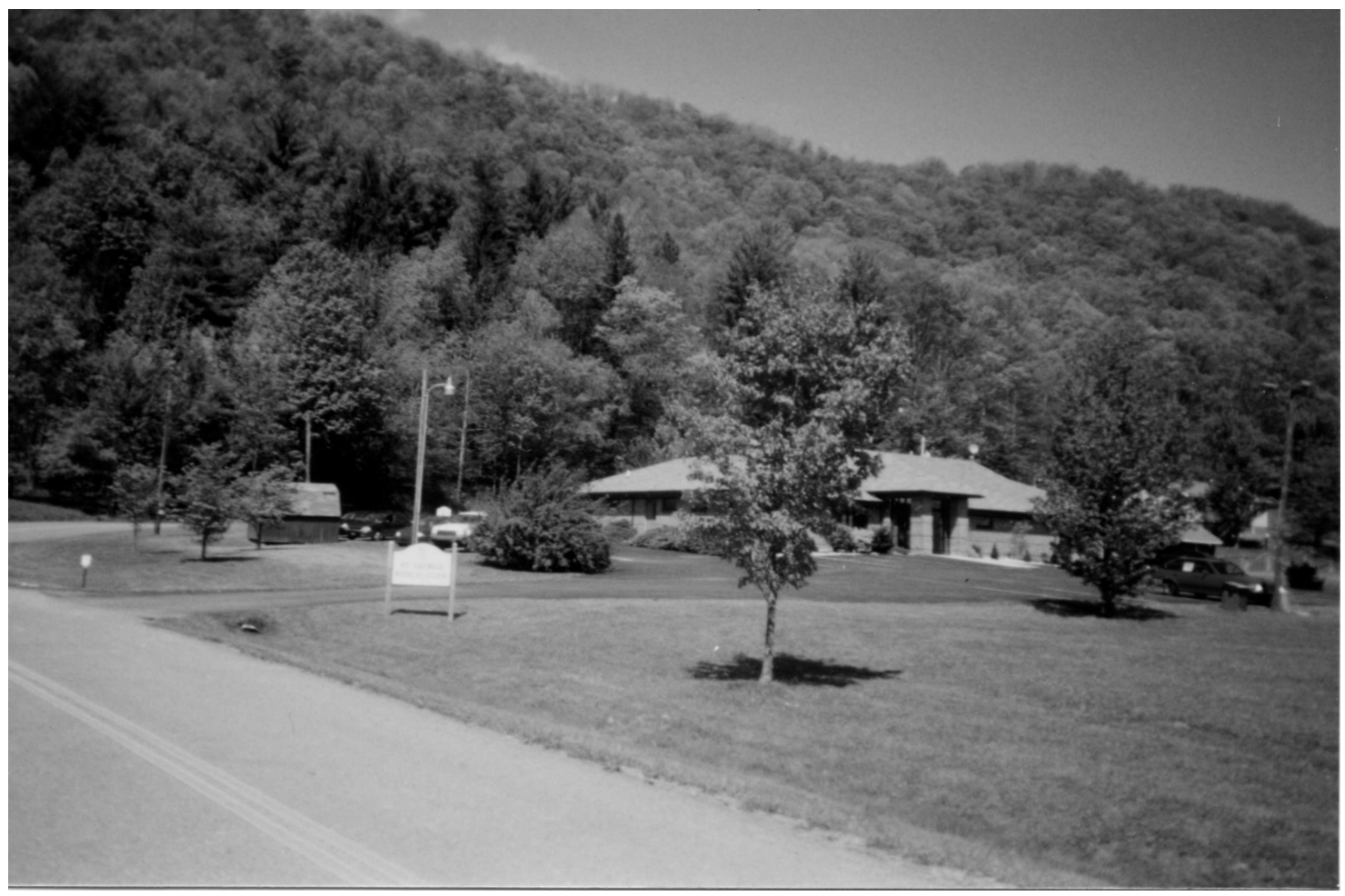




\section{Appendix D \\ Regression Plots for the 13 Rates \\ Not Meeting ITE Requirements for Equations \\ (Presented for Information Only)}




\section{West Virginia Rural Clinics}

\section{Average Vehicle Trip Ends vs: 1000 Sq. Ft. Gross Floor Area \\ On a: Average Weekday}

Number of Studies: $\quad 5$

Average Number of Variable: 2.62

Directional Distribution: $\quad 50 \%$ entering, $50 \%$ exiting

Trip Generation per 1000 Sq. Ft. Gross Floor Area

\begin{tabular}{|ccc|}
\hline Average Rate & Range of Rates & Standard Deviation \\
\hline 88.00 & $14.10-191.07$ & 65.67 \\
\hline
\end{tabular}

Data Plot and Equation

Use Caution - Small Sample Size

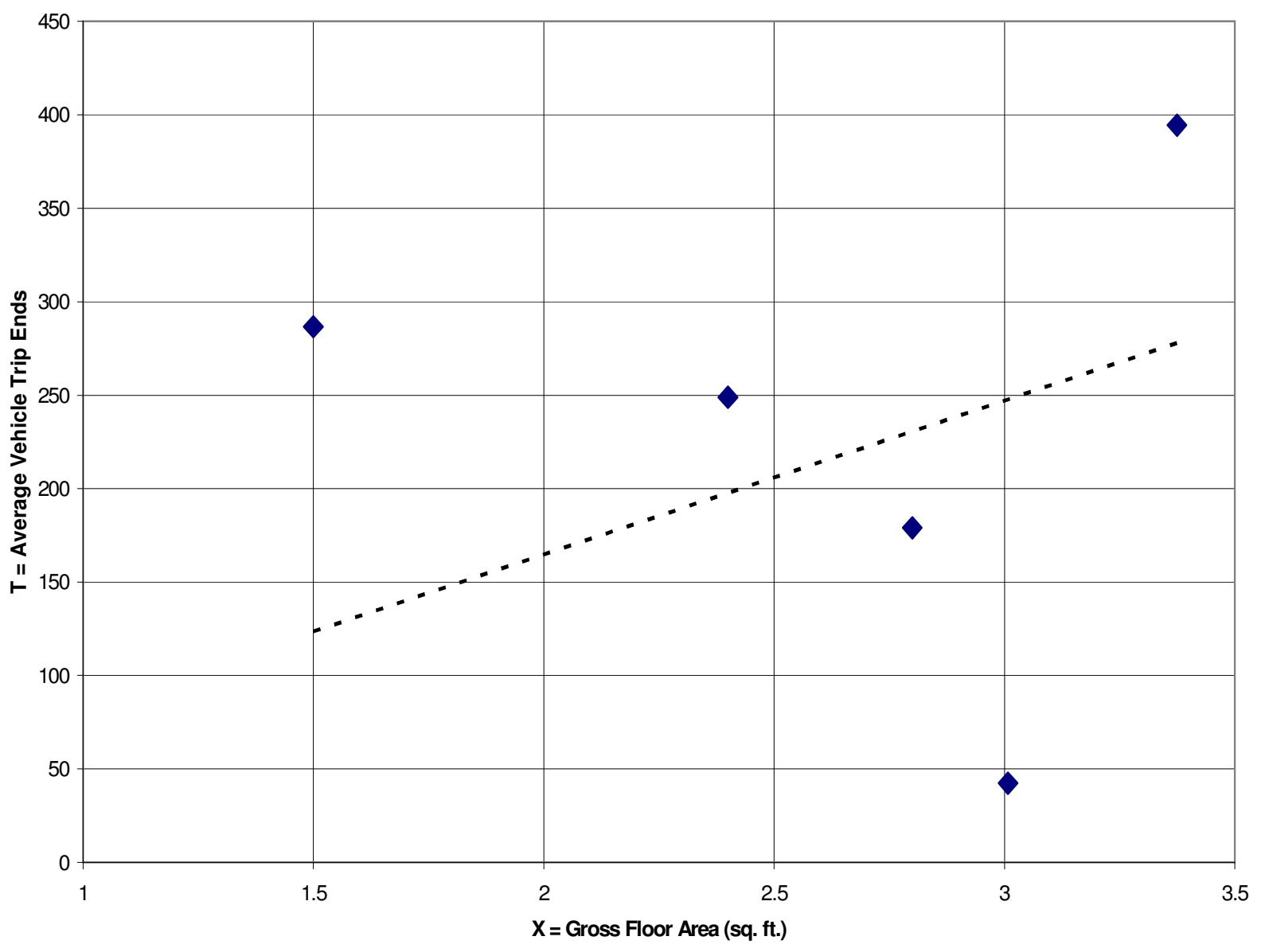

X Actual Data Points

- - - - - - Fitted Curve

Average Rate

Fitted Curve Equation: $\mathrm{T}=$ 


\section{West Virginia Rural Clinics}

\section{Average Vehicle Trip Ends vs: 1000 Sq. Ft. Gross Floor Area \\ On a: Average Weekday Peak Hour}

Number of Studies: 5

Average Number of Variable: 2.62

Directional Distribution: $\quad 50 \%$ entering, $50 \%$ exiting

Trip Generation per $1000 \mathrm{Sq}$. Ft. Gross Floor Area

\begin{tabular}{|ccc|}
\hline Average Rate & Range of Rates & Standard Deviation \\
\hline 15.32 & $3.32-34.00$ & 11.17 \\
\hline
\end{tabular}

Data Plot and Equation

Use Caution - Small Sample Size

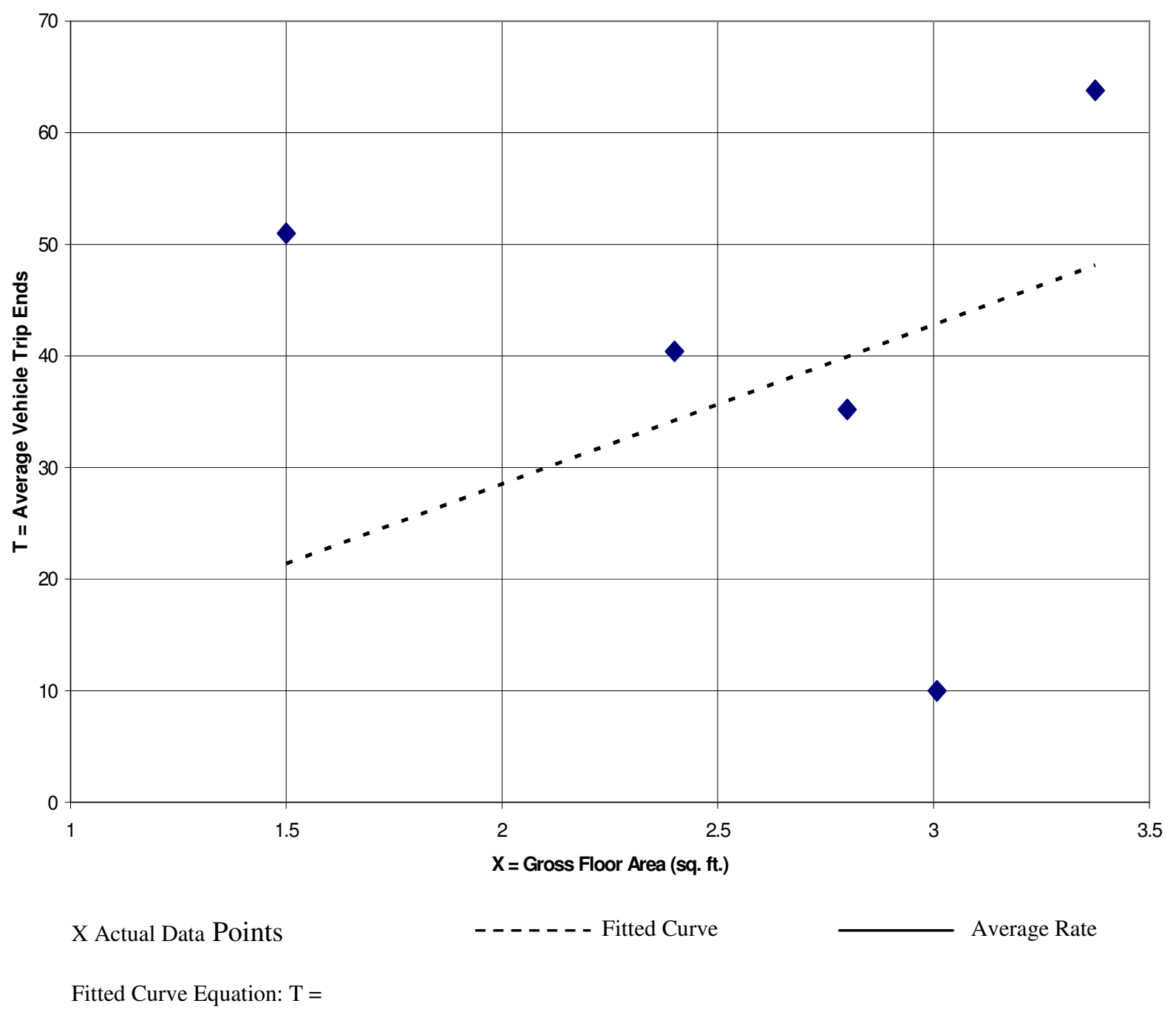




\section{West Virginia Rural Clinics}

\section{Average Vehicle Trip Ends vs: 1000 Sq. Ft. Gross Floor Area \\ On a: Maximum Weekday AM Peak Hour}

Number of Studies: 5

Average Number of Variable: $\quad 2.62$

Directional Distribution: $50 \%$ entering, 50\% exiting

Trip Generation per 1000 Sq. Ft. Gross Floor Area

\begin{tabular}{|ccc|}
\hline Average Rate & Range of Rates & Standard Deviation \\
\hline 4.88 & $1.66-6.64$ & 1.99 \\
\hline
\end{tabular}

Data Plot and Equation

Use Caution - Small Sample Size

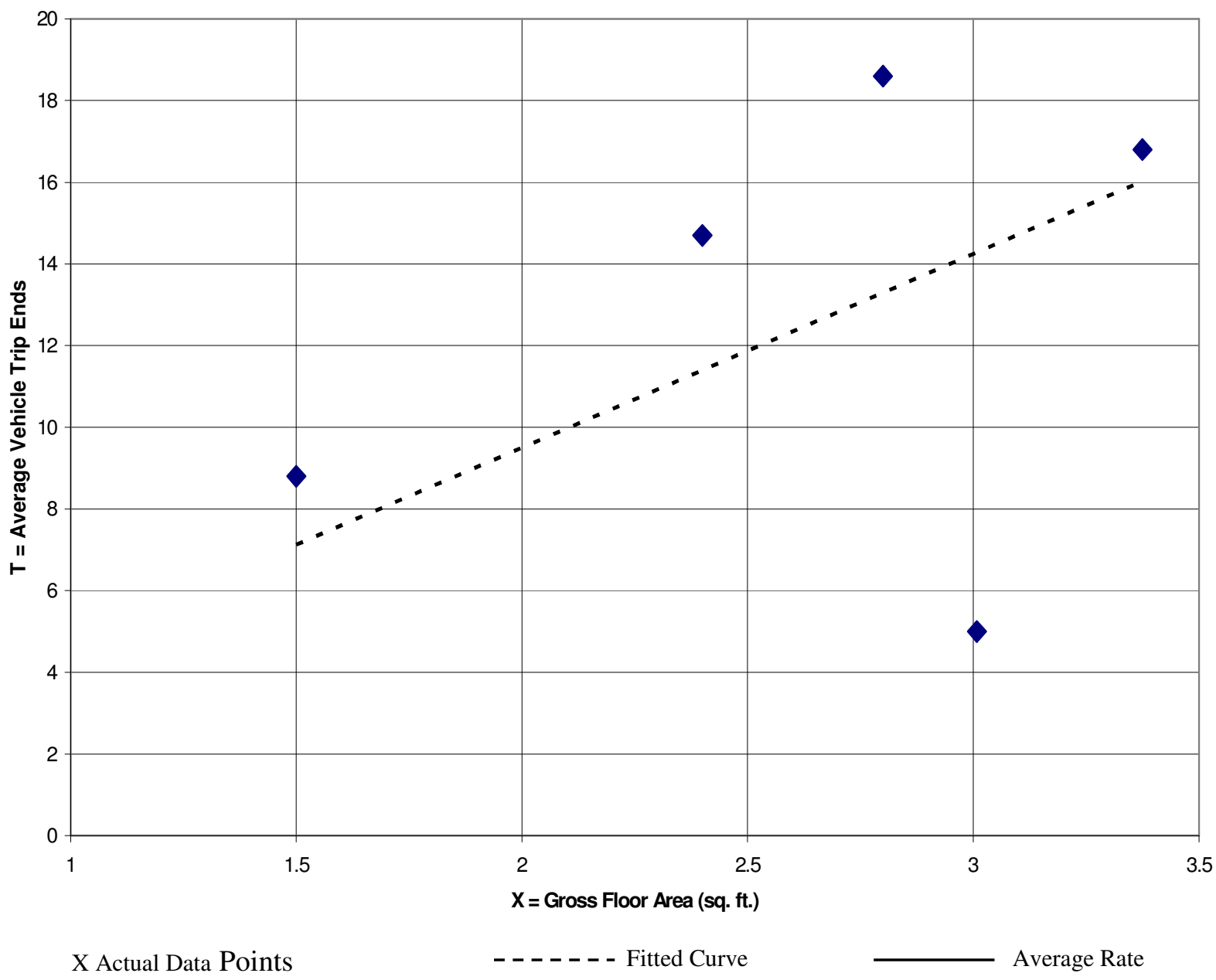

Fitted Curve Equation: $\mathrm{T}=$ 


\section{West Virginia Rural Clinics}

\section{Average Vehicle Trip Ends vs: 1000 Sq. Ft. Gross Floor Area \\ On a: Maximum Weekday PM Peak Hour}

Number of Studies: 5

Average Number of Variable: $\quad 2.62$

Directional Distribution: $\quad 50 \%$ entering, $50 \%$ exiting

Trip Generation per 1000 Sq. Ft. Gross Floor Area

\begin{tabular}{|ccc|}
\hline Average Rate & Range of Rates & Standard Deviation \\
\hline 9.94 & $0.47-22.80$ & 8.92 \\
\hline
\end{tabular}

Data Plot and Equation

Use Caution - Small Sample Size

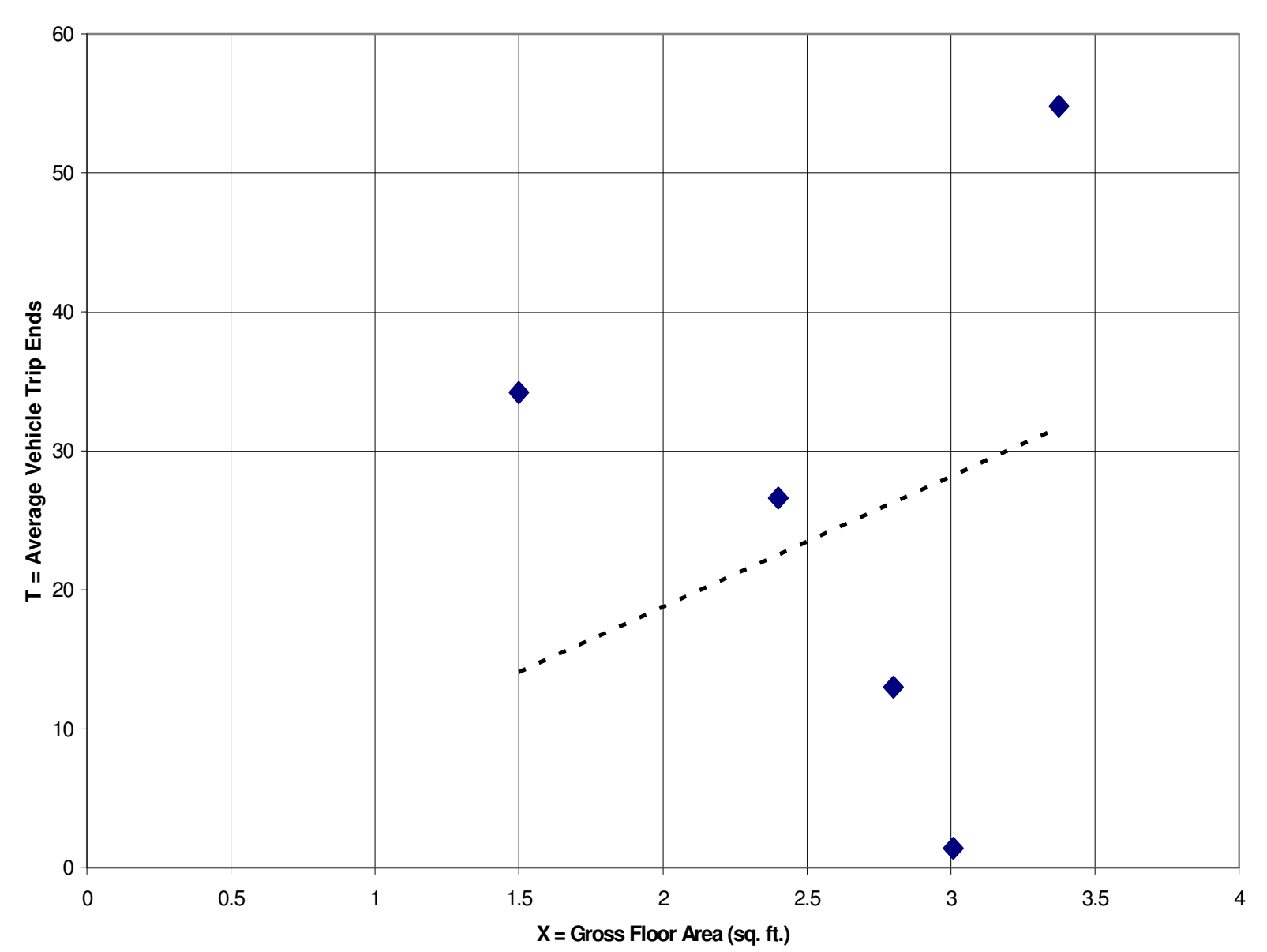

X Actual Data Points

- - - - - - Fitted Curve

Average Rate

Fitted Curve Equation: $\mathrm{T}=$ 


\title{
West Virginia Rural Clinics
}

\section{Average Vehicle Trip Ends vs: Employees \\ On a: Average Weekday}

\author{
Number of Studies: 5 \\ Average Number of Variable: 8 \\ Directional Distribution: $\quad 50 \%$ entering, 50\% exiting
}

Trip Generation per Employee

\begin{tabular}{|ccc|}
\hline Average Rate & Range of Rates & Standard Deviation \\
\hline 29.52 & $12.72-47.77$ & 12.72 \\
\hline
\end{tabular}

Data Plot and Equation

Use Caution - Small Sample Size

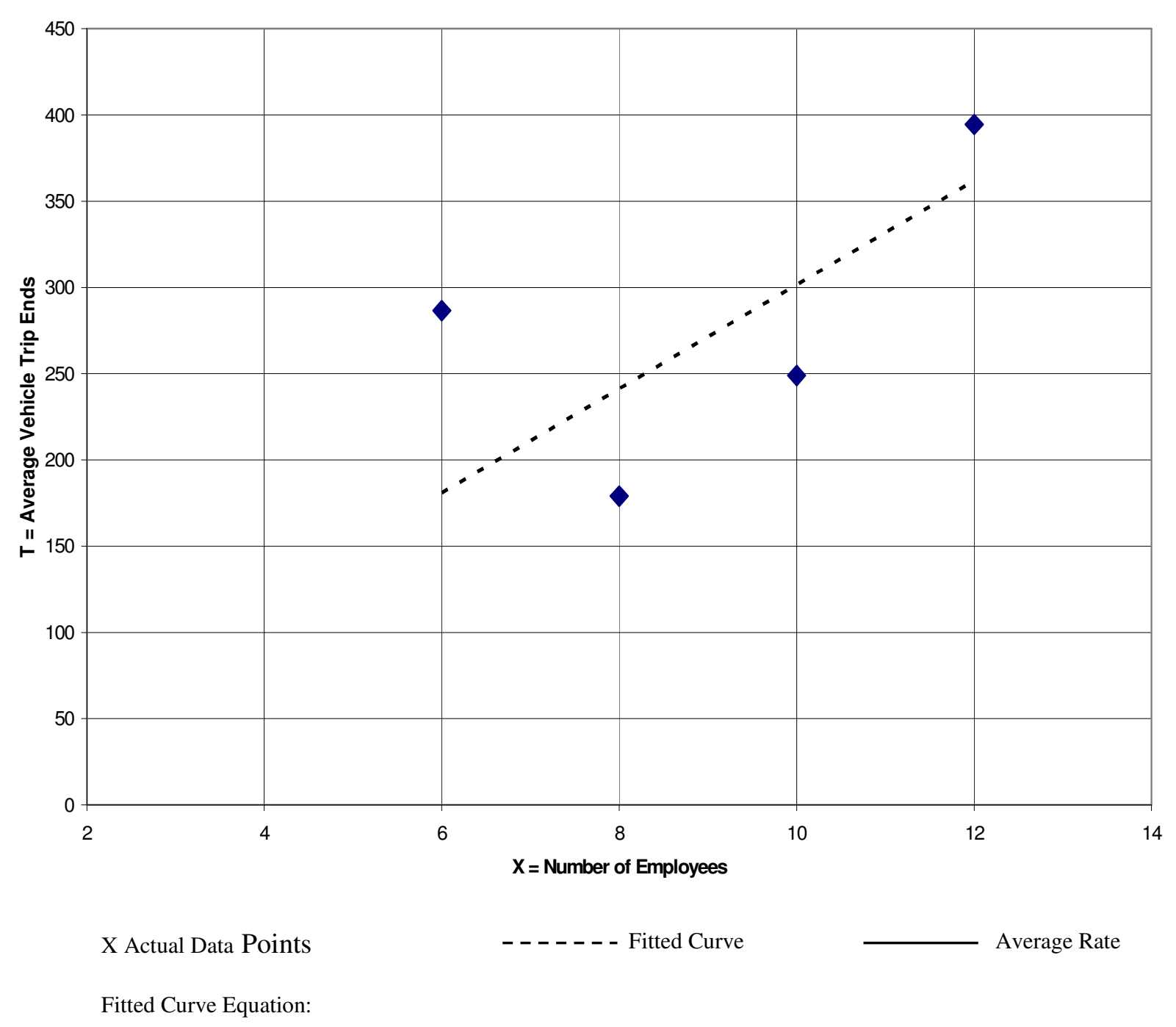




\section{West Virginia Rural Clinics}

\section{Average Vehicle Trip Ends vs: Employees \\ On a: Average Weekday Peak Hour}

Number of Studies: 5

Average Number of Variable: 8

Directional Distribution: $\quad 50 \%$ entering, 50\% exiting

\section{Trip Generation per Employee}

\begin{tabular}{|ccc|}
\hline Average Rate & Range of Rates & Standard Deviation \\
\hline 5.14 & $3.33-8.50$ & 2.02 \\
\hline
\end{tabular}

Data Plot and Equation

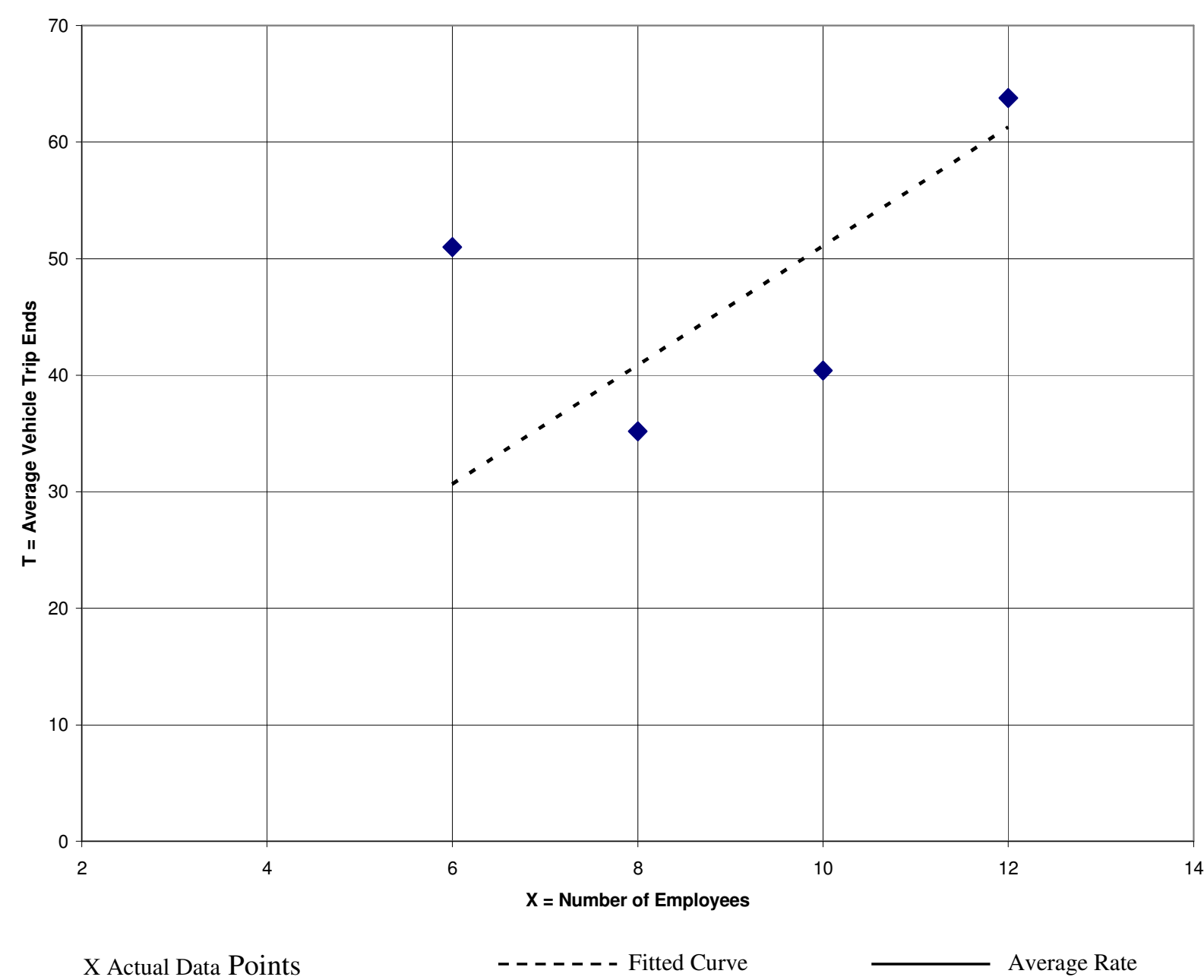

Fitted Curve Equation: 


\section{West Virginia Rural Clinics}

\section{Average Vehicle Trip Ends vs: Employees \\ On a: Maximum Weekday PM Peak Hour}

Number of Studies: $\quad 5$

Average Number of Variable: 8

Directional Distribution: $\quad 50 \%$ entering, $50 \%$ exiting

\section{Trip Generation per Employee}

\begin{tabular}{|ccc|}
\hline Average Rate & Range of Rates & Standard Deviation \\
\hline 3.33 & $0.47-5.70$ & 2.13 \\
\hline
\end{tabular}

Data Plot and Equation

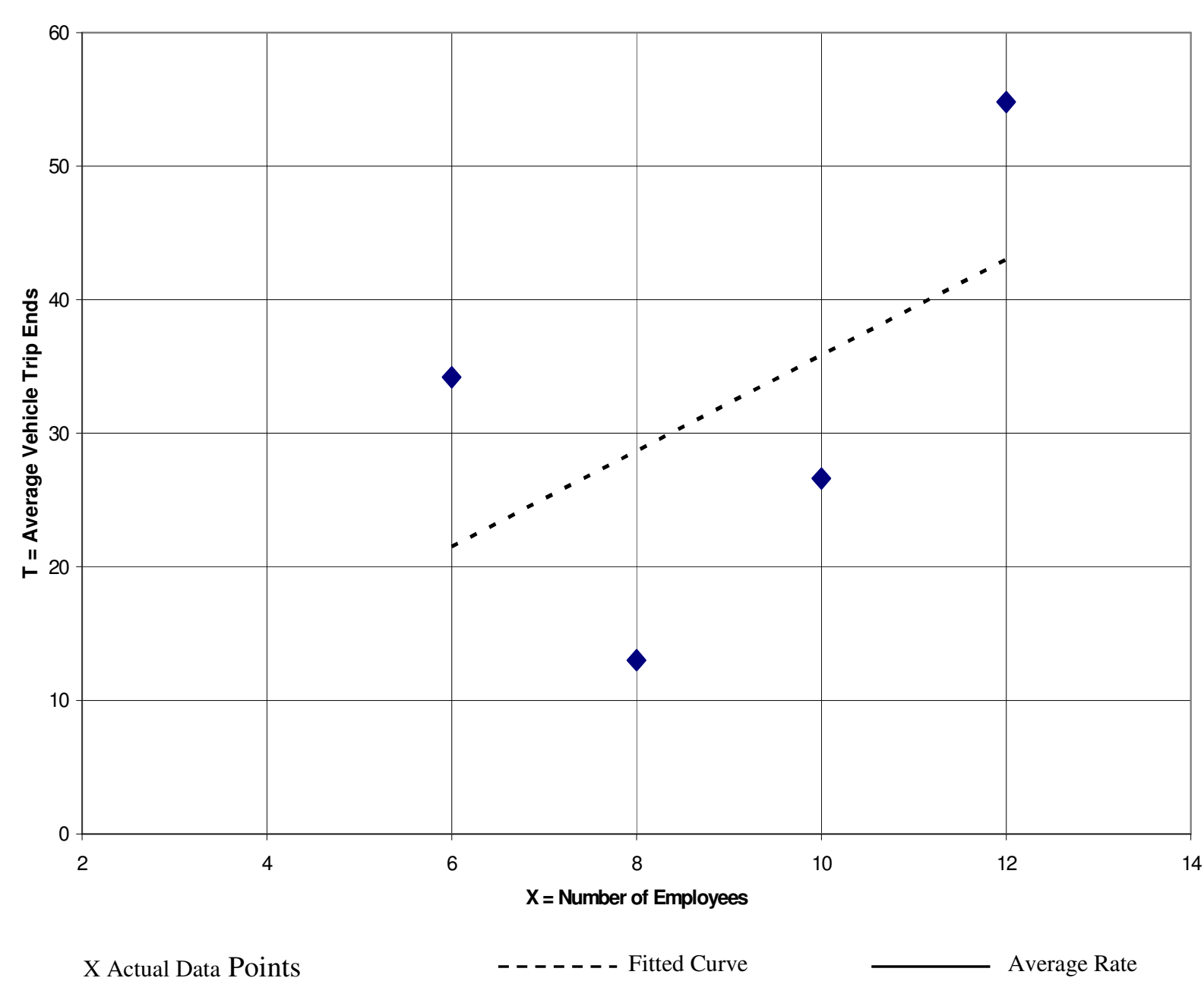

Fitted Curve Equation: 


\section{West Virginia Rural Clinics}

\section{Average Vehicle Trip Ends vs: 1000 Sq. Ft. Gross Floor Area \\ On a: Average Weekday}

Number of Studies: $\quad 5$

Average Number of Variable: 2.62

Directional Distribution: $\quad 50 \%$ entering, $50 \%$ exiting

Trip Generation per 1000 Sq. Ft. Gross Floor Area

\begin{tabular}{|ccc|}
\hline Average Rate & Range of Rates & Standard Deviation \\
\hline 88.00 & $14.10-191.07$ & 65.67 \\
\hline
\end{tabular}

\section{Data Plot and Equation}

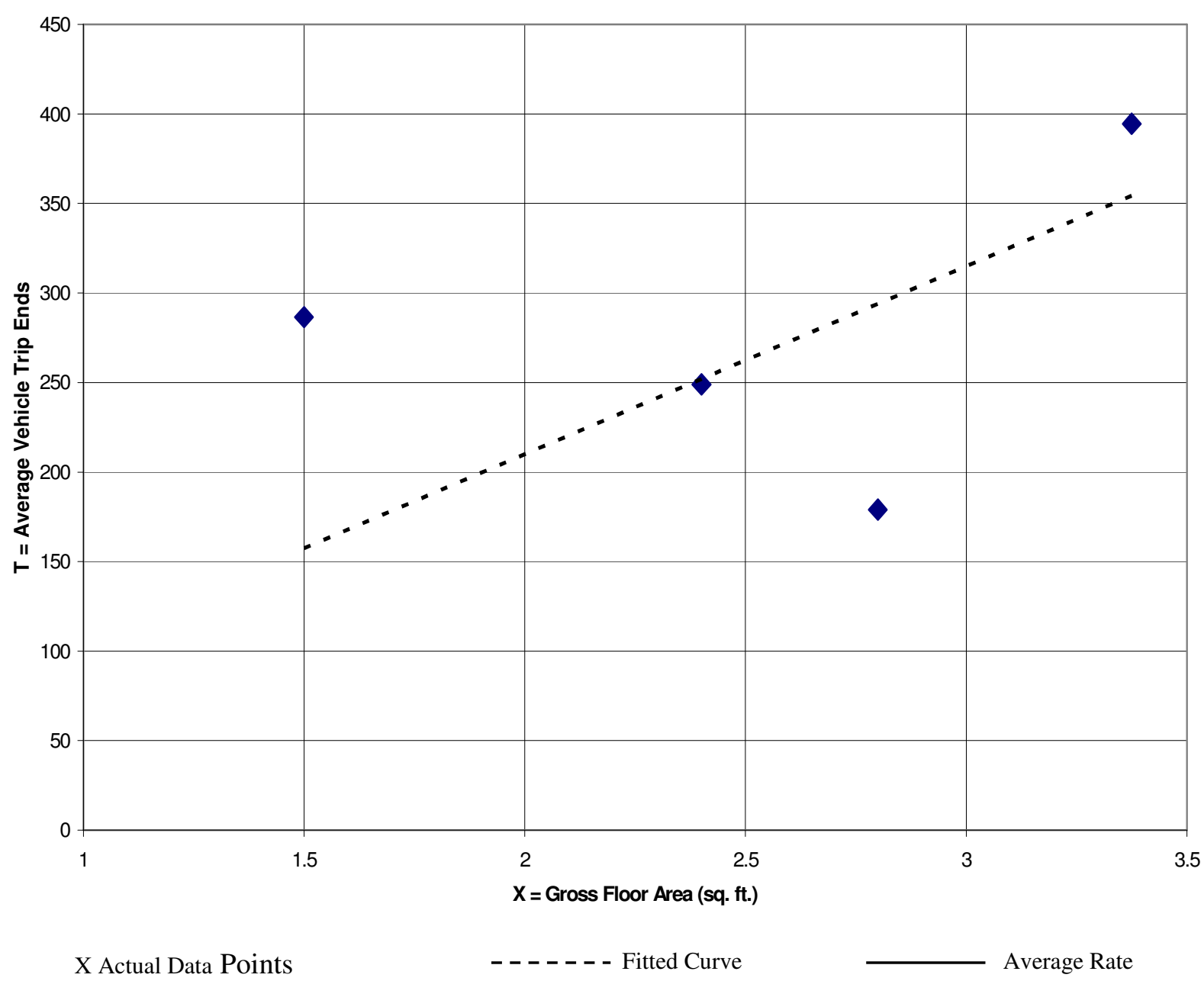

Fitted Curve Equation: $\mathrm{T}=$ 


\section{West Virginia Rural Clinics}

\section{Average Vehicle Trip Ends vs: 1000 Sq. Ft. Gross Floor Area \\ On a: Average Weekday Peak Hour}

Number of Studies: 5

Average Number of Variable: 2.62

Directional Distribution: $\quad 50 \%$ entering, $50 \%$ exiting

Trip Generation per $1000 \mathrm{Sq}$. Ft. Gross Floor Area

\begin{tabular}{|ccc|}
\hline Average Rate & Range of Rates & Standard Deviation \\
\hline 15.32 & $3.32-34.00$ & 11.17 \\
\hline
\end{tabular}

\section{Data Plot and Equation}

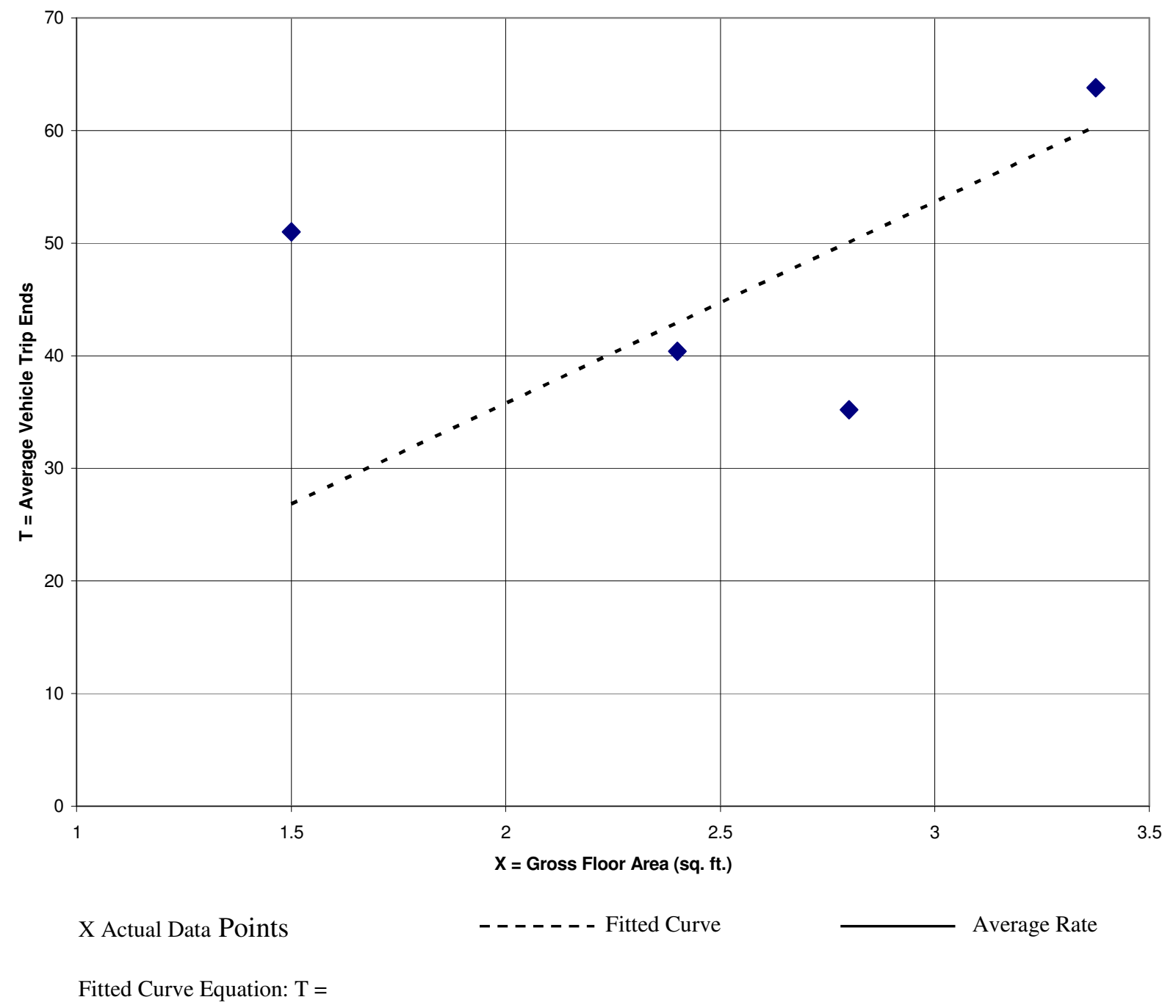




\section{West Virginia Rural Clinics}

\section{Average Vehicle Trip Ends vs: 1000 Sq. Ft. Gross Floor Area \\ On a: Maximum Weekday PM Peak Hour}

Number of Studies: 5

Average Number of Variable: $\quad 2.62$

Directional Distribution: $\quad 50 \%$ entering, $50 \%$ exiting

Trip Generation per 1000 Sq. Ft. Gross Floor Area

\begin{tabular}{|ccc|}
\hline Average Rate & Range of Rates & Standard Deviation \\
\hline 9.94 & $0.47-22.80$ & 8.92 \\
\hline
\end{tabular}

Data Plot and Equation

Use Caution - Small Sample Size

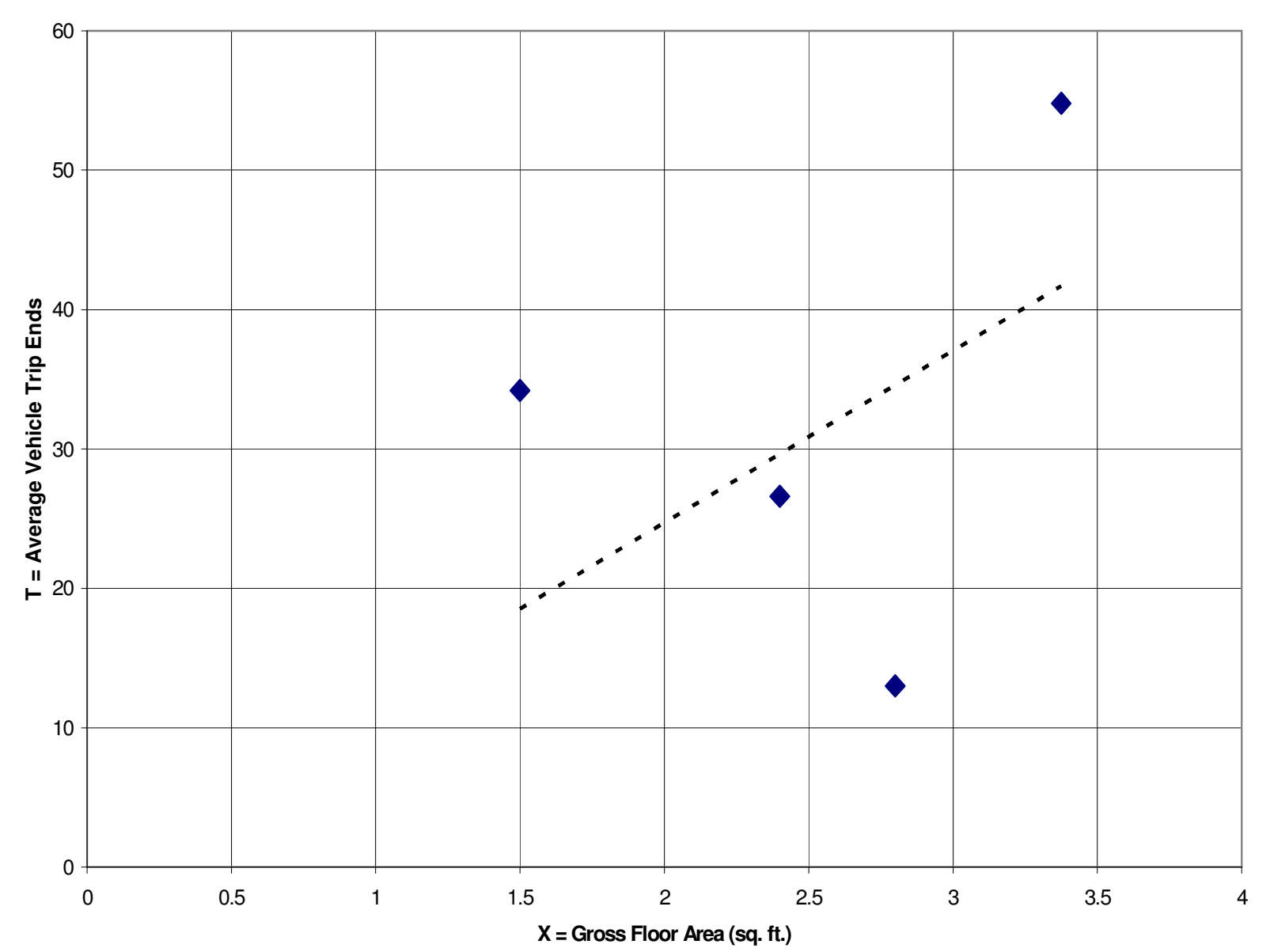

X Actual Data Points

- - - - - - Fitted Curve

Average Rate

Fitted Curve Equation: $\mathrm{T}=$ 


\section{West Virginia Rural Clinics}

\section{Average Vehicle Trip Ends vs: Doctors \\ On a: Average Weekday}

Number of Studies: 4

Average Number of Variable: 2

Directional Distribution: $\quad 50 \%$ entering, $50 \%$ exiting

\section{Trip Generation per Doctor}

\begin{tabular}{|ccc|}
\hline Average Rate & Range of Rates & Standard Deviation \\
\hline 138.61 & $82.97-286.60$ & 97.04 \\
\hline
\end{tabular}

\section{Data Plot and Equation}

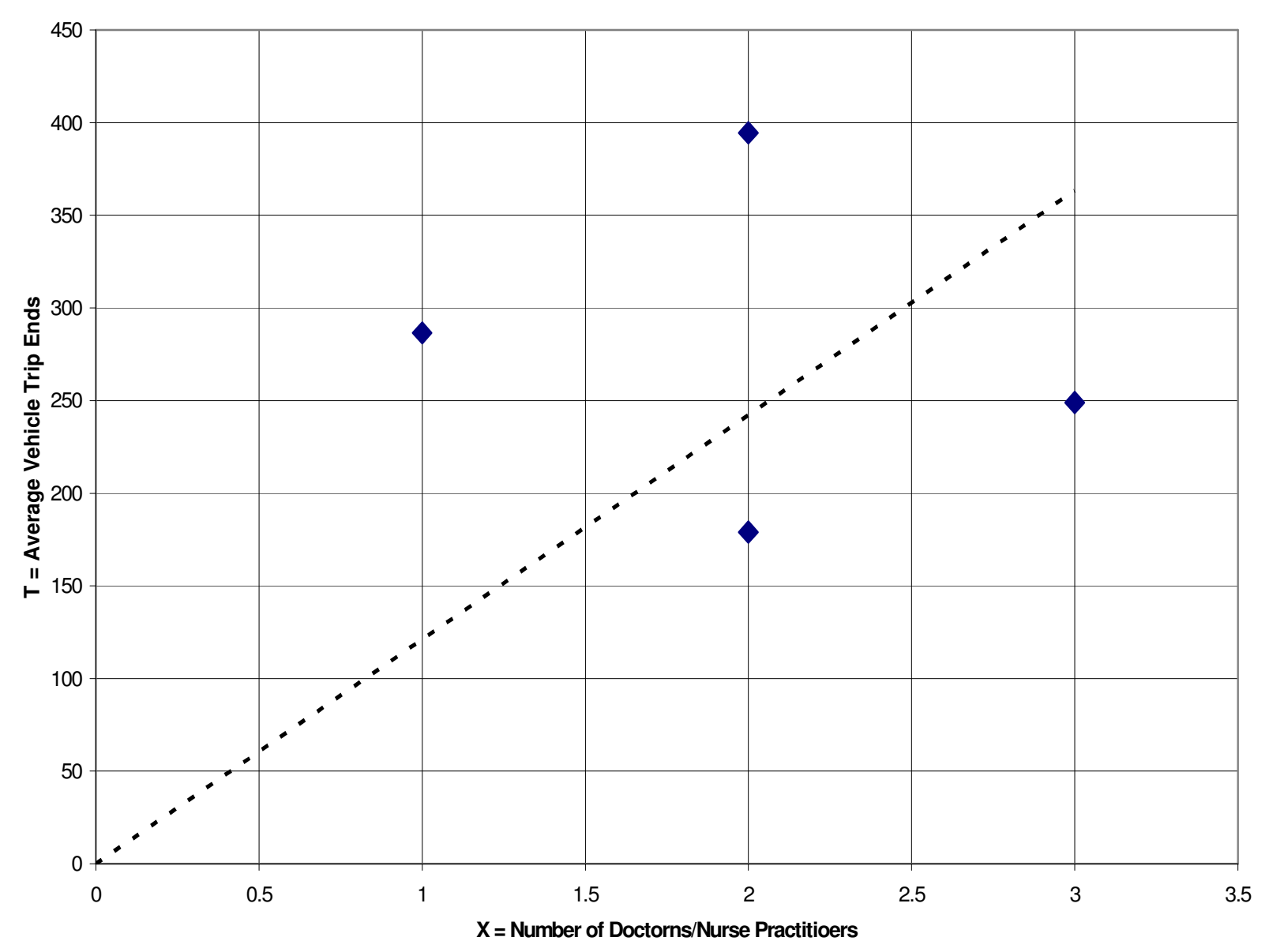

X Actual Data Points

- - - - - - Fitted Curve

Average Rate

Fitted Curve Equation: $\mathrm{T}=$ 


\section{West Virginia Rural Clinics}

\section{Average Vehicle Trip Ends vs: Doctor \\ On a: Average Weekday Peak Hour}

Number of Studies: 4

Average Number of Variable: 2

Directional Distribution: $\quad 50 \%$ entering, $50 \%$ exiting

\section{Trip Generation per Doctor}

\begin{tabular}{|ccc|}
\hline Average Rate & Range of Rates & Standard Deviation \\
\hline 23.80 & $13.47-51.00$ & 16.96 \\
\hline
\end{tabular}

\section{Data Plot and Equation}

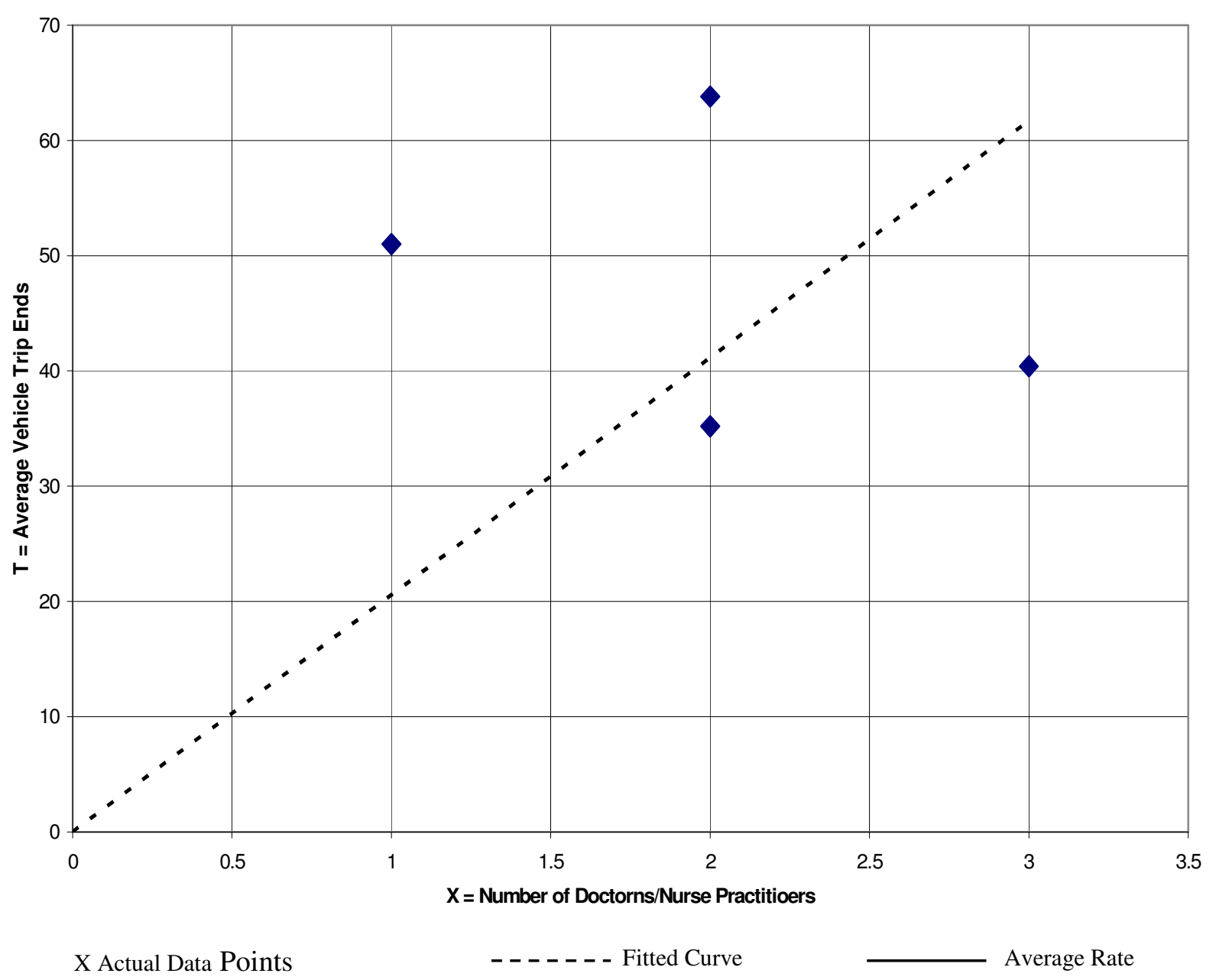

Fitted Curve Equation: $\mathrm{T}=$ 


\title{
West Virginia Rural Clinics
}

\section{Average Vehicle Trip Ends vs: Doctor \\ On a: Maximum Weekday PM Peak Hour}

\author{
Number of Studies: 4 \\ Average Number of Variable: 2 \\ Directional Distribution: $\quad 50 \%$ entering, $50 \%$ exiting
}

Trip Generation per Doctor

\begin{tabular}{|ccc|}
\hline Average Rate & Range of Rates & Standard Deviation \\
\hline 16.08 & $6.50-34.20$ & 13.67 \\
\hline
\end{tabular}

Data Plot and Equation

Use Caution - Small Sample Size

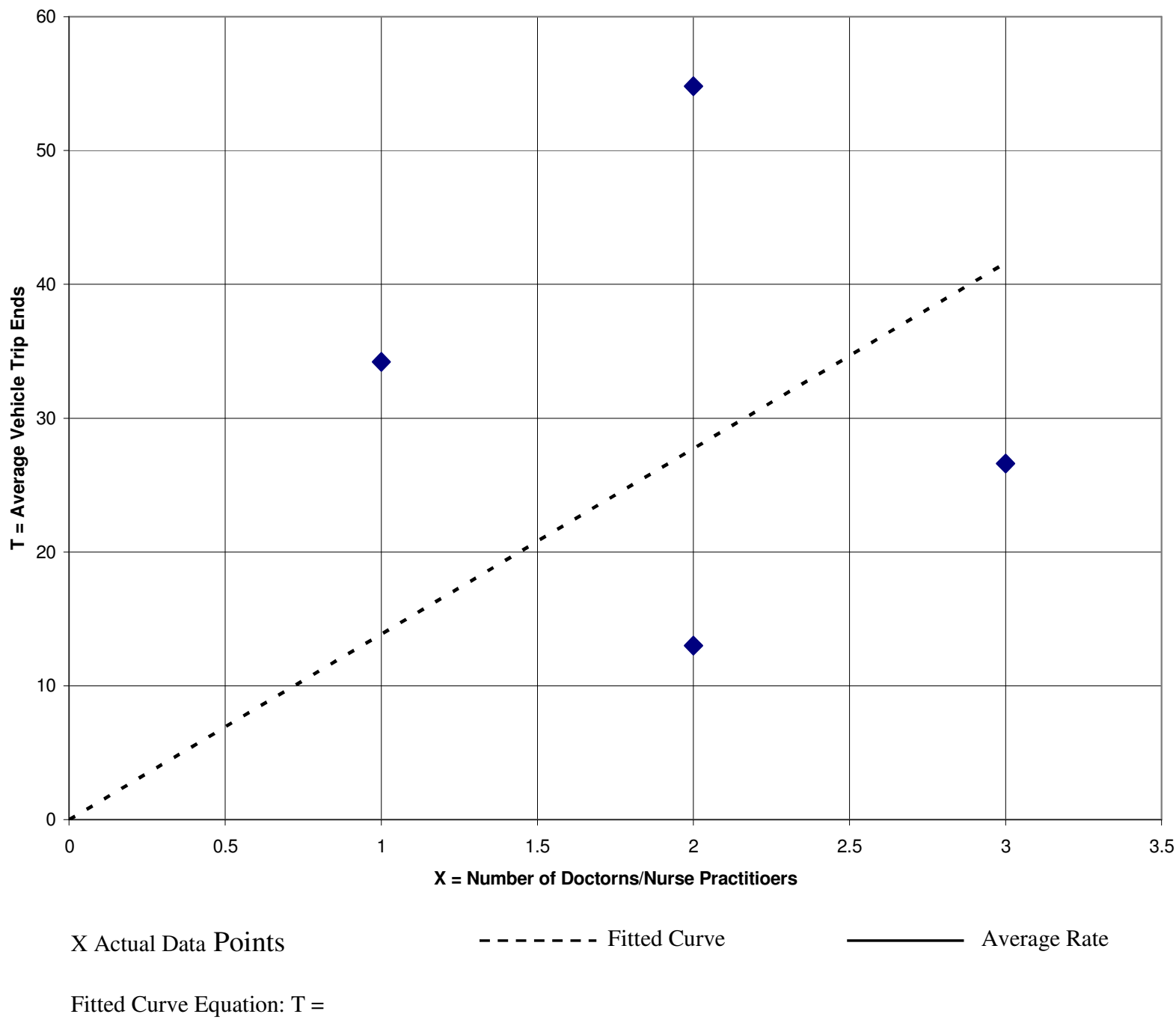




\section{Vita}

Andrew Morgan was born in Parkersburg, West Virginia, on January 22, 1980. He was raised in Vienna, West Virginia, attended Parkersburg High School, and graduated in 1998. Andrew received his Bachelor of Science in Civil Engineering in 2001 from West Virginia University. Currently, he is a Candidate for the Master's of Science Degree in Civil Engineering at West Virginia University specializing in Transportation Engineering. 